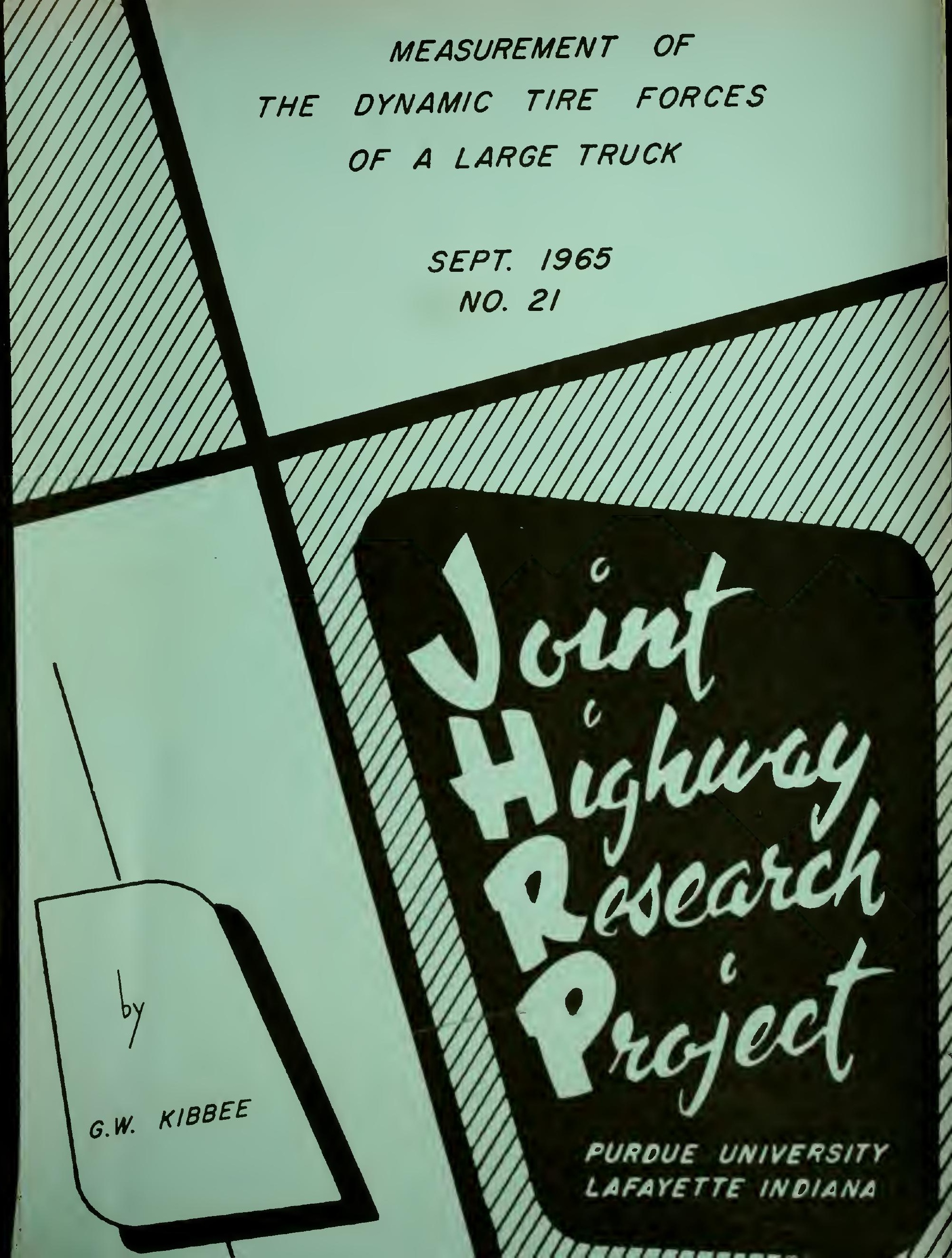





\section{OF A LARGE TRUCE}

To:

G. A. Leonards, Direcror

Jolne Ald ghry Reoesch Project

Septerner: 24, 1965

Fron: H. L. Michaed, Associate Director

Bile Ho: $6-20-6$

Joint Mighay Recearch Rroject

Project No: C-35-52Y

Atcached id a Iinal Reporc shessurestent of the Dynanic Tire Poices of a Large Truch." This report together with the sccompanying

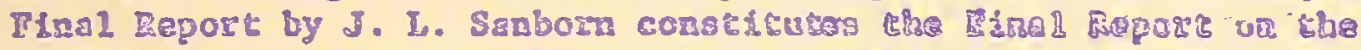
Stresser and DeElection tyR reserrch project.

The artached raport has been suthored by $8 \mathrm{H}$. Gery W. TLbbee tho also used it for hie Pl.D. dissercation. The research reported was conducted under the guidance of Frofessor 3 . F. Quinn of the School of Mechenice 1 Engineer Lug.

The regort is sublrted sor cceprance by rine Borrd and for referzal to the IIgtrmy Conzigston sud the Bureau of Public Rads for their revier, contents and acceptance.

$$
\begin{aligned}
& \text { Regpectfully subatted, } \\
& 7 \text { dawef truble } \\
& \text { tarold I. Michael, Secrecary }
\end{aligned}
$$

HIX:bc

\section{Attachent}

\section{Copy:}

E. I. Ashbaucher

I. R. Cooper

J. W. Delleur

N. L. Dolcin

W. I. Coetz

H. L. Greceo

R. F. Barey

F. S. 2111

J. F. Keloughin
8. 3. Razdenha11

B. D. Miles

J. C. Oppenlander

V. P. Priverte

H. B. Scote

J. V. Smythe

E. H. Stubbs

R. B. Woods

B. J. Yoder 


\title{
Fisal Report
}

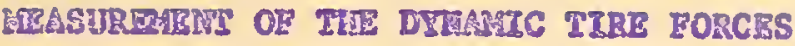

OP A LARGE TRUGR

\author{
by \\ Gary H. Kitbee \\ İescarch Assiscan
}

Joint haghway Resesren Project

E21e ㅂo: 6-20-6

Broject tio: C-36-52\%

Brepared as Pare of an Intestigation

Conducted by

Joint EL ghway Research Project

Enginesrirg lasperdrent station

Purdue Vהiversicy

in cooperacion win

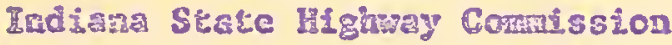

sind the

Rurcau of Public Rozds

U S Departhent of Comarce

Mot Released for Publicarion

Subject to Cherge

Hot Revigued by

Indiana Stree Mighray Comisaion or the Bureau of Public Rords

Purdue University

Lafayette, Iadiana

September 24, 1965 
Digitized by the Internet Archive in 2011 with funding from

LYRASIS members and Sloan Foundation; Indiana Department of Transportation 


\section{ACKNO ILDGMENTS}

The majority of the financial support for this investigation was furnished by the Jolnt Highway Research Eroject of the Civil Engineering School, Purdue University.

Special thanks are expressed to Dr. Bayard e. Qulnn, Professor of Mechanical Engineering, who as my major professor and project director furnished moral encouragement during this investigation. His long range plans made in the past for the project greatly expedited this particular invest1gation.

The loan of the test vehicle by the Indiana state Hilghway Commission was appreciated. The Wonderful cooperation of the commission personnel during the tests is acknowledged.

Thanks are due my fellow meinbers of the Vehicle Dynamics Group; Kjell Hagen, Doug Veenstra for helping With the data processing and Ken Perry for preparing the illustrations for this thesis.

Special thanks are given to my wife, Catherine. Her patience and careful attention greatly facliltated the typing of the entire manuscript for this thesis. 
TABLE OF CONTENTS

Page

IIST OF ILUUSTRATIONS. . . . . . . . . . . iv ABSTRACT . . . . . . . . . . . . . 1 . 1 .

I. INTRODUCTION . . . . . . . . . . 1

II. FUNDAIENTAT CONSIDERATIONS OF DATA PROCESSING 11 III. CAIIBRATON OF EQUTPHENT . . . . . . 45 IV. RESUITS OF HIGHAY TESTS . . • • • . . 98

V. HEASUREMENT AND P EDDICTION OF FORCE

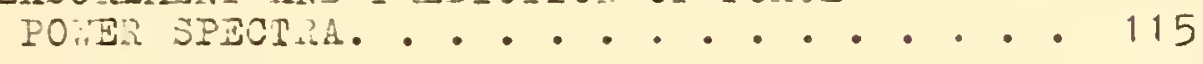

VI. CONCLUSIONS AND zECOIIENDATIONS. •. •. • 145

Measurement of Dynamic Tire Porces...... 145

Equilpment. .............. 145

Experimental Results........... 145

Prediction of Dynanic Tire Forces....... 147

BIBLIO 2 APHY . . . . . . . . . . 149

APPENDIX 1

Theoretical Frequency Response Relationsips for

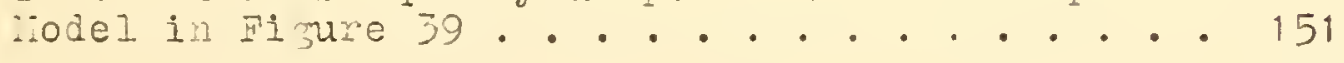

VIIA . . . . . . . . . . . . . . 155 


\section{LIST OF ILIUSTRATIONS}

Figure

1. Illustration of the Relationsip Between Static and Dynamic Forces.......... 2

2. Force That a Small Region in the Pavement Experiences as a Vehicle Passes....... . 3

3. Response of a second Order system to a Step Input . . . . . . . ....... . 16

4. Second Order System Response to a Decaying Exponential.............. . 22

5. Frequency Response for a Second Order System. 25

6. Magnitudes of the Fourier Transforms for the Input and output of a second order system . . 26

7. Illustration of Aliasing. . . . . . . 28

8. Numerically Determined Fourier Transform there Allasing Has Occurred . . . . . . . 29

9. Numerical Integration Error Per Step as a Function of Frequency . . . . . . . . . 31

10. Comoarison of the Frequency Response for a Second order system........... . 35

11. Comparison of Input and Output pourier Transforms of a second order system. . . . . . . 36

12. Frequency Response from Data of Varying Degrees of Accuracy . . . . . . . . . . . . 38

13. Fourler mransforms of the step Response (output) of a Second Order System for Varying Degrees of Data Accuracy ... . . . . . . . . . . . .

14. Magnitude of Frequency Response Determined from Truncated Data. 
15. Magnitude of Fourier Transforms Numerically Determined from Truncated Data... . . . . 43

16. Phase Anfle for the Fourier Transform of the Step Response (Output) of a Second Order System. 44

17. Pressure Measuring System. . . . . . . . 48

18. Drop Beam Callbrator . . . . . . . . . 50

19. Force and Pressure Records for Callbration Tests of Right Rear Inner Dual at Three Different Drop Heights. . . . . . . . . . . . . . 52

20. Magnitude of Frequency Responses for the $F / P$

Calibration Tests of the Right Rear Inner Dual. 53

21. Fourier Transforms of Force Records for $F / P$ Calibration of Ri jht Zear Inner Dual . . . . 55

22. Fourier Transforms of Pressure Records for $\mathrm{F} / \mathrm{P}$ Calibration of Right Rear Inner Dual . . . . . 56

23. F/P Test Results from a .671 Inch Drop Test of a Right Rear Inner Dual. . . . . . . . . 57

24. F/P Test Results from a .291 Inch Drop Test of the Right Rear Inner Dual. . . . . . . . 53

25. F/P Test Results from a .086 Inch Drop Test of the light Rear Inner Dual. . . . . . . . . 59

26. Averaged $F / P$ Frequency Response for the Left Rear Inrer Dual. . . . . . . . . . . 62

27. Averaged $F / P$ Frequency Response for the Left Rear Outer Dual............. . . 63

28. Force and Displacement Records for Calibration Tests of 31 ght Rear Inner Dual at Three Different Drop Heights........... 65

29. Magnitude of Frequency Responses for the $F / X$ Calibration Tests of the Right Rear Outer Dual . 66

30. Nagnitude of Frequency Responses for the $F / X$ Calibration Tests of the Right Rear Inner Dual . 67

31. Displacement Fourier Transform for $F / K$ Calibration of Rlght Rear Duals .......... 68 
32. F/X Test Results from a .086 Inch Drop Test of the Right Rear Inner Dual . . . . . . 70

33. Low Frequency $\mathrm{F} / \mathrm{X}$ Frequency Response for RIght Rear Inner Dual. . . . . . . . . . 71

34. Seven Degree Freedom Model of Test Vehicle.. 73

35. Definition of Terms Used for Seven Degree of Freedom Model of Test Vehicle....... 74

36. Relative Displacement between Rear Axle and Truck Bed................. .

37. Change in Static Ioad under Tires for Static Changes in Displacement. . . . . . . . 78

38. Comparison of $F / X$ Frequency Response for Three Different Veh1cles.......... 80

39. 3 Dezree of Freedom Model of a Truck . . . . 83

40. Comparison of Transient Response of Model with Experimental Results . . . . . . . . .

41. Comparison of the Model Frequency Response with Experimental Results . . . . . . . . .

42. $\mathrm{F}_{I} / \mathrm{K}_{4}$ Frequency Curves for Case I. . . . . . 91

43. $\mathrm{F}_{I} / \mathrm{x}_{4}$ Frequency Response curves for Case II at Various speeds. . . . . . . . . . 94

44. $\mathrm{F}_{\mathrm{I}} / \mathrm{X}_{4}$ Frequency Response Curves for Case III at Varlaus speeds. . . . . . . . . 96

45. Force Records of Left Rear Tires on wheel Faths Centered about Test Point. ........ 101

46. Force Records of Left Rear Tires on theel Paths Centered 11 Inches Right of Test Point. . • : 102

47. T1re Forces and Favement Deflection..... 104

48. Pressure Record and Fourier Series Approximation................ 
F1 gure

49. Comparison of Force Records Obtained from Two Conversion Processes . . . . . . . . 111

50. Comparison of the Total Force of an Automoblie and the Test Truck. . . . . . . . . . 112

51. Comparison of the Automobile and Truck Dynamic Tire Forces Proressed as a Percentage of the Static theel load. . . . . . . . . . 114

52. $30 \%$ Confidence Interval for the Ratio of the Value of a Chi-square Random Variable to the Average Value.............. . 118

53. Data Preprocessing and Power Filtering Characteristic for Data Preprocessing. . . . . .

54. Comparison of Results Using Tro Different Data Preprocessing Techniques. . . . . . .

55. Comparison of Elevation Power Spectra of the Same Pavement Section for the 1962 and 1964 Surveys. . . . . . . . . . . . . .

56. Predicted Force Fower Spectra for Truck and Model of Truck ............. 123

57. Predicted Force Power Spectra for Nominal speeds of 20,30 , and $40 \mathrm{MPH} . . . . . .$.

58. Predicted Force Power Spectra for Nominal speeds of 50 and $60 \mathrm{kHH}$. . . . . . . . .

59. Experienced Force Power Spectra for Nominal speeds of 20,30 , and $40 \mathrm{MPH}$. . . . . .

60. Experienced Force Power Spectra for Nominal speeds of 20,50 , and $60 \mathrm{NPH}$....... 134

61. Comparison of Experimental Results for an Automobile and the Test Truck. . ..... 136

62. Predicted and Measured Force Fover Spectra. . 137

63. Comparison of Predicted and Experlenced

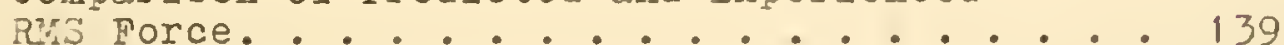

64. Experienced Force Power Spectra for isht Rear Outer Tire. 
65. Experienced Force Power Spectra for Right Rear Outer Tire. . . . . . . . . . 142

66. Force Power Spectra for Ieft Rear Duals at $60 \mathrm{MPH}$......................... 143

67. Force Power Spectra for left Rear Duals at $50 \mathrm{MPH}$. . . . . . . . . . . 144 
Klbbee, Gary illard. Ph.D., Purdue University, August 1965. Measurement of the Dynamic Tire Forces of a Large Truck. Major Professor: Bayard E. Quinn.

The study of the dynamic tire forces of a moving vehicle is a relatively new subject that is recelving increased attention from both automotive engineers and highway engineers. This investigation was part of a jolnt effort between these two groups. The primary concern of this investigation was the measurement of the dynamic tire forces of a large truck as it passed over an instrumented section of pavement. The results of the investigation that deal with the pavement are presented in a Purdue Unlversity Ph.D. Thesis, "An Experimental Analysis of Transient Vehicle Loads and Response of Flexible Pavement", by John Sanborn. The problems associated with the measurement of the dynamic tire forces are discussed in this thesis.

Instrunentation was developed to measure independently the tire inflation pressure of the inner and outer rear dual tires of a large truck. These measurements were converted to dynamic tire force records by appropriate conversion techniques.

Because of the large amounts of data that were re- 
quired for this 1nvestigation, problems and criteria assoclated with the processing of discrete data were investigated.

The experimental calibration of the pressure system was determined by using transient ezcitation.

During the calibration tests, additional studies were conducted concerning the behavior of the vehlcle suspension system. The results indicated that the system response was amplitude dependent. However, for very small displacements, the system may be approximated as a linear system.

Typical records of dynamic tire force versus distance are given for highway tests conducted jolntly with the Stresses and Deflectlons Group of the Clvil Englneering School. These tests also indicated that the distribution of force between inner and outer dual tires 1 s strongly Influenced by the transverse road proflle.

A comparison was made of the tire forces of the truck with those of an automobile for the same pavement section. The dynamic forces of one wheel of the truck were in some cases as great as the total force of one wheel of an automoblie.

By combining a pavement elevation power spectrum with the characteristics of the suspension, it was possible to calculate a predicted dynamic force power spectrum. These results were then checked by calculating an experimental force power spectrum for the forces recorded when the vehicle traversed this section of pavement. The predicted 
values were generally higher than the experimental values. An example is also given of the use of spectral techniques to determine a system malfunction.

As a consequence of this investigation 1t was possible to obtain the dynamic tire force measurements that were of interest to those who were concerned with pavement behavior. 
CHAPTEZ I

INIRODUCTION

Then a vehicle is pariced on a perfectly level and flat pavement, the only force transmitted to the pavement through the tires is the welght of the vehicle. If the vehicle moves at a constant speed over this 1.eal pavement, eacin wheel will transmit the same force as when parked. If the pavement is not perfectly flat, a conaltion that usually exists in any normal road, each of the tires of the moving vehicle wil exert on the pavement the sum of the static force and a dynanic force that produces the vertical accelerations of the venicle. Since the dynamic force may be positive or negative, the total force vill fluctuate above and below the static load of a tire when the venicle is parked. A typical total force versus time record is shown in Figure 1.

This record can be made by recording the dynamic forces in a tire and then ading them to the static force. It is convenient to view this record as a history of the force exerted on the vehicle by the road. As the velicle traverses one small region in the pavement, this rejlon vill experience a total force versus time relationship of a transient nature as shown in fisure 2. Tre initlal and 


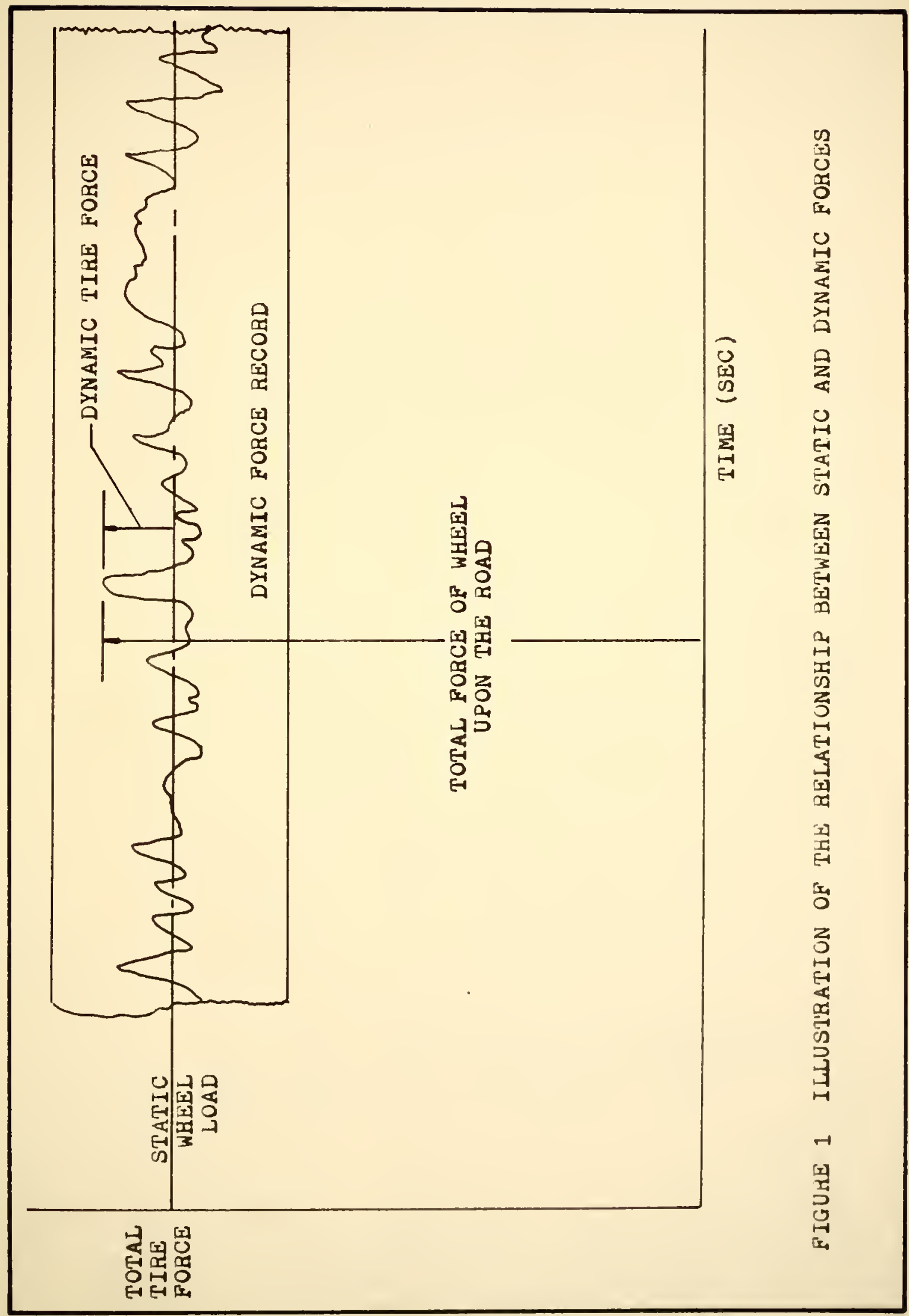


3

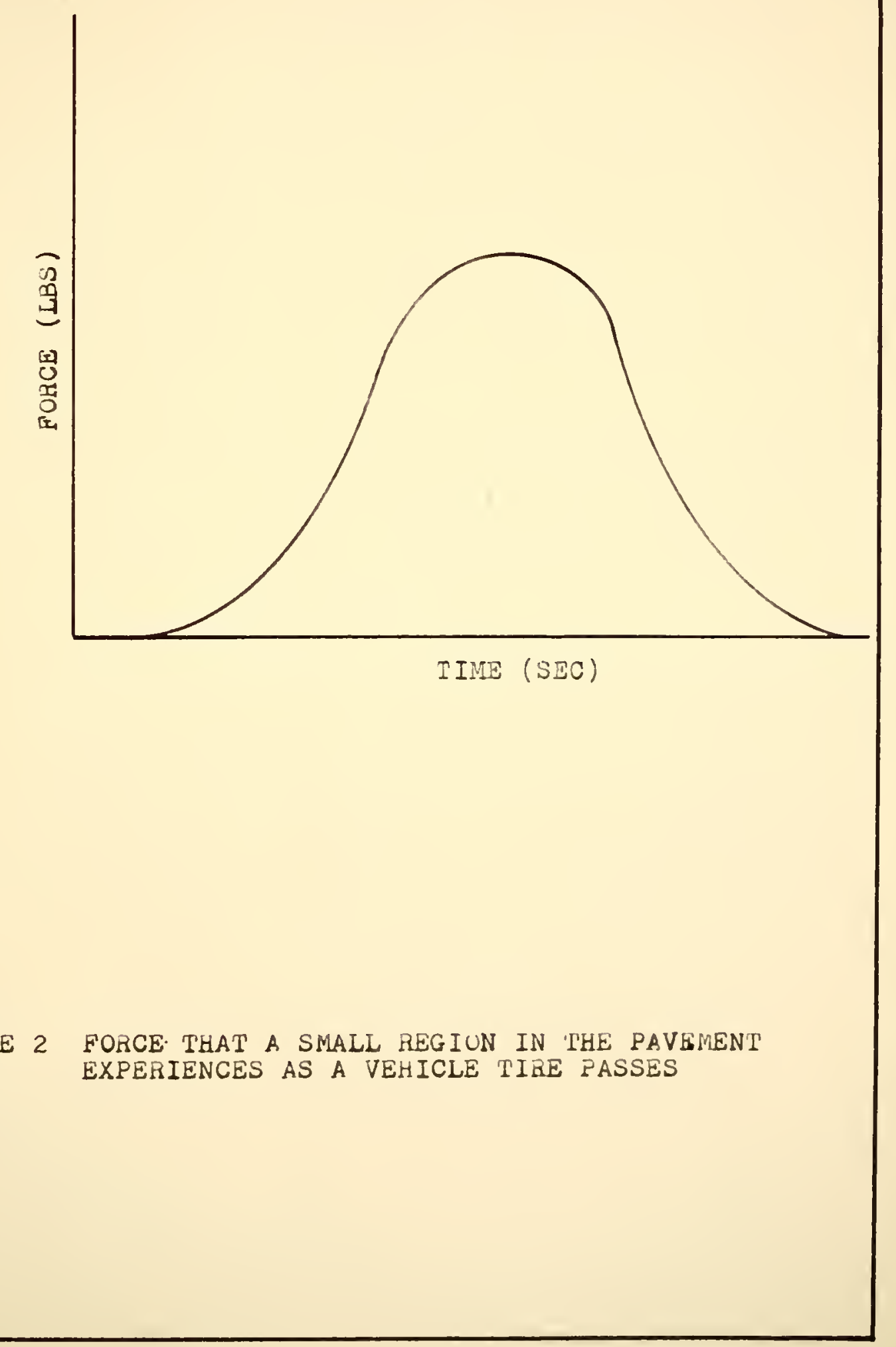


and final value of the force will be zero and the maxinum value will usually occur when the tire is directly above the region under study. This maximum force is related to the total tire force.

Recently the Stresses and Deflections Group of the Civil ingineering school undertook an investigation of the pavement deflections caused by vehfcles. One of the objectives of this investigation was to jetermine tine effect that the dynamic vehicle forces had on the pavement deflections at one location.

The Vehicle Dynamics Group of the Secnanical Enjineering School developed and calibrated the instrunentation necessary to measure the dynamic tire forces of a test vehicle in the form shom in Figure 1.

These two groups performed tests jointly on specific pavement sections. Whe Vehicle Dynamics Group then furnished the Stresses and Deflections vroup with records of total force for pavement loadin; infornation. The results of tne invest1gation tilat dealt with the pavement are presented in reference (1).

since the venicle had been instrumented for tirese tests, it afforded an excelient opportunity to ciecis experimentally the results of certain procedures used to predict the dynamic force when the pavement condition (elevation profile) is known.

The measurement of the dynamic tire forces of a 
moving vehicle is a relatively ner field of interest. Various procedures have been applied, with varying degrees of success, to make these measurenents.

The best method of measuring dynamic tire force rould be to mount force transiucers dinectly on the tire tread. However, instrumentation is not now avaliable for this procedure. The procedures that have been used to experimentally determine these forces for a truck may be classified into three seneral cateronies:

1. Measurement of the strain in axle housing

2. Measurement of the tire siderall deflection

3. Measurement of the tire inflation pressure

In 1957, Hopkins and Bos:ell ${ }^{2}$ applied all three of these procedures simultaneously to a tro axle truck wita $9.00 \times 20$ tires to jetermine the nost practical method for measuring dynamic tire force. The instrunentation ras used with the right rear outer dual tire. line right rear inner tire was renoved for the tests to permit installation of the equipment. To produce a 4500 lb rear wheel load, concrete blocks vere used as ballast. Simultaneous recordings vere made of tie outputs of each of the three devices as the truck drove over an electric scale. By comparing

2. Superscripts refer to references listed in the Bibliography 
these results with the forces measured by tine scale, the authors concluded that the most practical method for measuring the weight variations involving all wheels of a vehicle was the tire pressure method. The disadvantage of the strain gage method was that the inertia of the vehicle suspension system affected the results. If both dual tires would have been used, the changing moment arm would be a problem in finding the total dynamic force of both tires. Furthermore, it would not be easy to separate the dynamic force of the inner tire and outer tire.

Tile measurement of tire siderall deflection was subject to errors caused by small imperfections in the tire siderall. It rould be difficult to construct this type of equipment for simultaneous measurement of both inner and outer tire sidewall deflection because of space Iimitations between the tires.

The pressure measuring systen used by Hopkins and Boswell eaployed a 0 - 50 psig pressure transducer mounted on the wheel. Flectrical slip rings were used to transfer the pressure transducer output to recording instruments in the truck. The severe acceleration environment of tae pressure transducer when it was mounted on the wireel may have caused errors in the results. Also the electrical resistance of the slip rings changed with wheel rotation speed. Further, tize pressure gage sensitivity was not adequate for the small pressure changes that occur. 
The authors recommended several refinements for the system. The most important recomendation was to mount a differential pressure transducer on the side of the truck and use a rotating pressure slip joint and flexible tubing to carry the pressure from the tire to the transducer.

In 1962 , Fisher and fuckins ${ }^{3}$ reported the results of an improved pressure neasuring system. These investigators had followed the recommendations of Hopkins and Boswell ${ }^{2}$ and had used a differential pressure transducer mounted on the side of the truck. A rotating pressure joint and flexible tubing were used to bring tire pressure from the rotating wheel. This device was used on certain trucks that vere operated as part of the AASIO Road Tests ${ }^{4}$. The pressure neasuring systen could be used with either a front tire or one rear dual tire. Calibration of the pressure syster was performed by placing the test tire on an electric scale and usins a mechanical oscillator lashed to the truck bed to produce a sinusoidal force. In this manner, the frequency response that related the dynamic force to the tire inflation pressure ias determined for frequencies up to $10 \mathrm{cps}$.

iilson ${ }^{5}$ in 1964 leveloped further the pressure measuring system for an automoblie. He developed certain system design criteria to minimize resonant effects of the pneumatic system.

Ianilton ${ }^{6}$ developed a procedure that could be employed 
to calibrate a passenger car suspension systen together with a pressure measuring system. Using this technique, the frequency response of the system in question could be determined from the transient response of the system to an experimental excitation.

Mclemore ${ }^{7}$ developed the necessary equipment for the calibration of large vehicles. ilith tinis equipment, it was possible to apply a tire displacement disturbance to a set of dual truck tires. The resulting transient force under the tire and the transient differential tire inflation pressure supplied the information necessary to determine the frequency response of the pressure measuring systen that could be used to relate dynamic force to tire pressure. This equipment was also used to callbrate the vehicle suspension system to detemine the relationship between vertical tire displacement and tine force. Iamilton ${ }^{6}$ developed digital computer programs for use in processing calibration data and the conversion of pressure records to force records. An investigation of the integration procedures of these plograms and other aspects of data processing was conducted to determine the errors that are introduced in numerical calculations. De Vries $^{10}$ developed the necessary techniques required to calculate power spectra for highway profiles. Seve_al investigators $9,11,12$ have worled with the relationship amons elevation power spectra, vehicle 
characteristics, and power spectra of experienced tire forces or center of gravity accelerations. However, the results obtained by these investigators indicated that further investigation should be conducted in this area.

In all previous investications, no provision had been made for the simultaneous measurement of tire inflation pressure in tine inner and outer tires on a truck rear axle. Special equipment vas designed frior to this investigation for measuring these two pressures independent1y. An independent pressure measuring system was connected to each tire of a dual set. The pressure transiucers were mounted on the side of tile truck and were connected to the tires by flerible tubing and a special double pressure joint.

In order to conduct the proposed investigation, it was decided to make maximum use of the experience and equipment that had been developed by previous investigators. It was necessary, however, to develop a special double rotatin; pressure joint that was necessary to transfer the pressure disturbances from the rotating tire to the pressure transducers.

Prior to the investifation, t..e pressure systems and the auxiliary equipment were installed in the test veincle. The trio electrical amplifiers were mounted inside of the cab of the truck on tire passenger side. Tire instrument operator sat on a small sat above the amplifiers. An 
WG set for 110 vac power was nounted on the front of the truck.

The calibration procedure was improved in order to apply to large venicles. A method for finding the static theel load for various theel dispositions vas developed. A procedure of operation for the calibration of large vehicles by transient excitation was developed since the available equipment had not been used vith a vehicle of the size used in this investigation.

The numerical accuracy of the data processing techniques was determined. Ihese techniques were extended and improved.

A test procedure had to be developed for the tests that were conducted jointly with the Stresses and Deflections Group. This included a methoä for correlating the records obtained by each suoup.

The significant problems associated vith this effort are described in the subsequent chapters. 


\section{CHAPTPR II}

FUNDAIENTAL CONSIDERATIONS OF DATA PROCQESINA

Under certain conditions a time function can be transformed into the frequency amain by one of several methods. The methods that transform the time function directly vill result in a frequency domain description in the form of a complex function of frequency. The magnitude of this function gives an indication of the extent to which various frequencies are present in the tine function and can thus be used to indicate the frequency content of the time function. For example, a periodic wave of infinite extent in time can be represented in the frequency domain by complex Pourier coefficients. Each coefficient indicates the extent that a particular frequency is present in the time record. An aperiodic time function can be represented in the frequency domain under certain conditions by its Fourier transform. The nagnitude of the Fourier transform expresses the frequency content as a function of frequency. This magnitude is sonetimes referred to as the spectral distribution of the time function.

A direct Fourier transformation can not. be made on a random function of infinite extent in time. However, when these functions satisfy certain requirements they can be represented in the frequency domain by the power spectrum. The power spectrum shows the distribution of the mean square 
value of the time function over frequency.

Just as it is possible to describe in the frequency domain the input and output time function of a linear. dynamic system, it is also possible to describe the dynamic system in. the frequency domain by the frequency response of the system. The frequency response, also called the transfer function, describes the steady state response of the system to sinusoidal 1nputs. The nasnitude of this complex function represents the attenuation or magnification of the sinusoidal input by the system. The phase angle represents the phase shift betreen the output and input sionsoids.

For a system that can be described by linear ordinary differential equations with constant coefficients, the response to an arbitrary time function can be found by using the response characteristics of the system. The time domain characteristic is the impulse response and the frequency domain characteristic is the frequency response. Results obtained by using either characteristic are equivalent.

The time response is obtained directly by convolution of the input with the impulse response of the system. If the frequency domain representation of the input is multiplied by the frequency response of the system, the frequency domain description of the time response is obtalned.

A frequency response description was chosen to represent the vehicle suspension system and the pressure 
measuring system used in this investigation. There are several reasons for adopting this vierpoint. One reason is that the integration associated with convolution in the time domain is more difficult than the multiplication used in the frequency domain. Another reason is that an experimental frequency response of a vehicle or pressure measurins systen was easier to obtain than the impulse response. A method of applying a true impulse to a large vehicle was not available during the time that this investigation vas conducted. A thind reason is that with a frequency response description of the system, the effects of amplitude distortion and phase distortion may be ezamined independently.

The frequency response of a linear system can be found in an analytical form if all the parameters of the system are knom. However, when the parameters are not known, as thas the case with the vehicle and pressure measuring system used in this investigation, the frequency response may be found experimentally. The obvious ray of doing this is to subject the vehicle to sinusoidal inputs and to compare the steady state output with the input. However, the vehicle used in this investigation was of such a nature as to require a very large and expensive device to produce sinusoidal inputs. Consequently, the experimental frequency response could not be obtained in this manner.

As has been indicated, the frequency characteristics of a system can be used to determine the response of the 
system to an arbitrary input. Conversely, the response of the system to an arbitrary input can be used to determine the frequency characteristics. The use of this method does not require a detalled prior knowledge of the systen. The determination of the frequency resporse characteristics of a vehicle suspension system wil be referred to as the F/s calibration. For this frequency response, the vertical tire displacement $x$ is considered the input and the change in force on the pavenent is considered as the output. The deterinination of the frequency response characteristic of the pressure measuring system inll be referred to as $\mathrm{F} / \mathrm{P}$ callbration. Formally, the change in force would be considered as the input and the pressure change as the output, but since the pressure systen is employed to indicate force, the inverse relationship is more convenient for this investigation. Thus pressure $r i 11$ be considered as input and force as output.

The systems used in this investigation iere callorated by subjecting them to a transient input $x(t)$. The input and output $y(t)$ were recorded on an osclllograph record. A Fourier transformation was made on $y(t)$ and divided by a Fourier transformation that was made on $x(t)$. This then was the frequency response $Y(f)$.

$$
Y(f)=\frac{\int_{-\infty}^{\infty} y(t) e^{-j 2 \pi f t} d t}{\int_{-\infty}^{\infty} x(t) e^{-j 2 \pi f t} d t}
$$




$$
\begin{aligned}
& j=\sqrt{-1} \\
& f: \text { frequency (cycles per second) } \\
& t: \text { time (seconds) }
\end{aligned}
$$

An analytical expresston was, of course, not known for $y(t)$. lior was an analytical expression knom for $x(t)$.

Numerous problems were encountered when iquation 1 was applied to the transient records of the experimental tests of the venicle and pressure systens used in this invostication. Several criteria had to be established in oruer to minimize inherent data processing errors. To best illustrate the need for these criteria, the response of a knom Inear second order systen to a unit step input will be used. Although this system vill not exactly represent the vehicle suspension system or the pressure measurin; sjstens, it has some zencral properties that are comon to both types of systems. A step input was chosen as a representative input since the displacement input produced by the testing device closely approximates this input. The differential equation that describes the systen and the unit step response are show in Fisure 3. The analytical solution of the time response is easily fousi as ic tire analytical e:pression for the frequenoJ response. The input and output can then bo subjected to the rame data nrocesing proceiures that re used for the actual syster calibrations and the results co:nared to the analyical results to illustrate 


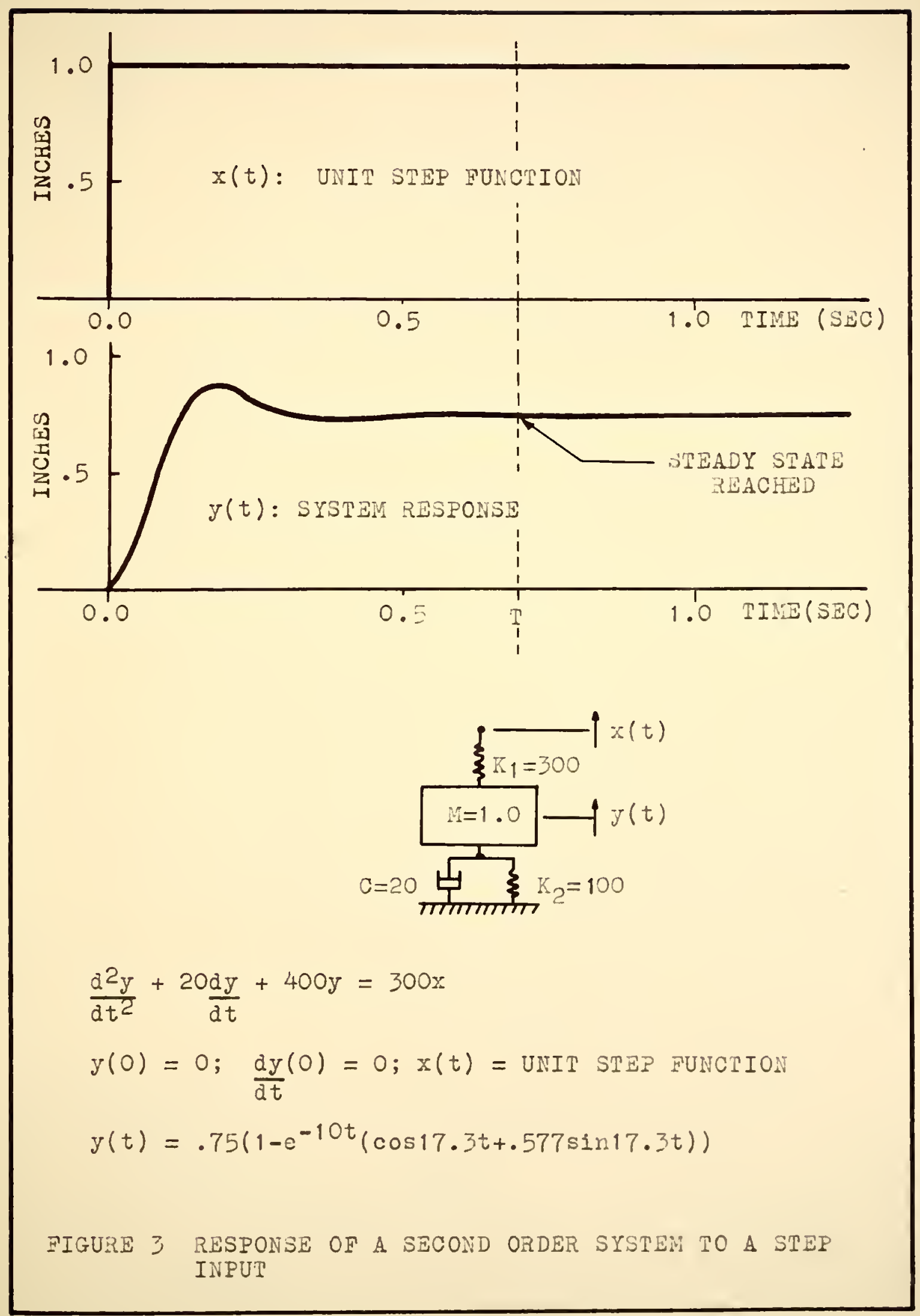


why the criteria were chosen.

Using the input and response shown in Figure 3 , there results

$$
Y(f)=\frac{\int_{0}^{T} y(t) e^{-j 2 \pi f t} d t+\int_{T}^{\infty} \cdot 75 e^{-j 2 \pi f t} d t}{\int_{T}^{T} e^{-j 2 \pi f t} d t+\int^{\infty} e^{-j 2 \pi f t} d t}
$$

I : Iime at wich response has reached steady state position.

The second integrals of the numerator and denominator of equation 2 are meaninjzess in the form 3 mom. An artiPlee that is used to overcone this difficulty is to multiply the integranos by tine function $e^{-\beta(t-1)}$, integrate the $0=0-$ duct, and then yass $\boldsymbol{\beta}$ to a limit of zeco in that orlen. 13,14 Followin's this procedure gives

$$
Y(f)=\frac{\int_{0}^{\mathcal{L}} y(t) e^{-j 2 \pi f t} d t+\lim _{0 \rightarrow 0 \mathrm{~T}} \int_{0}^{\infty} \cdot 75 e^{-\beta(t-T)} e^{-j 2 \pi f t} d t}{\int_{0 \rightarrow 0 T}^{T} e^{-j 2 \pi f t} d t+\lim _{\Delta \rightarrow-\beta} e^{-\beta(t-T)} e^{-j 2 \pi f t} d t}
$$




$$
\begin{aligned}
& Y(f)=\frac{\int_{0}^{T} y(t) e^{-j 2 \pi f t} d t+\operatorname{Lim}_{B \rightarrow 0} \frac{.75}{B+j 2 \pi f} e^{-j 2 \pi f T}}{\int_{B \rightarrow 0}^{T} e^{-j 2 \pi f t} d t+\operatorname{Lim}_{B \rightarrow j 2 \pi f} \frac{1}{B+j 2 \pi f T}} \\
& Y(f)=\frac{\int_{0}^{T} y(t) e^{-j 2 \pi f t} d t+\frac{.75}{j 2 \pi f} e^{-j 2 \pi f T}}{\int_{0}^{T} e^{-j 2 \pi f t} d t+\frac{1}{j 2 \pi f} e^{-j 2 \pi f T}}
\end{aligned}
$$

This method was employed to determine the iatecrals of Equation 1 when the input and response did not return to the initial value as was the case for both the $F / P$ and $F / \delta$ calibration tests.

The mathematical deteils which show that the orioinal time functions are recovered witen the Fourier integrals are obtained from these Fourier transforms are uiven in references (13) (14).

For the representative system described by the differential equation in Figure $j$, the analytical expression for the frequency response may be iritten at once by substituting j2nf for d/at in this differential equation. The result is 


$$
Y(f)=\frac{.75}{1-.0986 f^{2}+j .314 f}
$$

Then evaluated by the ruethod under consideration, the Fourier transforms $Y(f)$ and $Y_{i}(f)$ of the unit step input and response of the system of pisure 3 are

$$
x(f)=\frac{1}{j 6.28 f}
$$

$$
Y_{1}(f)=\frac{.75}{6.28 f\left(j\left(1-.0986 f^{2}\right)-.314 f\right)}
$$

Division of Equation 3 by Lquation 7 gives

$$
Y_{1}(f)=\frac{.75}{X(f)}=\frac{.}{\left(1-.0986 f^{2}+j .314 f\right)}
$$


Which is identical to equation 6 .

Although this method of calculating the Fourier transform is fustified mathematically in reference (13) and (14), and the resulting Fourier transforms produced the correct frequency response for tine system of Fi gure 3, a physical explanation of the situation w1l be ziven to aid in the understanding of the validity of this procedure when findinf a frequency response. A physical explanation can be given then the problem is consideved in a different manner. Tis explanation holds in particular for tie system shown in Figure 3, and in zeneral for many systens.

Phis problem would not have occurred if the aperlodic function would have returned to zero. If at some time i after the system had reached a practical steady state, the input were brought back to the initial position accordins to the relation

$$
x(t)=e^{-\beta(t-I)},(t>I)
$$

\section{B: real constant jreater than zero}

the system output would also approach zelo displacement. For the system of Flgure 3, the exact analytical expression 
for the system response is given by the relation

$$
\begin{aligned}
y(t)= & \frac{.75}{\left(.0025 B^{2}-.05 B+1\right)}\left[e ^ { - 1 0 ( t - T ) } \left[\left(.0025 B^{2}-.05 B\right) \cos 17.3(t-I)\right.\right. \\
& \left.\left.+\frac{\left(.025 B^{2}+.5 B\right)}{17.3} \sin 17.3(t-T)\right]+e^{-B(t-T)}\right]
\end{aligned}
$$

Tizis expression is shom in Figure 4 for various values of $B$. lrotice that for small values of $\beta, y(t)$ may be croressed anproximately by the term

$$
y(t) \cong .75 e^{-B(t-I)}
$$

This is because there is not an abrupt chanje of the input displacenent as at time $t=0$ and a relatively small discontinuity in the velocity of the input. Consequentiy, the system transients decay quicirly and the output approaches the steady state decaying condition.

using 10 and $12, Y(f)$ may be expressed approximately by 


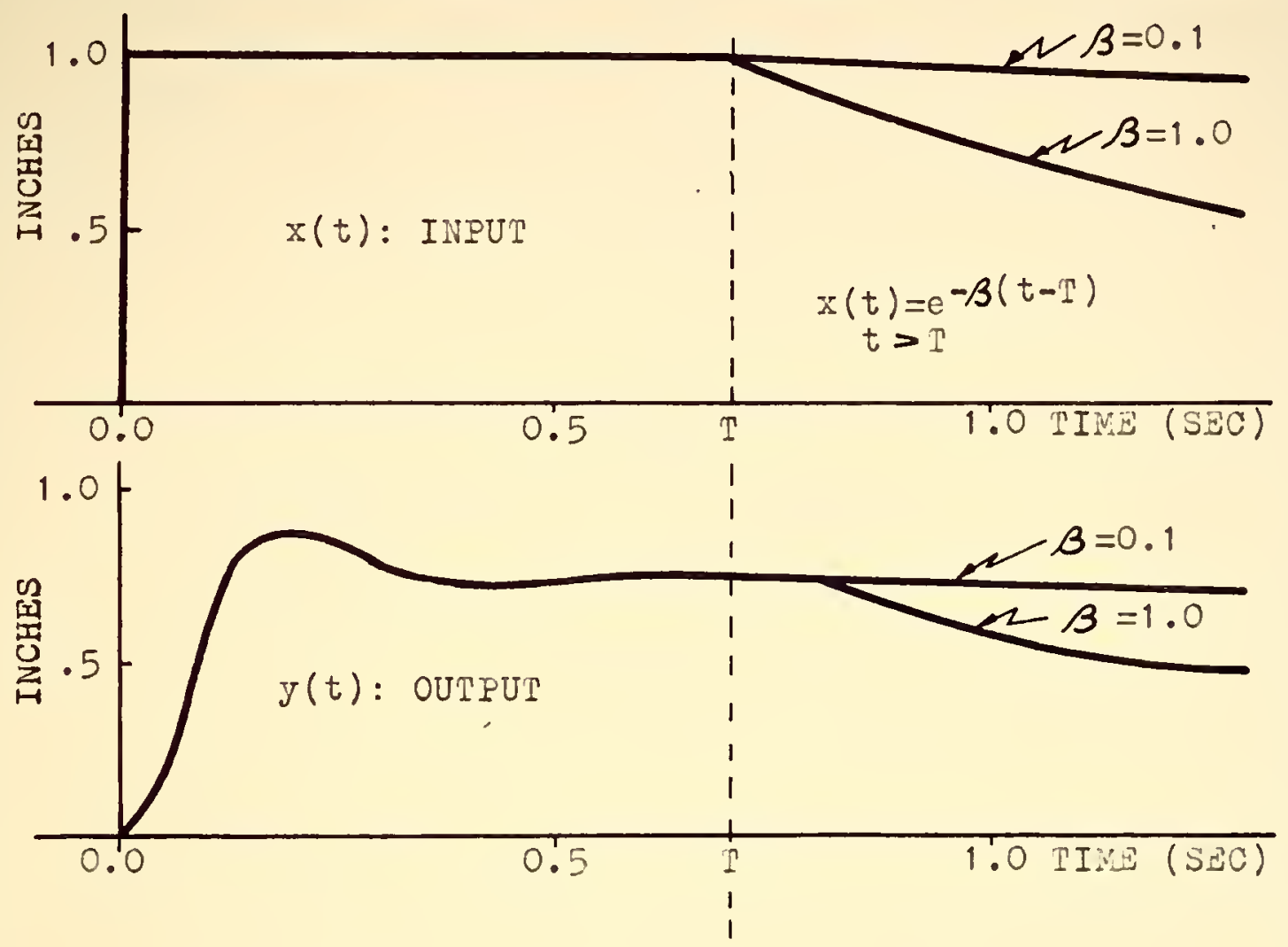

RESPONSE OF THE SYSTEM OF FIGURE 3 FOR $t>T$

$$
\begin{aligned}
y(t)= & \frac{.75}{\left(.0025 B^{2}-.05 B+1\right)}\left[e^{-10(t-T)} \mid\left(.0025 B^{2}-.05 B\right) \cos 17.3(t-T)\right. \\
& \left.\left.+\frac{\left(.025 B^{2}+.5 B\right)}{17.3} \sin 17.3(t-T)\right)+e^{-\beta(t-T)}\right]
\end{aligned}
$$

FIGURE 4 SECOND ORDER SYSTEM RESPONSE TO A DECAYING EXPONENTIAL 
$Y(f) \cong \frac{\int_{0}^{P} y(t) e^{-j 2 \pi f t} d t+\int_{T}^{\infty} \cdot 75 e^{-\beta(t-T)} e^{-j 2 \pi f t} d t}{\int_{0}^{T} e^{-j 2 \pi f t} d t+\int_{I}^{\infty} e^{-\beta(t-T)} e^{-j 2 \pi f t} d t}$

$I(f) \cong \frac{\int_{0}^{T} y(t) e^{-j 2 \pi f t} d t+\frac{.75}{B+j 2 \pi I} e^{-j 2 \pi f I}}{\int^{I} e^{-j 2 \pi f t} d t+\frac{1}{B+j 2 \pi I} e^{-j 2 \pi f I}}$

The smallex $B$ is taken the more nearly the equality of 12 will hold and hence those of 13 and 14 . $B$ can be taken as snall as needed in 14 for all $f$ of practical interest except $\boldsymbol{f}=0$. Thus instead of considerine $e^{-\boldsymbol{B}(t-I)}$ as an natheratical artifice, it may be viered as an experiment that could be periormed but ras not. In other rorks, all the information about the dynanics of the system is contained in the first is seconos. No additional information is obtained after 1 , except possibly a constant fain.

Although a completely knom second order system was used to demonstrate this point, similar reasoninj way be apolied to uninown systems that have a corstant steady state step response. 
inen an uninom physical system is experinentally subjected to transient excitation, the analytical erpression for the output is uncnown. The input is sometimes knom, but sere ally it is anj available disturbance that has proper frequency content. Duing the vest the input and output are recoried on an oscillograpin recora. Me values of these traces at uniformly spacei incenents of the tine scale are tabulated at a later tine. ine tabulation of output descibibes $\bar{j}(t)$ in iquation 1 anci t.ie input tajulation is $x(t)$. po cvaluate the intejals of jquation 1, a nunerical integration is persorned on these vabulations. For illustration, a frequency response as ande usinj the tabulations of the step input and the step response of the example linear second onder systen of igure 3 eolloring the same procodurcs as vere used in tine actual data pocessing of the rocords of input and output for the vehicle suspension and pressurc ajstens used in the investigation. Hire masnitude of tisis frequency response and the magnitude of the analytical expression for tive frequency response are illustrated in pigure 5 . Ine difference betreen the curves illustrates the inaccuracies that result from this nethod of data processin-. ine data used for $\mathrm{V}(t)$ was sampled at .005 second intervals and contained 3 significant ilyues. The erors of the frequency cesponse are primarliy aue to the "ourier transform of the output. The Fourier transforn of the input agreed well wit 


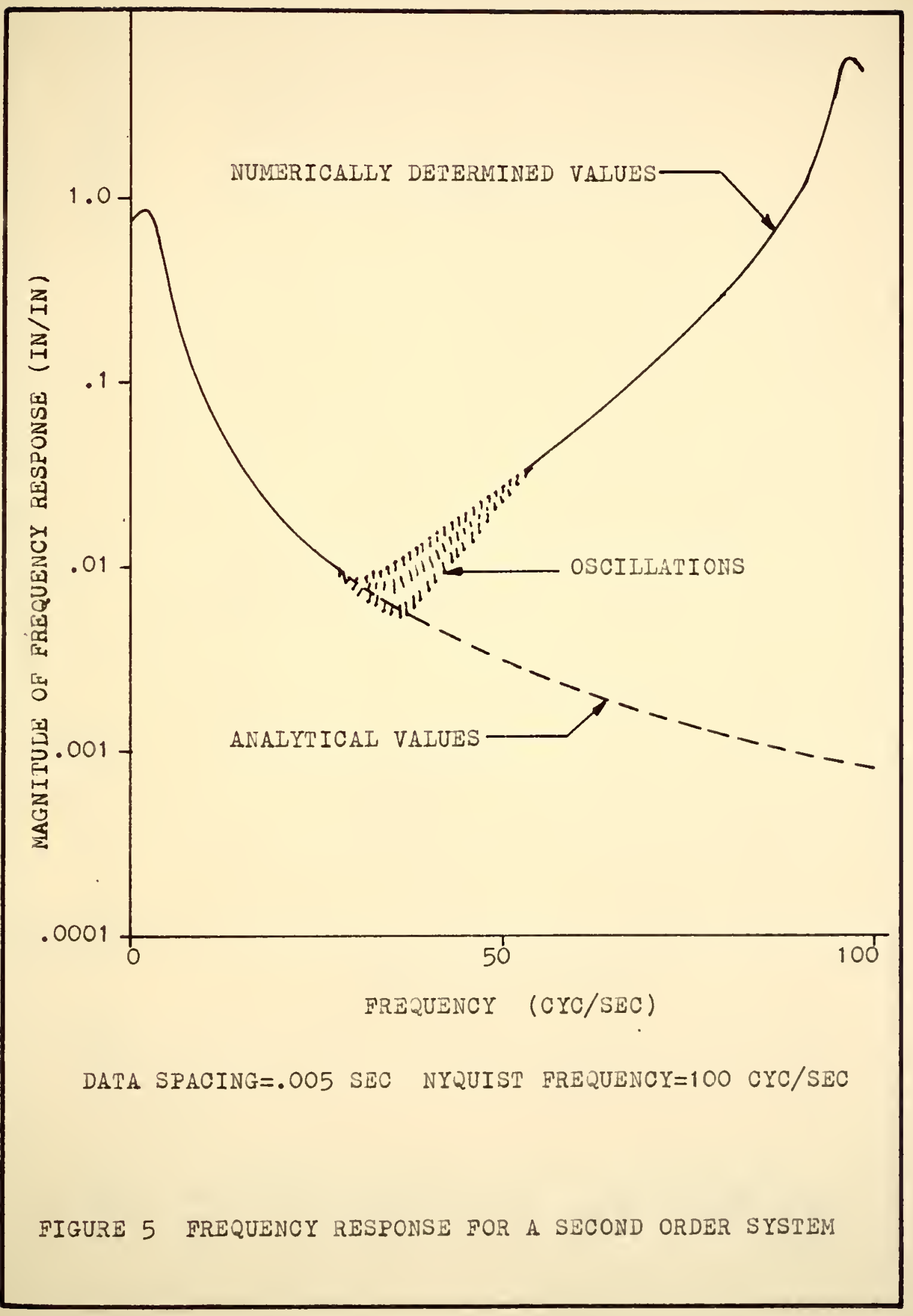




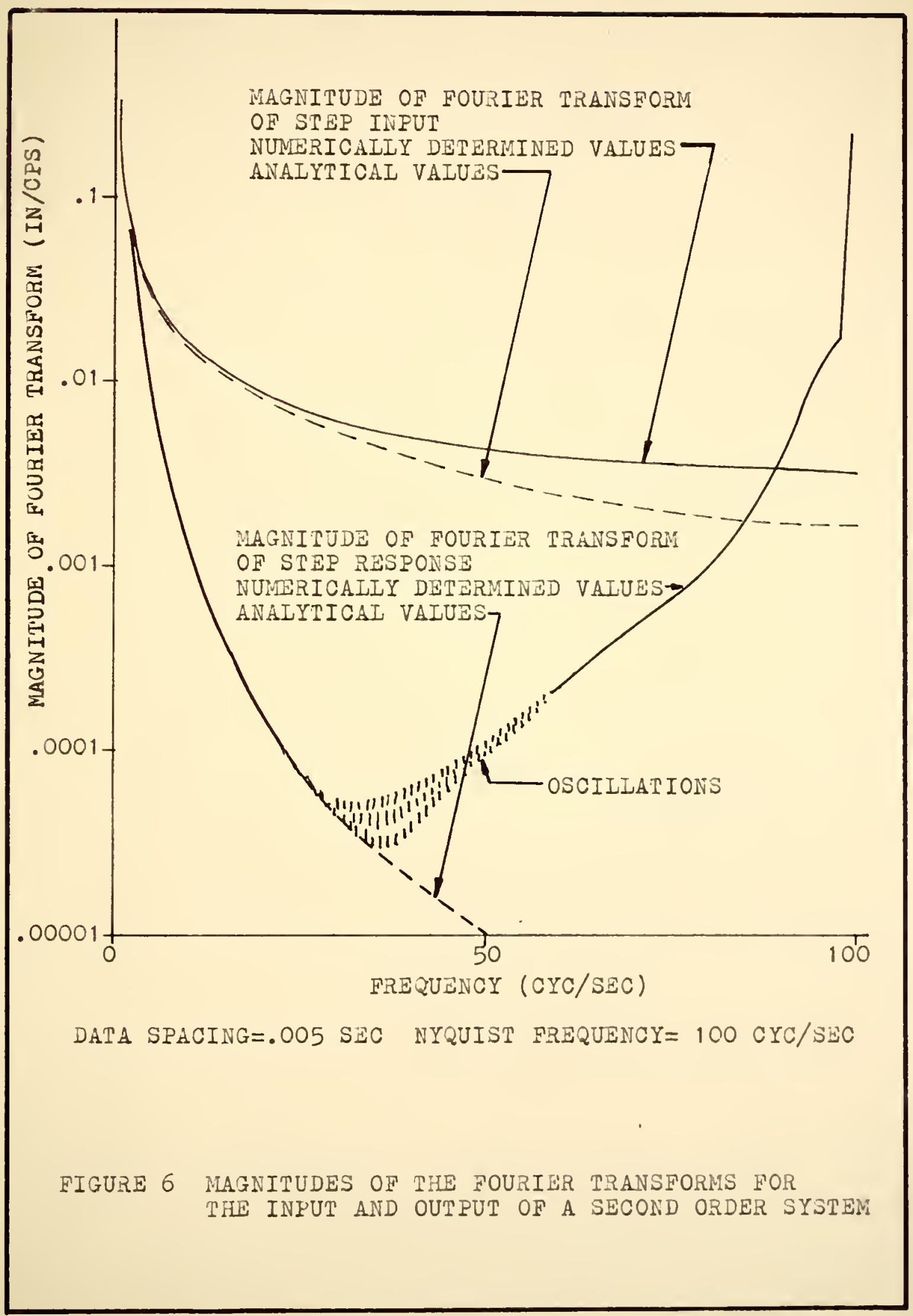


the analytical transform as is shown in figure 6 . The scale of Figure 5 was chosen to accentuate the errors that do occur. The representation is zood to $30 \mathrm{cps}$. There are many possible causes for the errors above $j 0 \mathrm{cps}$ and these will be discussed. Criteria rill be obtained that will minimize these errors.

One of the first problems that must be recosnized when working with sampled data is aliasing.15 If a functior. $z(t)$ is sampled at unifomly spaced time intervals of wiati $\Delta t$, then the maximu frequency $f_{m}$ that can possibly be detected from the sample is

$$
f_{m}=\frac{1}{2 \Delta t}
$$

This frequency will be referred to as the Nyquist frequency. That happens to frequencies in the ori ginal record that are higher than $f_{m}$ ? The answer is that they are confused with fiequencies betreen 0 and $f_{\mathrm{n}}$. This confusion, called aliasing, is illustrated in Figure 7. Ten a Fourier transform is made on the data, part of the frequency content of the high frequencies appears in the lower frequencies. The data used to numerically calculate the fourier transforms for pis jure 5 had a ryquist frequency vell above any expected appreciable frcquency content. To better illustrate the effect of aliasins on a Fourier transform, a small amplitude 120 cps sine rave ras added to the step 


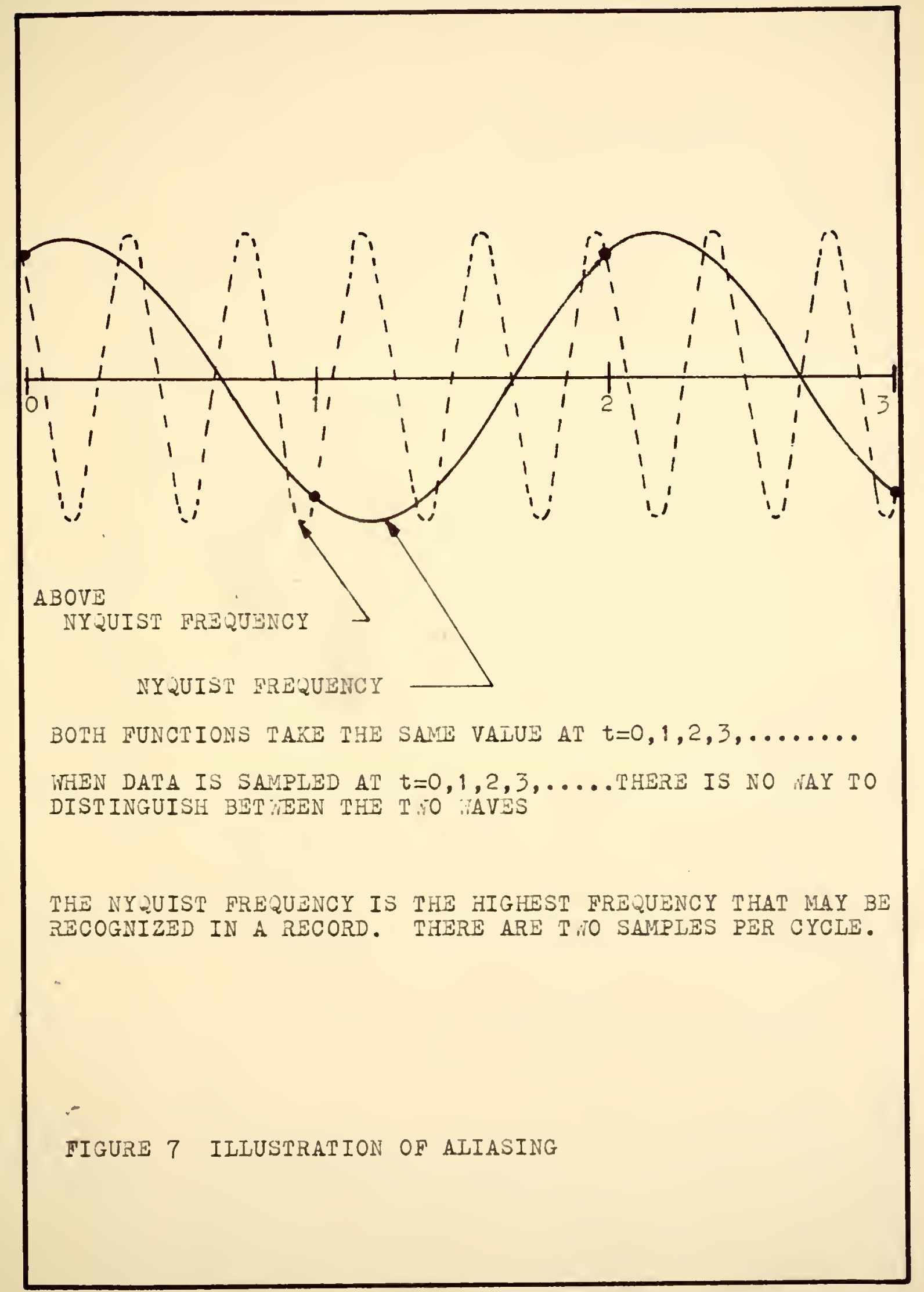


response function of the systen of Figure 3 during the time from $O$ to $T$. The data was then sampled at a rate that placed the Nyquist frequency at 100 cos mich ras below the high frequency sinusoid. Fisure 3 shows the marnitude of the Fourier transform that was numerically calculated from this data. Also shorn in rigure 3 is the plot of the ma gnitude of the analytical fourier transform of the sum of the step responze and the hish frequency finite length sinusoid.

The numerically determined transform in pizure $j$ exhibits two definite peaks that are not present in the transform obtained from data that dia not contain the 120 cps sine rave. These pears are caused by aliasing of the hisin frequency with frequencies between 0 and $100 \mathrm{cps}$.

Because there is only one finite lenjth hijh frequency discrete sine wave present in the data, it is possible to qualitatively explain the peaks at 20 and 30 cps. hen a 120 , 30, or $20 \mathrm{cps}$ sine rave is sampled at .005 second intervals starting at zero, the nagitude of all vaves at each interval vill be equal. The polarity of the 30 cps vave vill always be opposite to the polarity of the 120 cps sine rave. This fact can be shom to account for the peais at 30 cps. The polárity of the $20 \mathrm{cps}$ wave will be the same as the $120 \mathrm{cps}$ wave at even time increments and opposite at odd time increments. This property and the jimpson intesration coefficients will cause a peak to occur at 20 cps. 


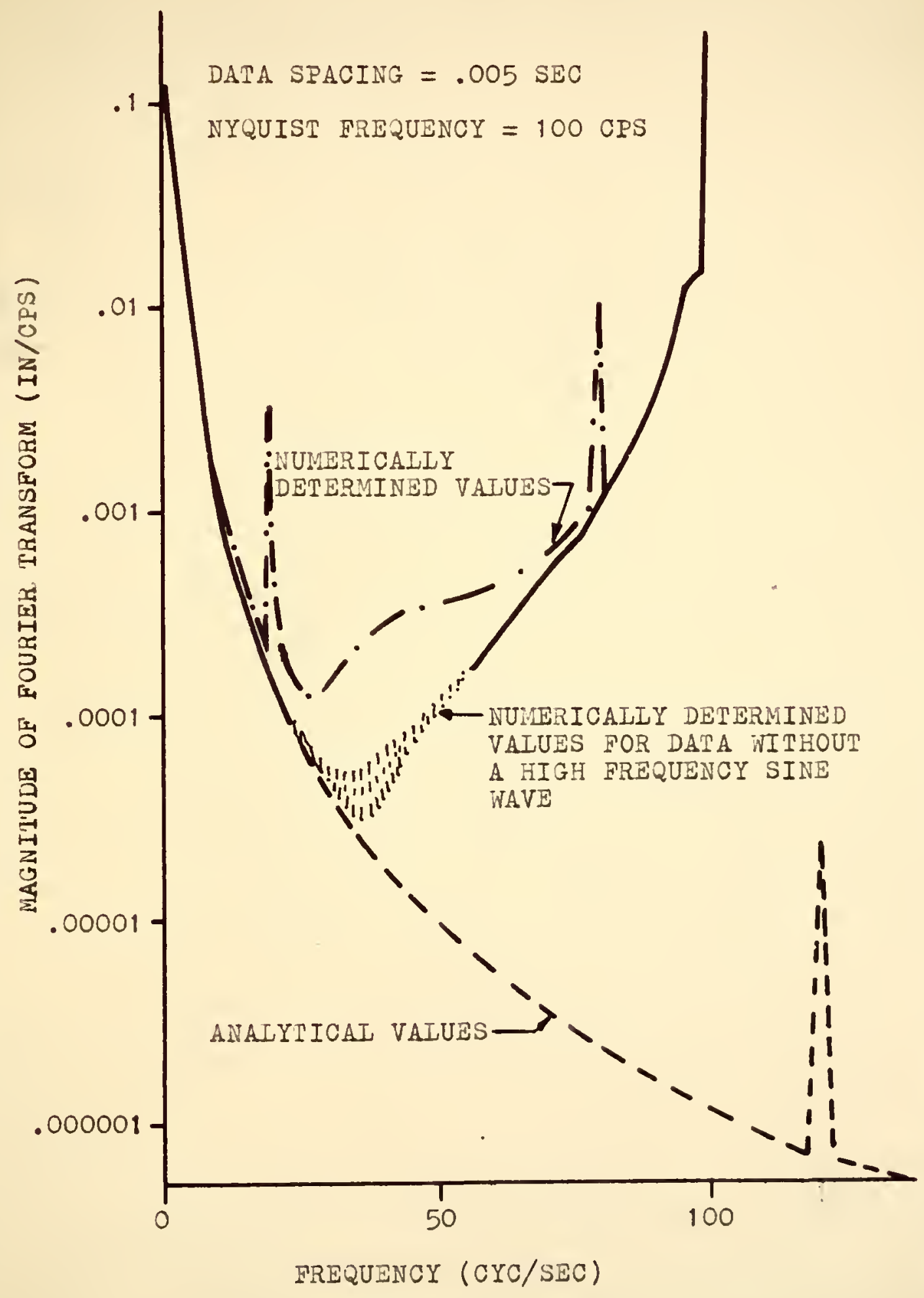

FIGURE 8 NUMERICALLY DETERMINED FOURIER TRANSFORM NHERE AIIASING HAS OCCURED 
The criterion that inay be stated from these results is that the sample spacing nust be small enough to cause the iyquist frequency to fall at a hisher frequency than any appreciable true frequency content of the time record.

A second problen encountered in the evaluation of Bquation 1 is the ecror produced by the nurerical integration procedure. Simpson's rule integration proceduce ras used to interrate the product $f(t) e^{-j a n t}$. Whis pocedure will glve eract results wen a polynonial of degree not sreater than three is integrated.16 hen the function to be integrated is only the sinusoid $e^{j 2 \pi t}$, the error per step of interiration can be expressez as a function of frequency.15 The error per step of integration for simpson's rule and the trapezoidal rule are shom as a function of frequenoy in Fisure 9. vote that at hifi crequencies, the simpson's procedure nagnifies the result and the trapezoidal pcocedure attenuates tise result.

It is not possible to apoly t.re results sizom in wigure 9 airectly to the evaluation of the interrals of Equation 1 because the product $r(t) e^{-j 2 \pi f t}$ is to be intesrated. Hovever, Figure 9 does sive an indication that jimpson's rule can not possibly give accurate results, even If $f(t)$ were a constant, for sample rates beloi 5 samples per cycle. This is confirmed in pigure 5 and Fisure 6 by the divergence of the numerically determined values from the analytical values at $40 \mathrm{cps}$. The transform of the step 


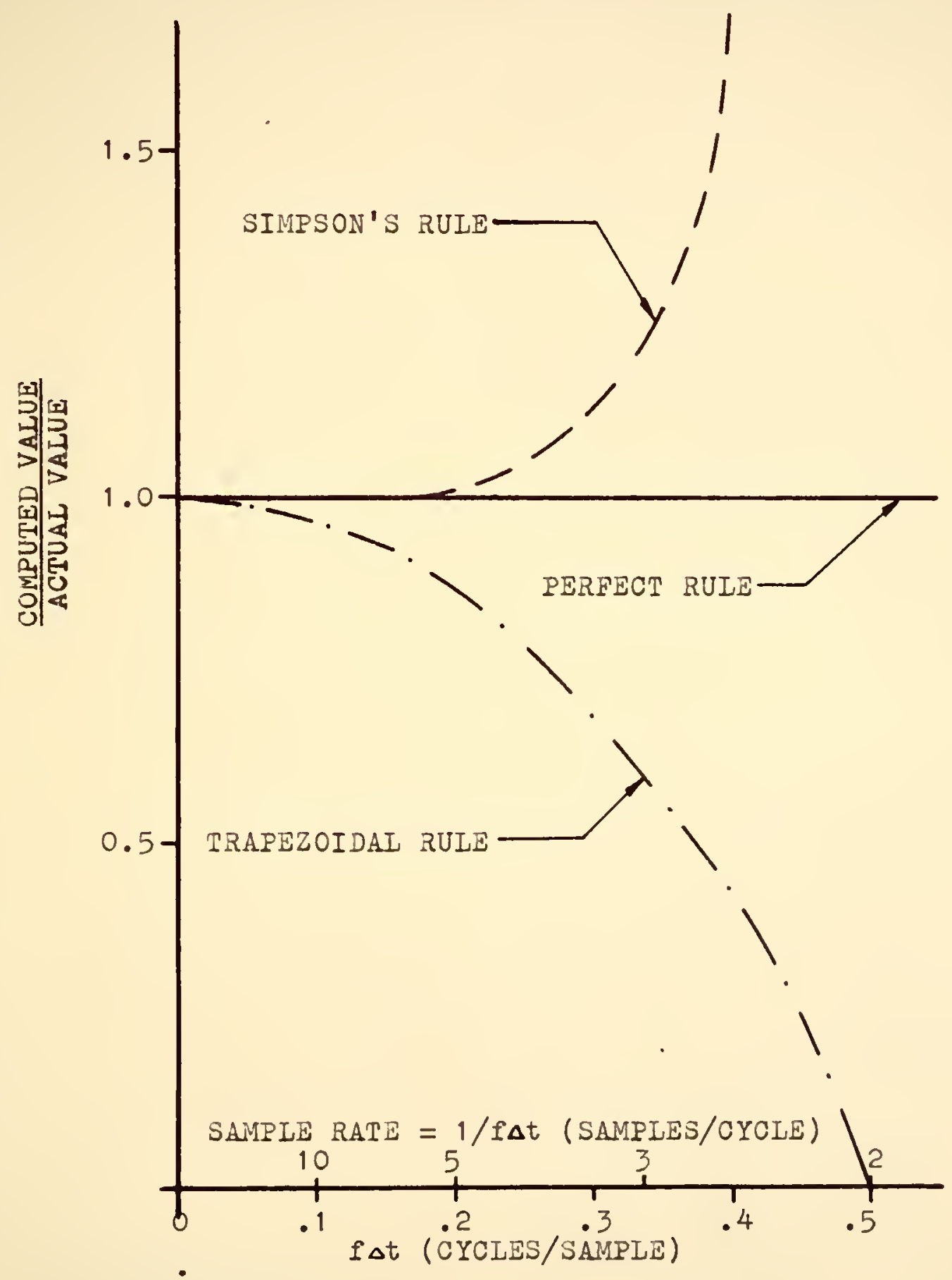

FIGURE 9 NUMERICAL INTEGRATION ERROR PER STEP AS A FUNCTION OF FREQUENCY 
input does not exhibit tinis distortion because only 3 data values vere used to determine it. The primary infomation for the step comes from the 1/jarf term which resulta from the step not returnit; to zero. Phis is to be contrasted ifth the Fourier transform of the output which ras calculated usins 200 data values.

The criterion developed to nininize the error due to simpson's rule distortion is to use only that part of the frequency response from zero to $f_{5} c p s$, inere $f_{5}$ can be expressed by

$$
f_{5}=\frac{1}{j \Delta t}
$$

Filon's nethod 17,13 is mil alernative numerical integration procedure. Although not used extensively for the calculation of Equation 1 ln this investigation, the results obtained by using this procedure rill be discussed as they are an improvement on simpson's rule. The method is an extension of sinpson's rule for the special case of evaluating integrals associated with Fourier transforins (or coefficients) of tire forn

$$
\int_{a}^{b} f(t) \sin 2 \pi f t d t
$$

anò 


$$
\int_{a}^{b} f(t) \cos 2 \pi f t d t
$$

The method will give exact results if $f(t)$ is of the form

$$
f(t)=A+B\left(t-t_{0}\right)+C\left(t-t_{0}\right)^{2}
$$

where $A, B, \Omega$, and to are constents.

Pi jures 10 and 11 iliustrate the results of the gilon procedure compared with the analytical values. Ine tabulated input and output data ras the same data as was used to calculate the results in pigures 5 and 6 . Fisure 10 sho:rs a rajor improvenent ove: the frequency response obtainea by iapson's rule integration in Figure 5. Also the oscillations betreen 30 and 40 cpe hare disappeared. Dxtreine distortion only occurs near the Nyquist rrequency.

$$
\text { Dreifle }{ }^{19} \text { investigated tire data processinj errors in- }
$$
curred when finding a systen frequency response from transient data. Ie used a nunerical lintegration procedure to cvaluate the interrals of Squation 1. Mile not as accurate as the Pilon method, this procedure way be better tian sinoson's rule. The following criteria vere offered for 


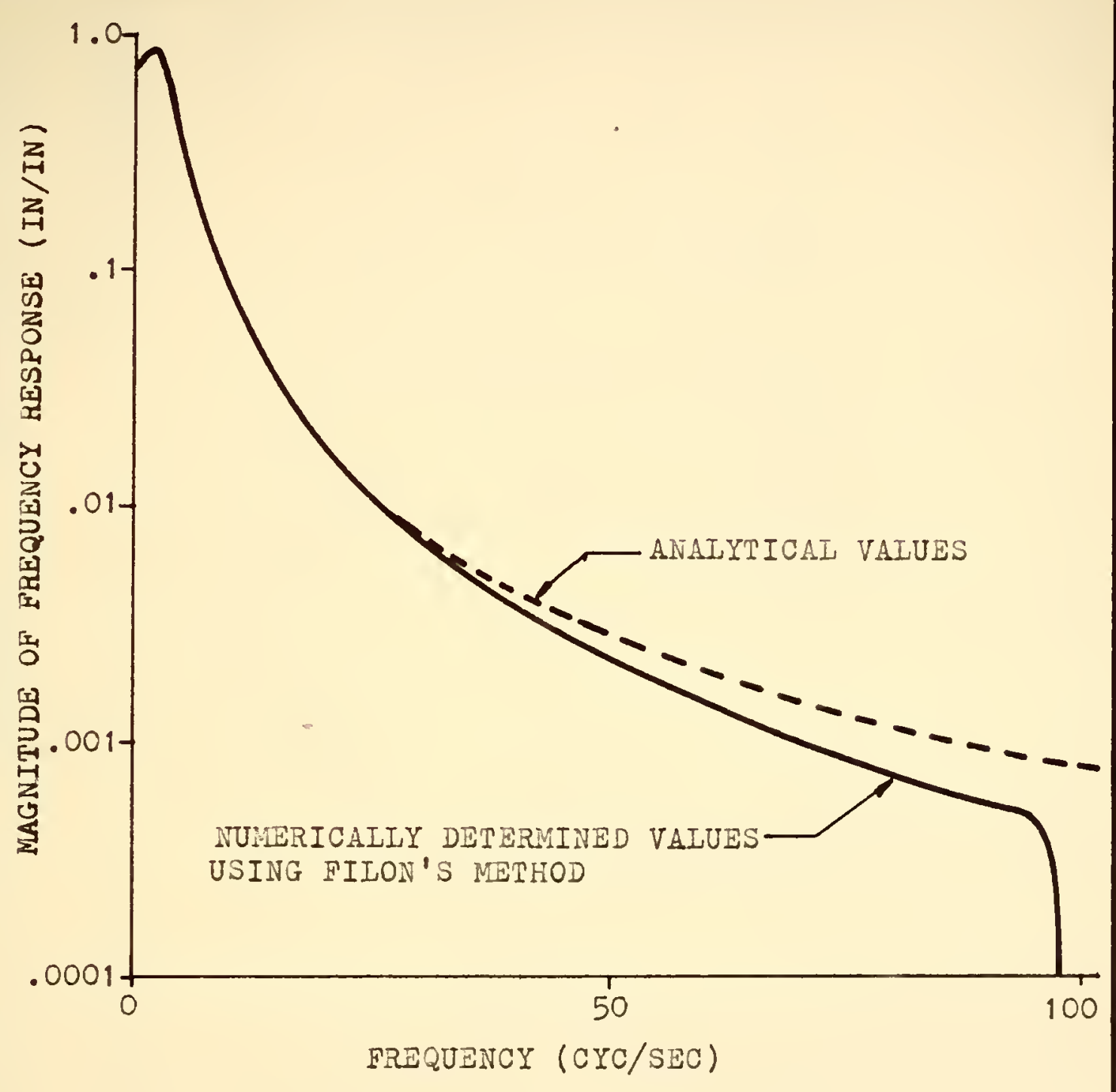

DATA SPACING $=.005$ SEC NYQUIST FREQUENCY $=100 \mathrm{cYC} / \mathrm{SEC}$

FIGURE 10 CONPARISON OF THE FREQUENCY RESPONSE FOR A SECOND ORDER SYSTEM 


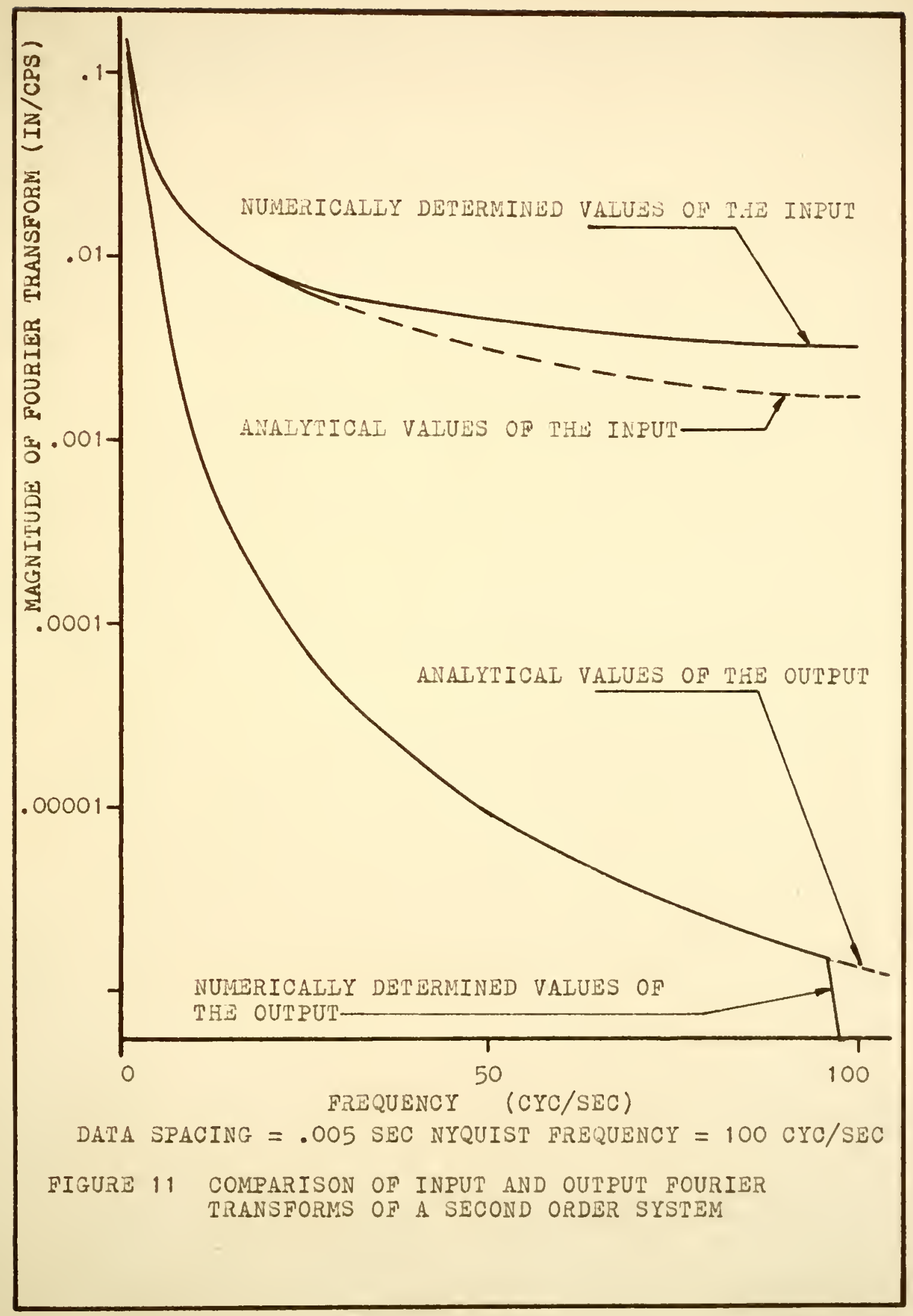


approximately 25 per cent gaximum error in the frequency response:

$$
\begin{aligned}
\omega_{\operatorname{mas}} \Delta t & <\pi / 2 \\
|j(j \omega)| & >e \\
\Delta t & <-1 / 10
\end{aligned}
$$

where

$$
\begin{aligned}
& z_{1}=\text { smaliest chanacterictic time of interest in } \\
& \text { tine systen } \\
& \text { e = estimated ordinate readin; enon in the tine } \\
& \text { do:nein } \\
& \omega_{\text {maz }}=\text { narinum anjular frequency to be usej }
\end{aligned}
$$

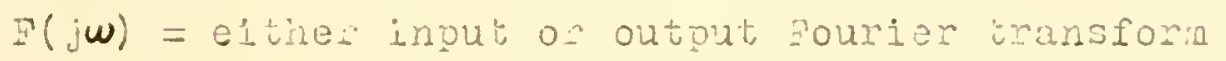

The risst criterion sujuests tirat the maninum usable frequancy is one-half tia iygulat frequency.

Ihe seconi criterion is pertinent to tibis investigation and till be considered in detsil. The apolication of this criterion can se shoin in the followinj example. The data that was used to obtain the resuits for pi gure 5 and vas rounded ofr by various anounte and then procesied by use of zinpson's rule. Fijures 12 and 13 illuatzate tile frequency responses and output Fouricr transforins obtained from this diati.

since the input function consisted of only three data 


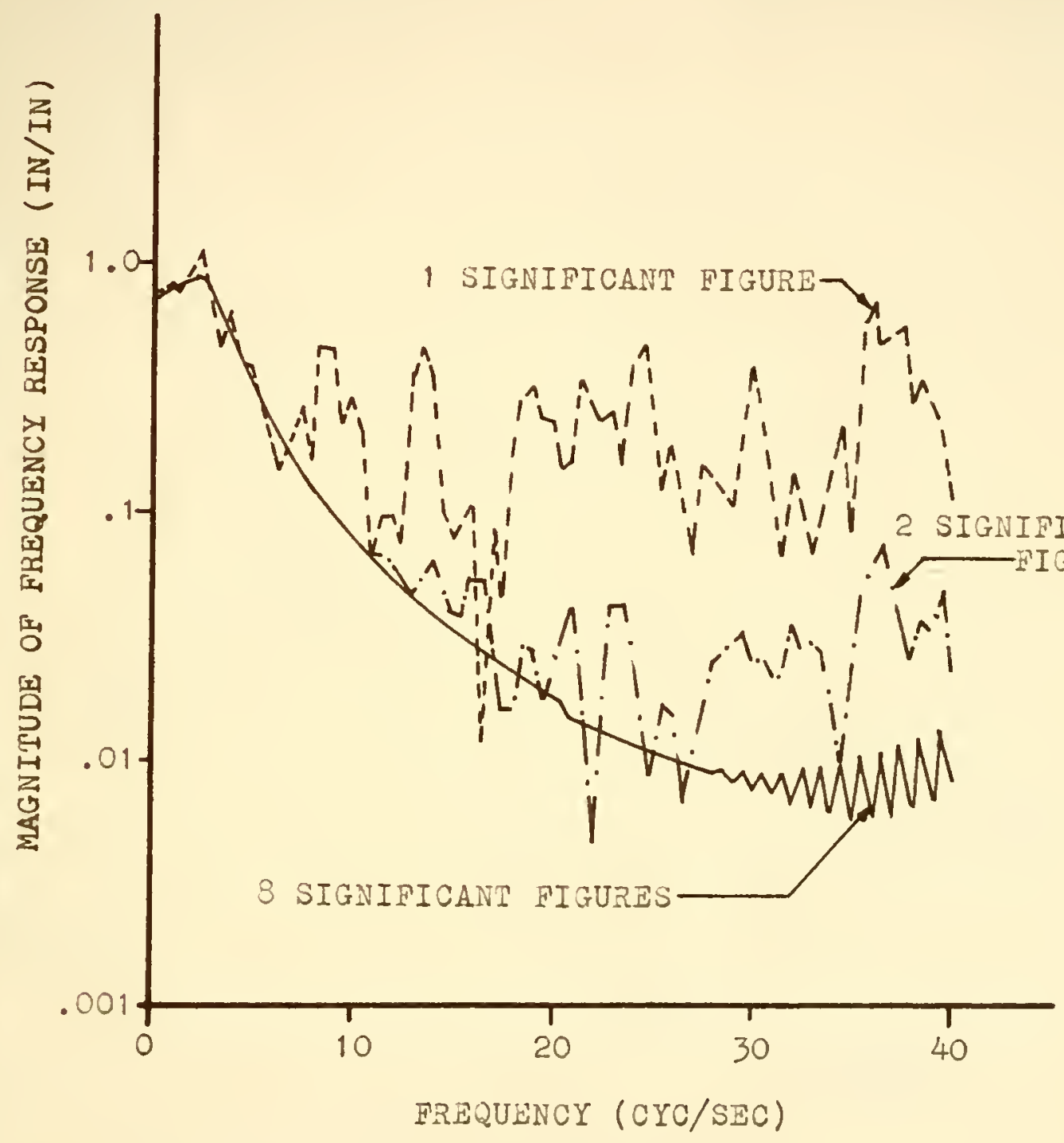

DATA SPACING $=.005$ SEC NYQUIST FREQUENCY $=100 \mathrm{CYC} / \mathrm{SEC}$

FIGURE 12 FREQUENCY RESPONSE FROM DATA OF VARYING DEGREES OF ACCURACY 


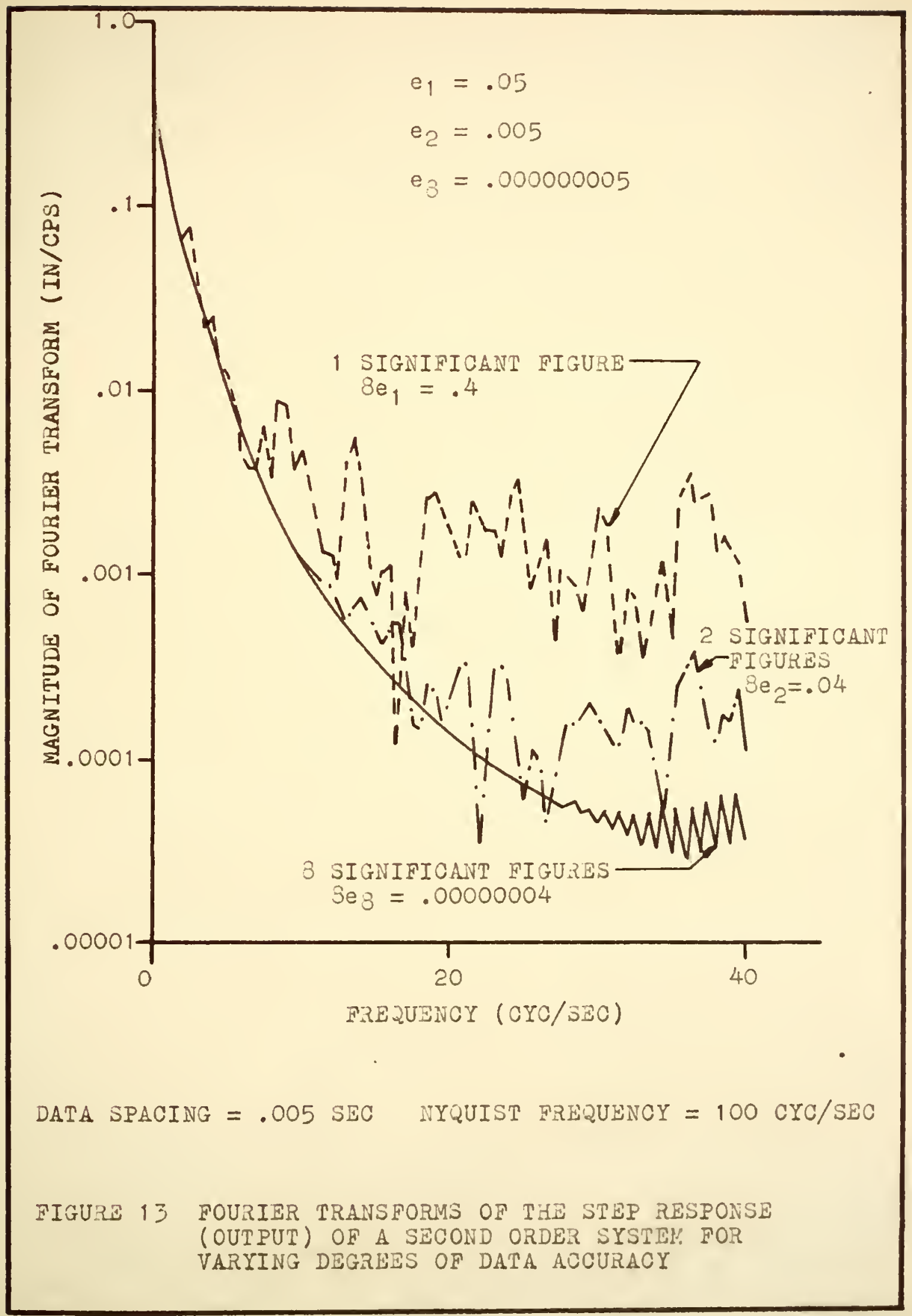


values $(0.0,1.0,1.0)$, the scatter of points of the frequency response is due entirely to the scattering of the output sounier tiansorn. If the secona criterion rere appliea to tire three transforms in givure 1 j rith e deing takej as the rounc off error in the last significant fisure of the data, tine ceaulting tince frequency responses rould do expected to bo accuate in the following manjes:

Fron data of one significant figure accuracy o - 5 cps From data of tro siorificant figure accuracy 0 - jops From data ol eight significant flume acouracy entire Lanje.

The analytical snequancy mesponse function for tins aystom is given in Fijure 5. Comparison of the various results shoin in Figure 12 with Figure 5 indicutes that the criterion holda for the resultis obtalied fron data of one significant figure accuracy, conservative results for the data of tro significant fijure accuracy, ani is not correct for the results obtained from data of einht sijnificant figure accuracy. rhe reason tint the criterion fails in the last case 1s that șinosol' rule irtegration aistorton overshadows the efrects of data inaccunacy.

The length of transient data raal anl tajulated must be considered as an additional source of error in evaluatins the Fourler transford. potal information can be obtalned 
only if the transient "econd is read to the point in time rinere the trace has reached a steady state value. But if the sampling interval is to be made as small as possible, it may not be economical to sead the recons this far. Pines 14 and 15 show the pesults when the data of the second order system shom in Fimure 3 is truncated at 1.0 and .75 second. me tcansient had practicaily died out at 1.0 second but it ras still present at .75 second. It appeans as if no lar.e arors will Iesult if the recoria are read only to 75 par cent of tic length of time unti the transleist has practically decayeo.

Mhu ran the phase an 1 e oI the Fourier trancfoms ana frequency resporses have not been discuasej. In porer spectoun work pasee ansle information is not reeded. nowever, for deterministic calculations, the phase angle of the frequency response as a function of frequency is required. Finure 16 illustrates the phase anjle of the gourier transform of the second order bysten stop response iliustiatea in Figure 3 . Above 20 cos the vhase anjie that resuits fron impson's rule analysis exhibits a laro oscillation. Asain Fizon's method shors much better resuits than simpson's rule. Up to 20 cps the rezulta froms inpson's sule fall on the analytica.l nesults. The gidon's vesults fall on the analytical results to $65 \mathrm{cps}$. 


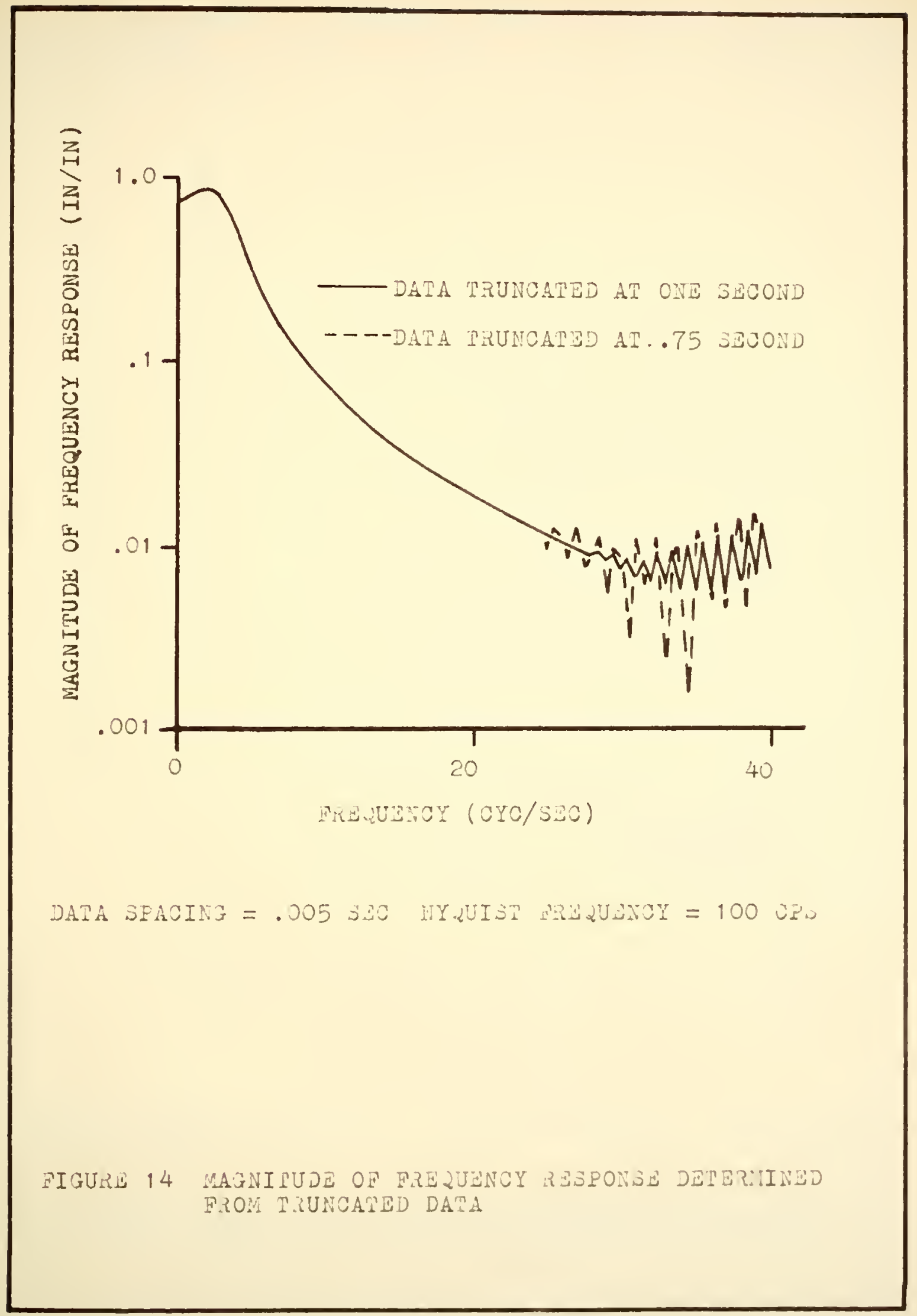




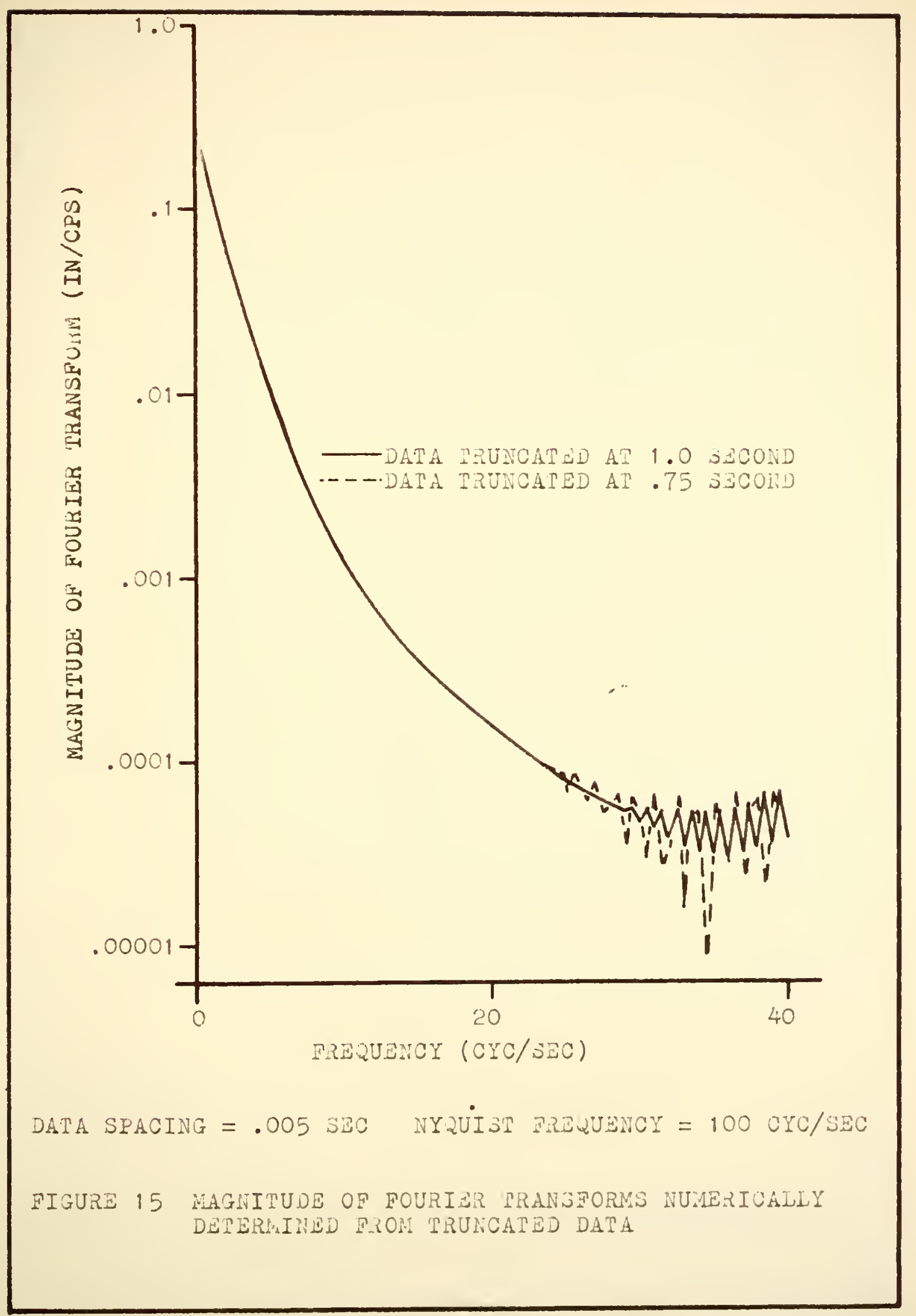




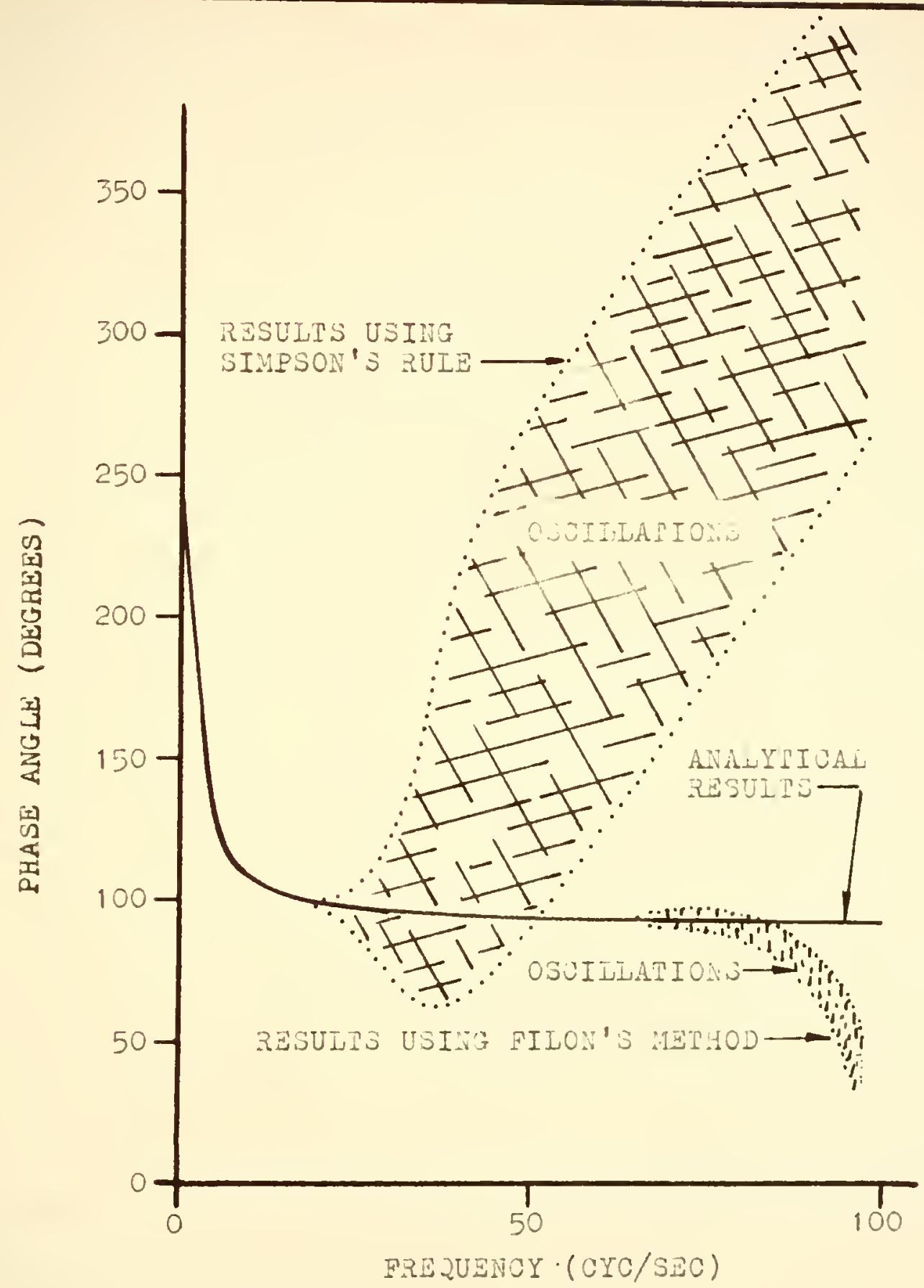

DATA SPACING $=.005$ SEC NYZUIST FREQUENCY $=100 \mathrm{IYC} / \mathrm{SEC}$

FIGURE 16 PHASE ANGLA POR TIS FOURIUR TIANSFOR:1 OF THE STIP RESPONSE (OUPPUT) OF A SECOND ORDER SYSTEM 


\section{CHAPTER III}

\section{OALIBRATION OF BQUIPMENT}

The vehicle used for this investigation was a single rear axle dump truck. The front tires and the dual rear tires were size $11.00 / 20-12$ ply nominally inflated to 75 psi. Gravel was used as ballast to obtain a total static load on the rear axle of 19000 lbs and a gross vehicle weight of $260001 \mathrm{bs}$.

In order to determine the dinamic tire forces exerted on the pavement by each tire of elther set of dual tires, the dynamic air pressure in these tires was measured.

ro overcome the difficulties listed in Chapter I, the pressure transducers were mounted on the side of the truck and were connected to the tires by flexible tubes and a rotating joint. The pressure measuring systems used for this investigation were specially designea and built since there were none avallable commercially. Part of this investigation dealt ith the forces on the left side of the truck and part dealt with the forces on the right side of the truck. Thus the pressure measuring systems were designed for interchangeable use on elther the left or right 
set of rear duals.

The principal design objective of the pressure measuring systems was to have the first natural frequency of the pneumatic components as high as possible. To meet this objective, a design procedure similar to that developed by ilison 5 was used.

In order to measure the tire pressure of the inner and outer dual independently, it was necessary to bring the two pressures through a rotating joint without cross-leakage. There were no commercially available rotating joints that could meet this requirement. Inis necessitated a rotatins joint being designed and built to meet the following specifications:

1. Continuous operation at $600 \mathrm{rpm}$

2. Continuous operation at 100 psi

3. Malntain a 60 psi pressure differential between channels

4. Prołuce negligible wheel unbalance

5. Produce no mecnanical resonances that would exc1te the pressure system

6. Easily adapted to either left or right side• operation

7. Produce no safety hazards 
The pressure measuring system for one tire is shown in Flgure 17. Valves 1 and 2 are open prior to testing as the system comes to an equilibrium temperature and pressure. During a test, valve 1 is closed and the pressure transducer then indicates the difference in pressure between the reference tank pressure and the pressure at the transducer which is related to the actual tire pressure.

The equalization restriction was provided to pass any slowly varying pressure components that would be caused by the heating and cooling of the tire. Fo minimize the resonant peaks of the pneunatic systen, two damping restrictions were provided in each pressure system. The relief valve was included for over-pressure protection of the transducer. In the event that the differential pressure across the transducer would become excessive, the relief valve dould rupture and reduce the differential pressure to zero.

In order to relate tine recorded differential pressure $P$ to the tire force $\$$, the system ras expeximentally callbrated. The results of tinis type of calibration will be referred to as $g / P$.

ro predict the dynamic tire force beneath a set of. dual tires from highwy elevation measurements, it is necessary to know the dynamic relationship between the displacement $A$ of the tread of the tires and the dynamic tire force $\vec{F}$ under each of tinese tires. It was thus necessary to calibrate the truck itself to determine the relationship 


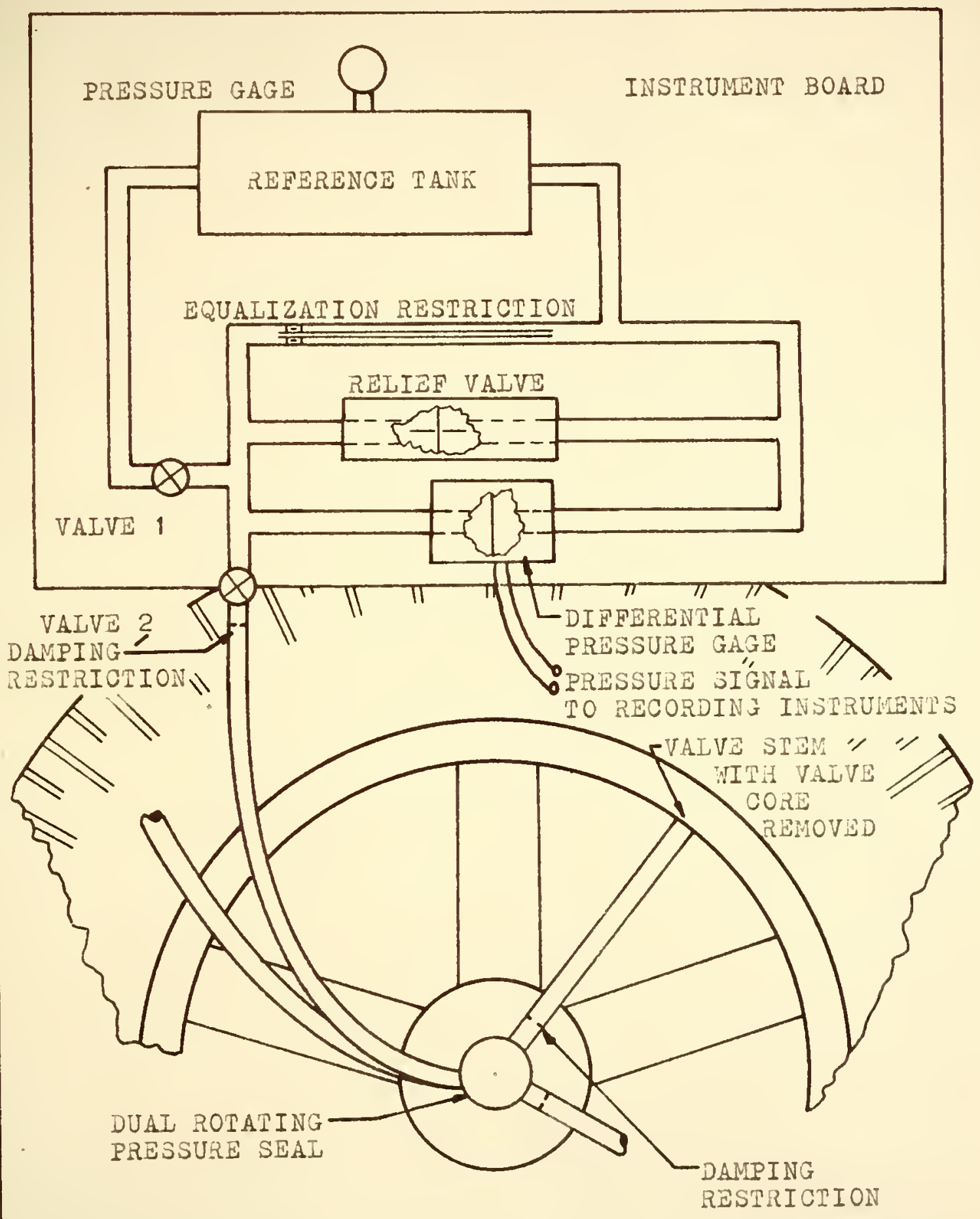

FIGURE 17 PRESSURE MEASURING SYSTEM 
between tire displacenent and tire force. This type of calibration relationship fild. be referred to $a s F / I$.

Both the $I / P$ and $I / X$ relationships vere found from recorded transient lata of tests performed on the truck Witi a drop beam calibrator. This calibrator is illustrated in ri ure 13 jonstruction details of this device are jiven in reference (7). The drop beam calibrator will produce a substantially vertical tire displacenent input that approxinates a step funotion. Lis input is applied simultaneously to both tires of the dual set. The test procedure was as follows: ith the trucli in position on the arop beau, the beam vas raised to a preselected height. Ine release device ias operated and the bean hropped to the dom position. Mis transient ilsplacenent input resulted in a tire force transient and a tive pressure transient. For an $F / A$ calibration test, tire force and displacement irere measurea similtaneously. The $I / P$ calibration test requined simultaneous seasurenent of tire force and tire pressure.

The dynanc tire force ras measured with tio load cells, one under each tire of the dual set. The placenent of these load cells is shown in fieure 13 . Sich load cell had a 7000 pound capacity and a sensitivity of approximately 0.2 min per pound at aximum anplifier sensitivity. Full scale deflection at this amplifier setting vas approximately 100 pourds. 


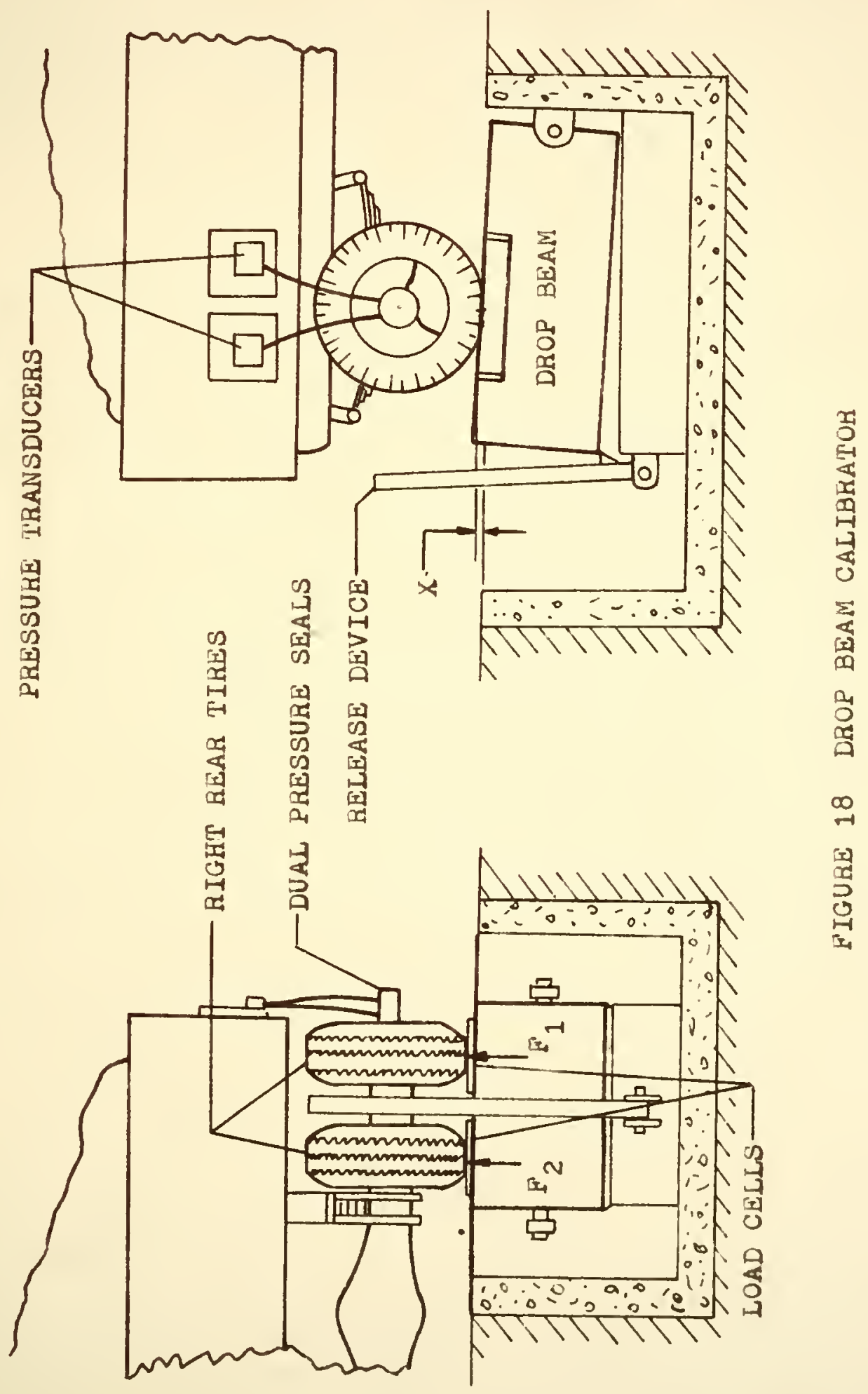


The displacenent of the dcop bean at the tires ras tine input tire aisplacement. Inds ilsplacenent ras indicated durinj the transient testin; with a potentioneter arrangement. jince the larjest tire displaccuent ras of tne order of $5 / 3$ inc.l, the motion of the beam beneath the tires vas susstantially vertical since the distance from the beam pivot to the load celle ras 36 incies. For all t.ie calibration tests, all of the truc: rineels rere at the same level wilen the beam was jom.

Tile sets of tire displacoment-tire force and tire pressure-tire force records were real, tabulated ard processed by using wuation 1 to obtain the $i / S$ and $I / P$ frequonoy responses.

Fine Initial portions of the three sets of force and pressure records are shom in Pi "ure 19. These are recoras for the $M / P$ calionation test of the night rean inger sual tire pressure measuring system. Waree different drop hefohts rere used in oraer to ietemine tho deperaence of the pressure response upon the manitude of the ingut. By using the complete transient recoris, the $i / 2$ frequency responae curvea show in $\mathrm{Fi}$ uc 20 rere obtained. iinpson's rule was used fow tire numerical inteontion. Note that, Ior the àta spacinj used in readinj the -ecoras, $f_{5}$ (the narlmur recomencel frequency to use the results fion tinis integration procedure) is $62.5 \mathrm{cps}$. Duplicate results rere obtained when Filon's procedure was employed 


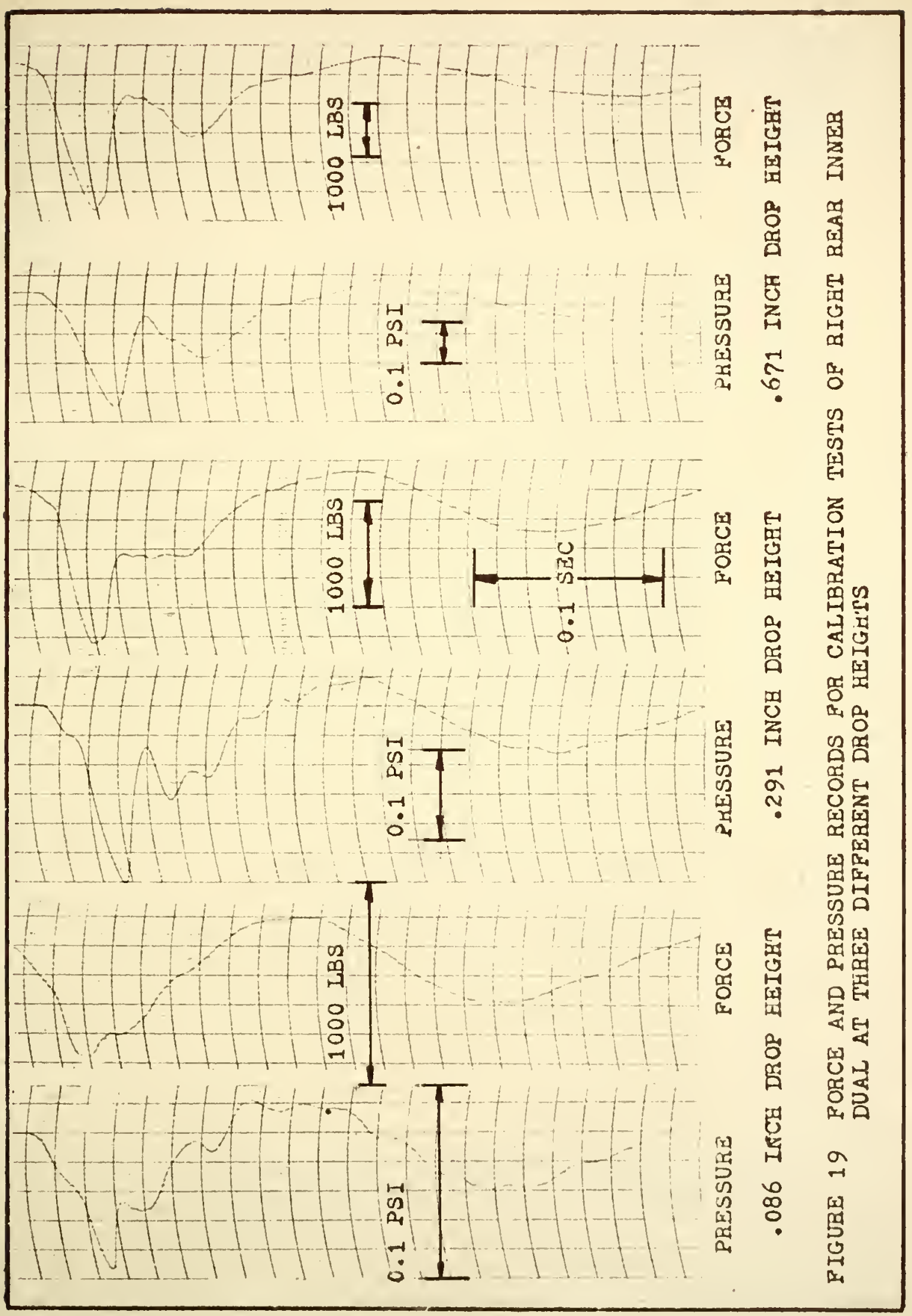




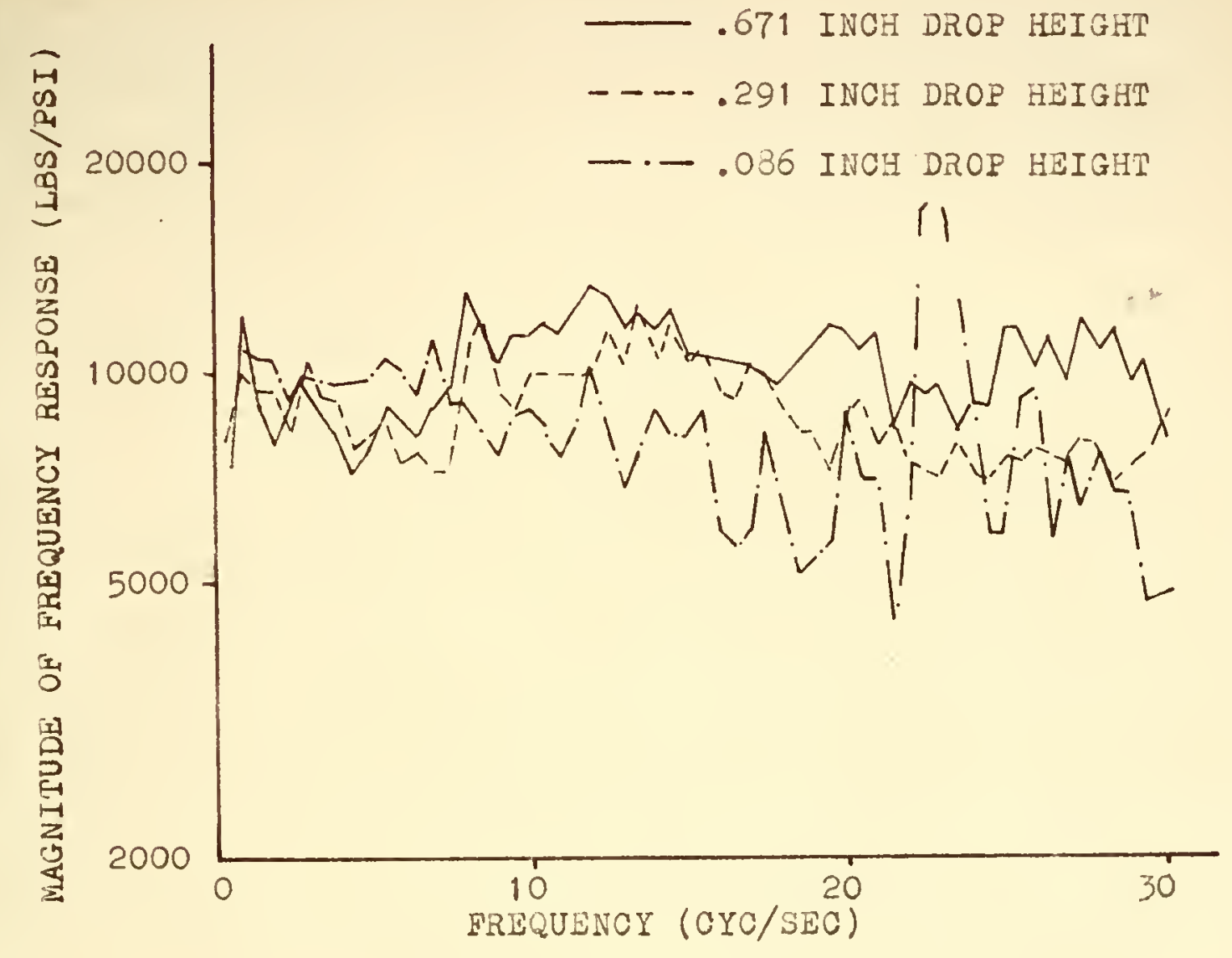

DATA SPACING $=.003205 \mathrm{SEC}$

NYQUIST FREQUZNCY $=156 \mathrm{CYC} / \mathrm{sEC}$

$f_{5}=62.5 \mathrm{CYC} / \mathrm{SeC}$

FIGURE 20 MAGNITUDE OF FREQUENCY RESPONSES FOR THE F/P CALIBRATION TESTS OF THE RIGHT REAR INNER DUAL 
for the nunerical intesration. svidently the numerical integration procedure was not the reason for the erratic results illustrated. Aliasing may be also ruled out since the record traces were recoraed on an oscillograph that had an 30 cps bandisth.

Figures 21 and 22 illustrate the apoarent reason for the questionable results inaicated in Fizure 20. These rigures show the magnitudes of the Fourier transforms of the transient force and pressure recoris. The transforms are used as the numerators and denominatore of squation 1 to determine the rrequency response curves shom in Fisure 20. The Se error criterion sugested by Driefke 19 is injicated for each transform. This criterion is in some respects analozous to a signal-to-noise ratio criterion where the spencl rould correspond to the transform and the noise rould correspond to the data readins error. It is apparent in Fisure 21 and 22 thst for both the force and the pressure transforms there is only a small portion of tire pourier transforms tiat fall above time 3e line. Hence only in a small rerion of rrequency rill the criterion be satisfied, i.e. the signal-to-noise ratio is in jeneral too $\sin 2 I 1$.

The frequency scale vas majified to clearly depict the low frequency igion from 0 to 3 cps in Fienues 23,24 , and 25. These figures illustrate the maynitude of the pressure transform, force transform, and frequency response 


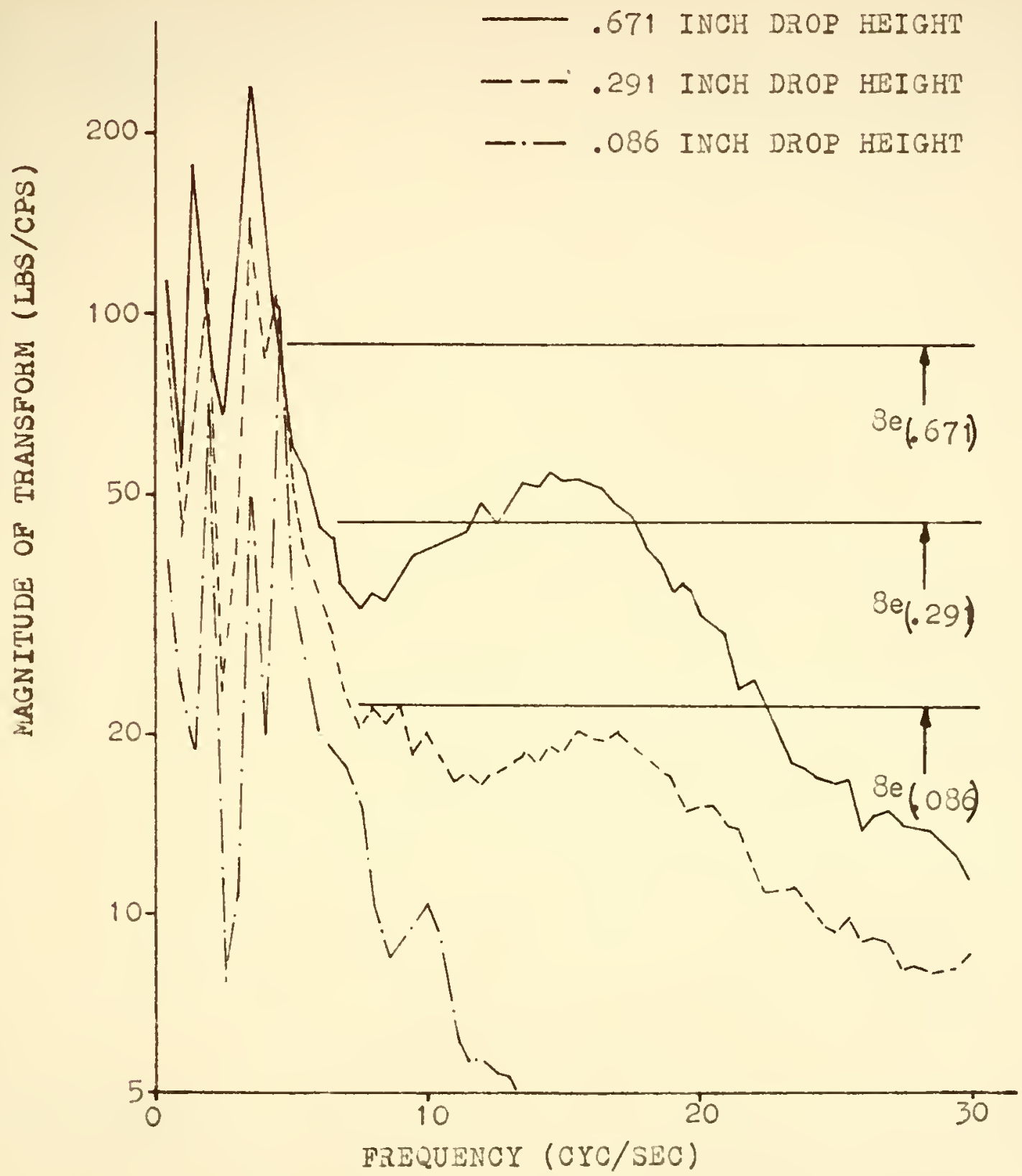

DATA SPACING $=.003205 \mathrm{SZC}$ NYQUIST FREQUENCY $=156 \mathrm{OPS}$ $f_{5}=62.5$ CPS

DATA ACCURACY (e):

$$
\begin{array}{ll}
e(.086)= \pm 2.8 \text { IBS } & 8 \mathrm{e}(.086)=22.4 \\
e(.291)= \pm 5.6 \text { IBS } & 8 \mathrm{e}(.291)=44.8 \\
\mathrm{e}(.671)= \pm 11.2 \text { LBS } & 8 e_{(.671)}=89.6
\end{array}
$$

FIGURE 21 FOURIER TRANSFORMS OF FORCE RECORDS FOR F/P CALIBRATION OF RIGHT REAR INNER DUAL 


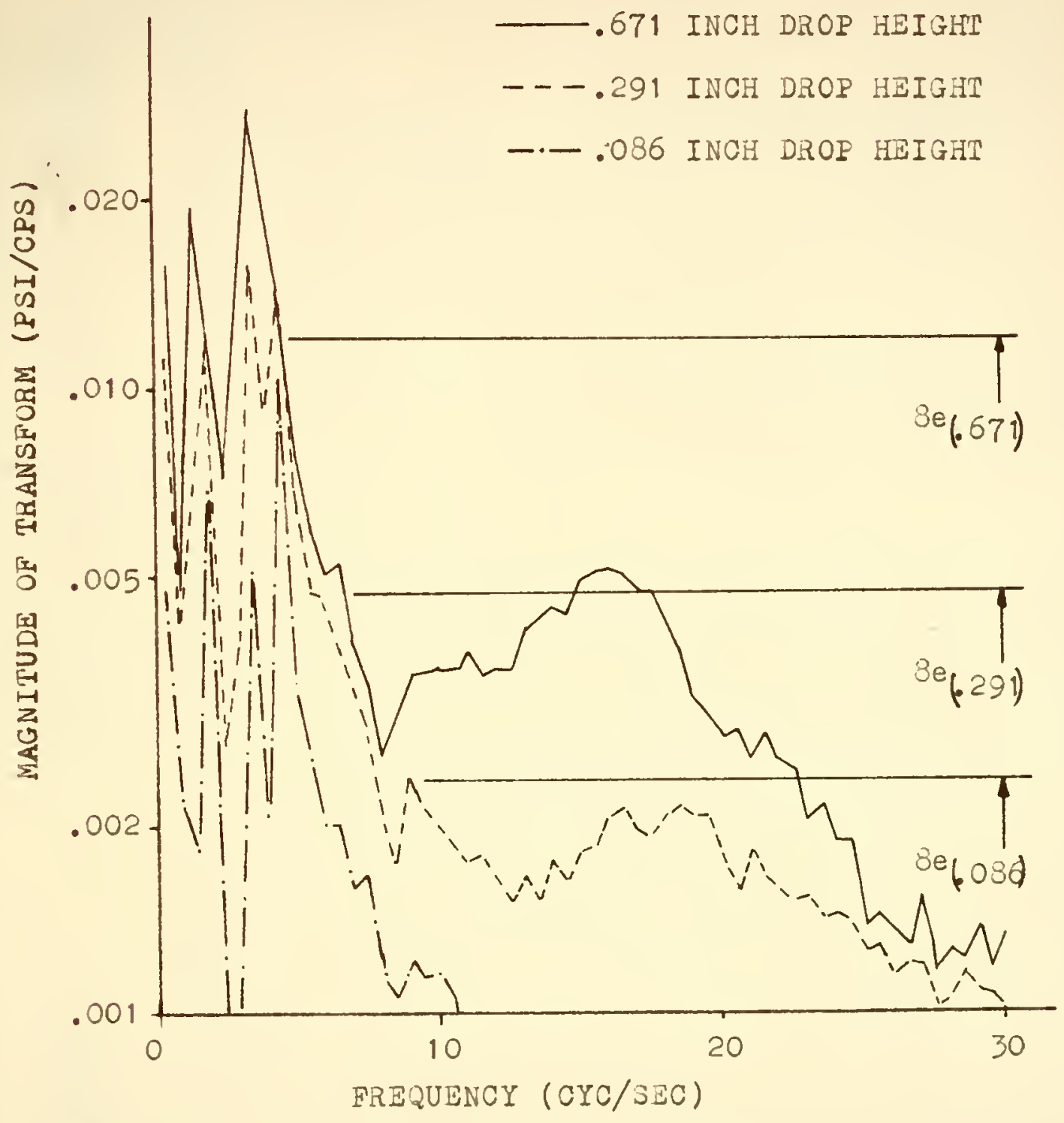

DATA SPACING $=.003205 \mathrm{SEC} \mathrm{NYQUIST} \mathrm{FREQUENCY}=156 \mathrm{cYC} / \mathrm{sEC}$ $f_{5}=62.5 \mathrm{crC} / \mathrm{SEC}$

DATA ACCURACY (e):

$\begin{array}{ll}e_{(686)}= \pm .000297 \text { PSI } & 8 e_{(.086)}=.00238 \\ \text { e(291) }= \pm .000594 \text { PSI } & 8 e_{(.291)}=.00476 \\ \text { e(67) }= \pm .001485 \text { PSI } & 8 e_{(.671)}=.01138\end{array}$

FIGURE 22 FOURIER TRANSFORMS OF PRESSURE RECORDS FOR F/P CALIBRATION OF RIGHT REAR INNER DUAL 


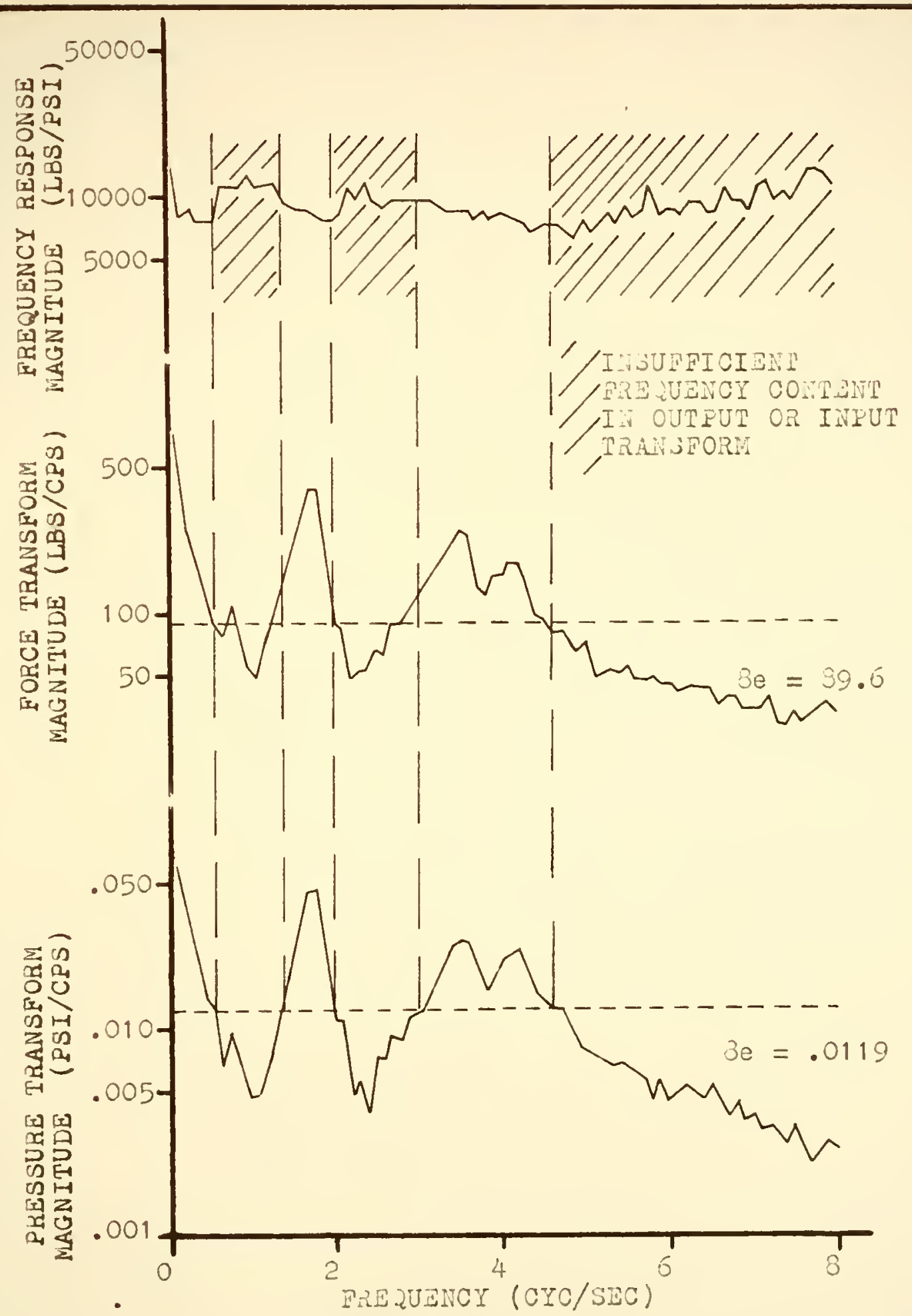

FIGU.2E 23 F/P TESI RESULTS FROM A 0671 INCH DROP TEST OF THE RIGIII REAR INNER DUAI 


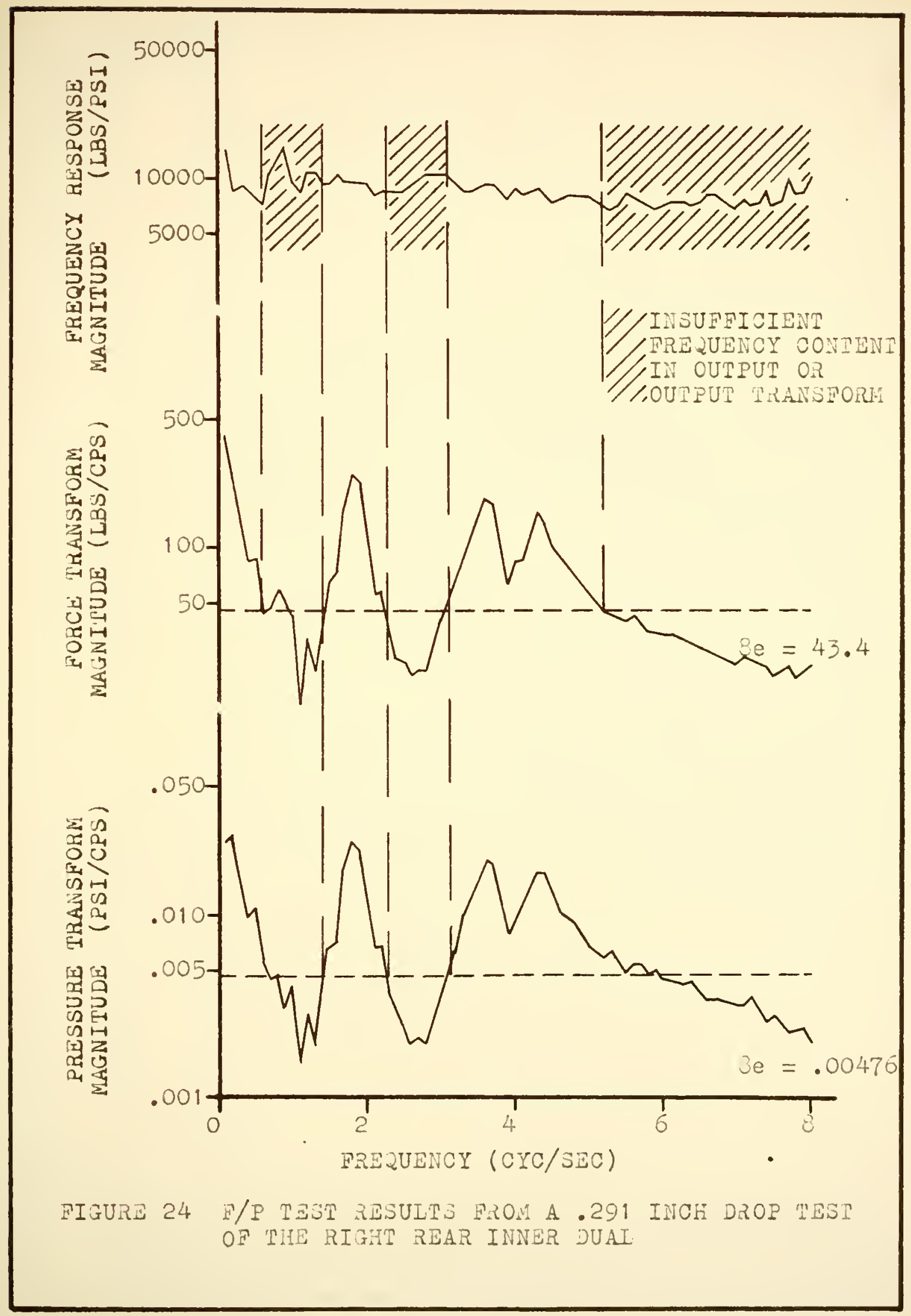




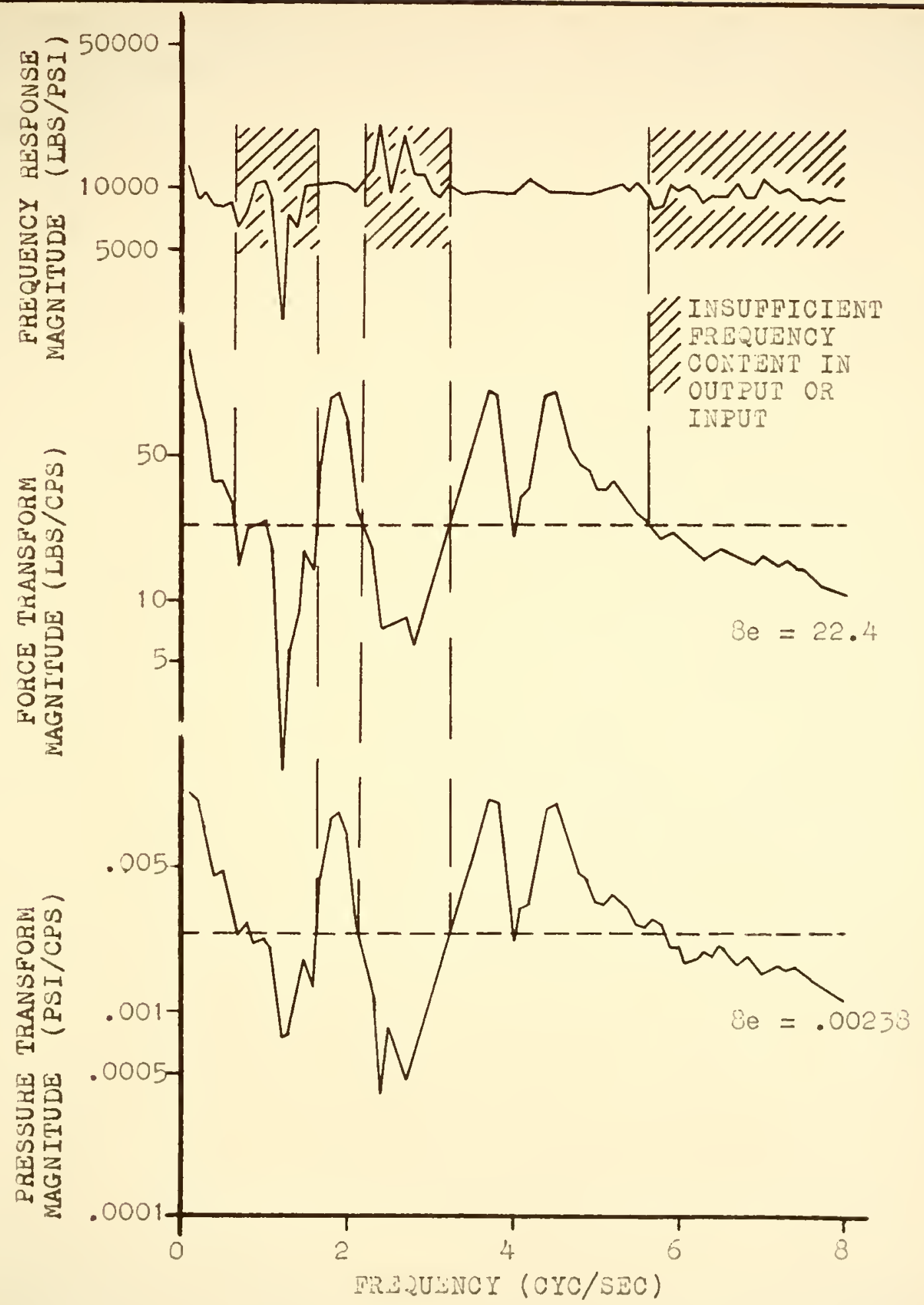

FIGURE $25 \quad \mathrm{~F} / 2$ TEST RESULTS FROM A .036 INCH DROP TEST OP THS RIGHT RIAR INNER DUAL 
for each arop height. The rejions of the frequency response curve there eitier the input or output transform falls below the be criterion are not as smooth as when this criterion is Satisfied:

This conition could not be detected until after the records had been processed. It is a direct result of inadequate recording equiprent since the pressure transducers, force cells, and amplifiers were not operated at theif maximum sensitivity. If the simal could be recorded on a device that would reduce the reading error, a laiger portion of the transforms would meet the be error criterion, provided of course, that their magnitudes are roughiy correct in the present form.

The $F / P$ frequency response curves thus obtained may not be accurate for frequencies greater than 6 cps. Hovever, this does not pose as jreat a problem as may appear. The regions in which the transforms had adequate rasnitude are precisely the resions that correspond to the resonant frequencies of the truck motion. The frequency content near these frequencies will be shown to be predominant in the test records when the truck was operated on the hishway. Thus a good estimate is available for the predominant frequercies of the recoras.

Two procedures that may be used to convert the pressure records to force records will be discussed. One is to choose a constant value of $g / P$. The value of $F / P$ in the 
cerions that satisfy tire Be error criterion would be used. In these regions the frequency response result for each drop height is approximately constant. There is approximately a 10 percent variation among the curves for the three arop heifhts in these resions which could be caused by the nonlinearities in the systen. For the risht rear inner tire pressure measuring system an average value for $\mathrm{I} / \mathrm{P}$ would be $92001 \mathrm{bs} / \mathrm{psi}$. Aowever, it must be recognized that the pressure measuring systen vill not measure a constant pressure change because of the equilization bypass. Iest results indicate that frequencies belor 0.1 cps will not be measured accurately.

The second procedure that may be used when converting the pressure records to force records is to use a weighted averaje of the frequency response curves obtained from the three drop heights. Shis procedure wil tend to snooth the 1nrezular experinental results that are caused by tie data processing. The averaged results of the left cear inner and left rear outer pressure measuring systens are siven in Figures 26 and 27. To show the sinilarity of tinese pressure measuring systems to a pure time lead system, the phase anjle for such a system with a .005 second lead is illustrated. The magnitude of the lead system frequency sesponse would be a constant. Ihis time lead corresponds to the average time it would take for a pressure pulse to travel from the pressure transducer to the tire-pavement contact point, in 


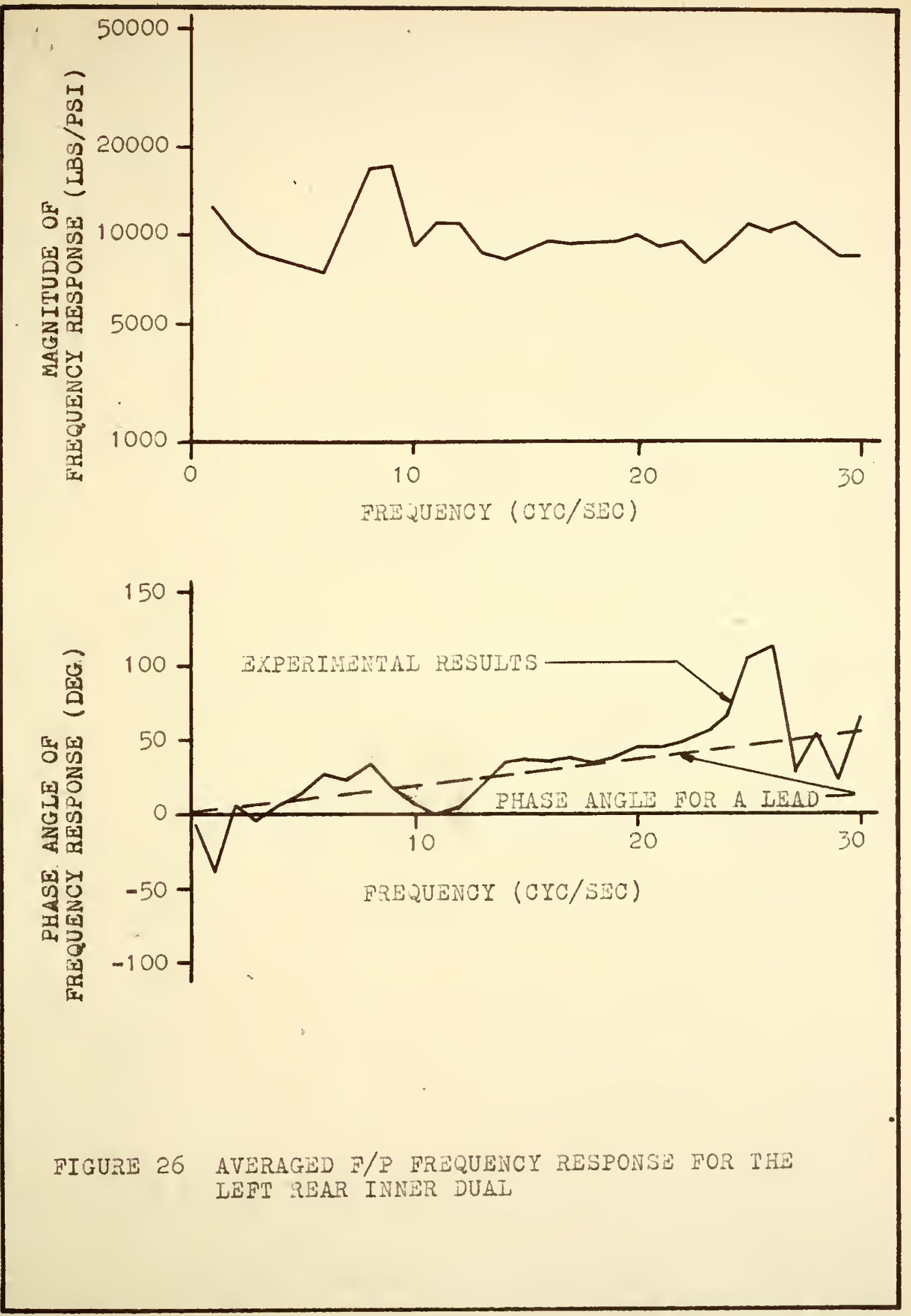




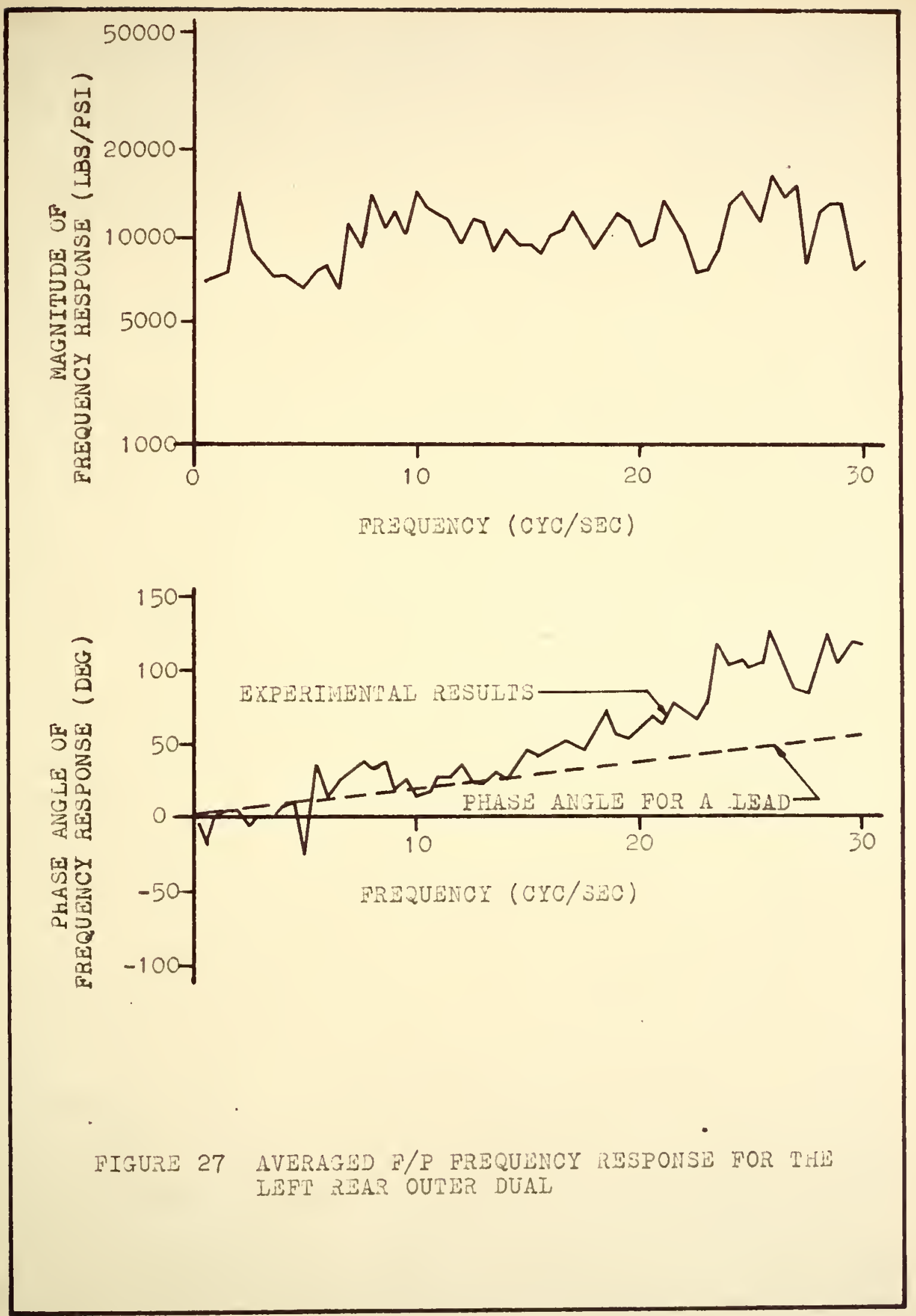


averase distance of approximately 6 feet. This distance is not constant since, as the tire rotates, the distance from the valve atem to tie tire-pavement contact point varies. Unlike the pressure measurin; systens, where resonances could be minimized by proper desizn, the ve.ricle suspension syatem was to be used tithout any modifications. Ine irequency response relationship betreen the force and the tire displacement $\mathrm{F} / \mathrm{K}$ ill then be expectal to exhibit resonances that correspond to certain moles of vehicle vibration. Initial portions of three transient test records of force ard kisplacenent are shown in sisure 2:. These records ane for displacenent of both nist rear dual tires and the force unde: the inne: riwt rear dual. inree tests at diffesent drop nei nts vere unde in orde: to deternine hoi the aginituke of the ingut affects the type of response. hen the entire lengths of the transient records are processed anc substituted into gquation 1, the cesulta in Fi jure 29 and 30 are outainej. Pre force transforms of the inne tire force recolds are almost identical to tiose illusbated in Plgure 21. The input aisplacenent transforms are shown in Fi wure 31. For comparison, Fourier tranzforns of pure steps are also siom in risure 31. The differences betreen each set of curves in pirure 31 anparentIy are not the result of data processin; errors, but the fact tinat the lnouts are not perfect steps as can be seen from the data of figure 28 . 


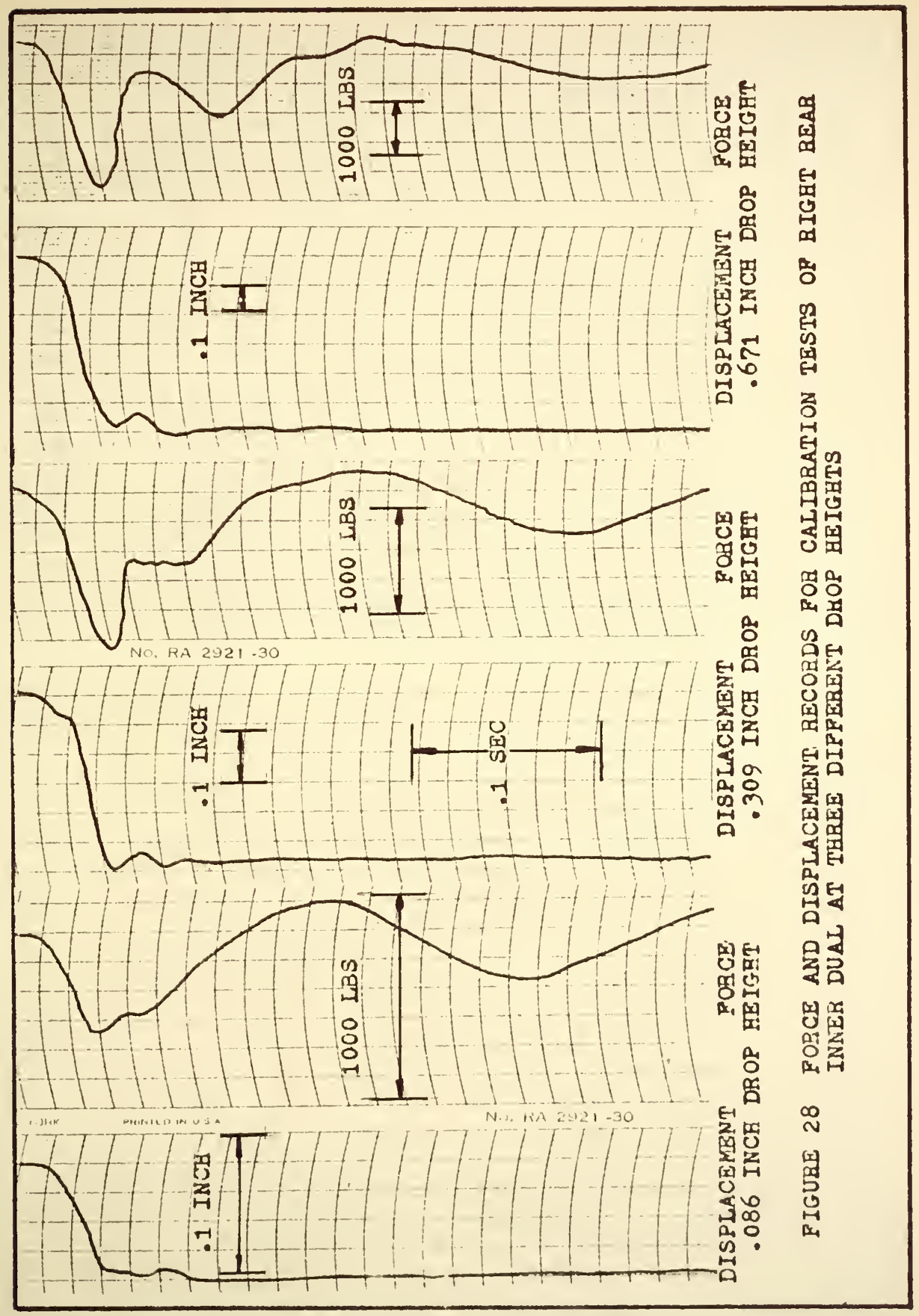




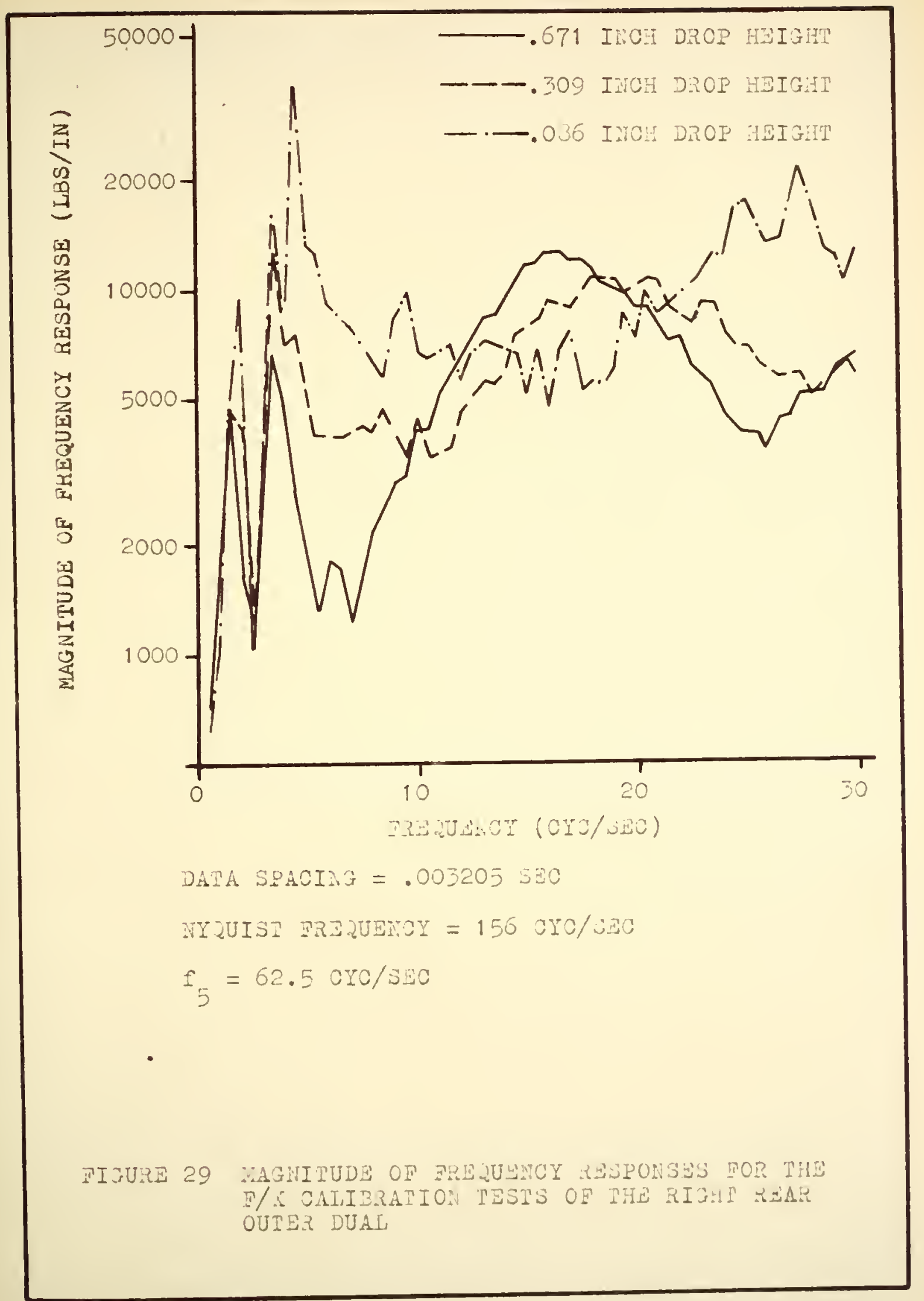




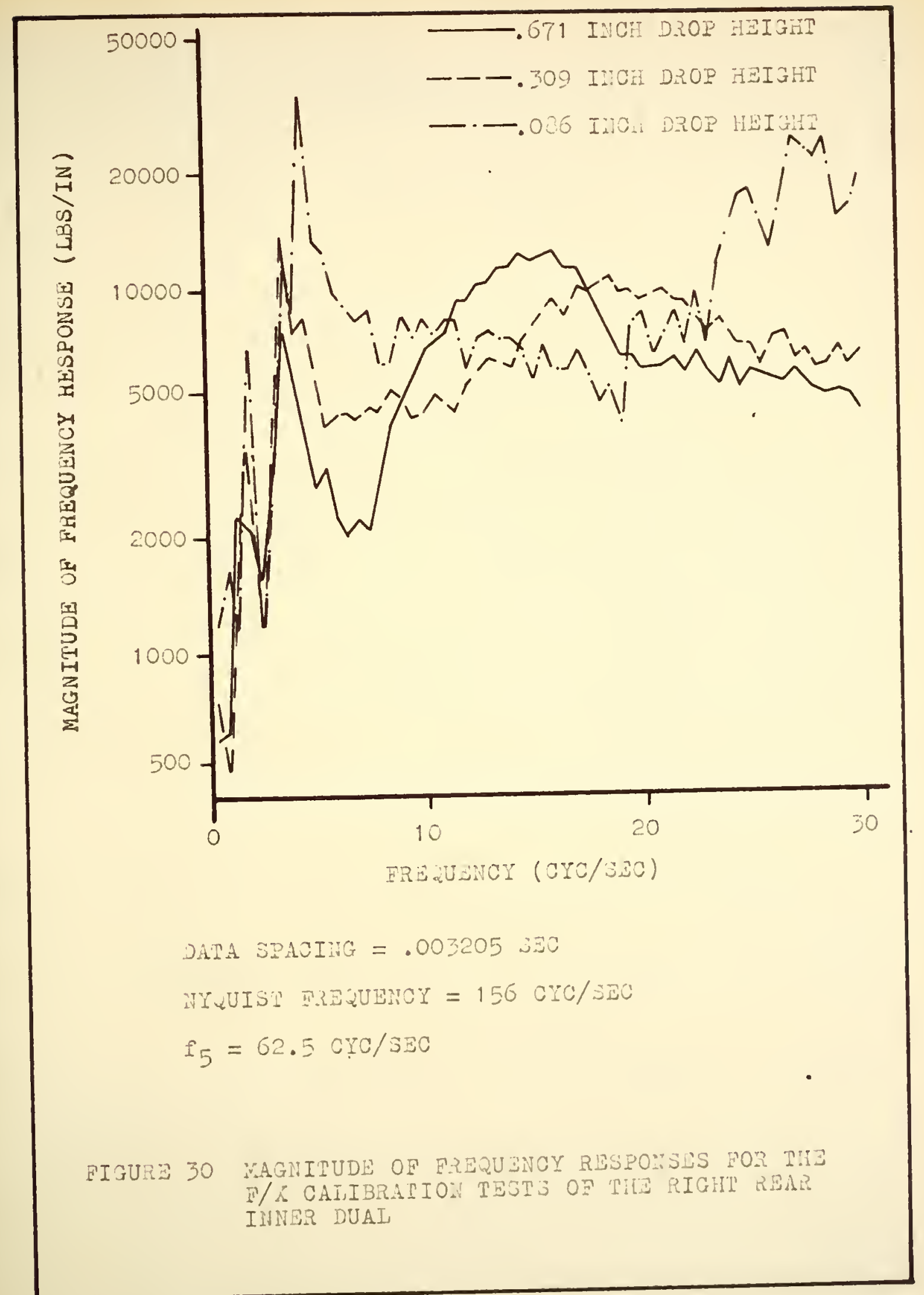




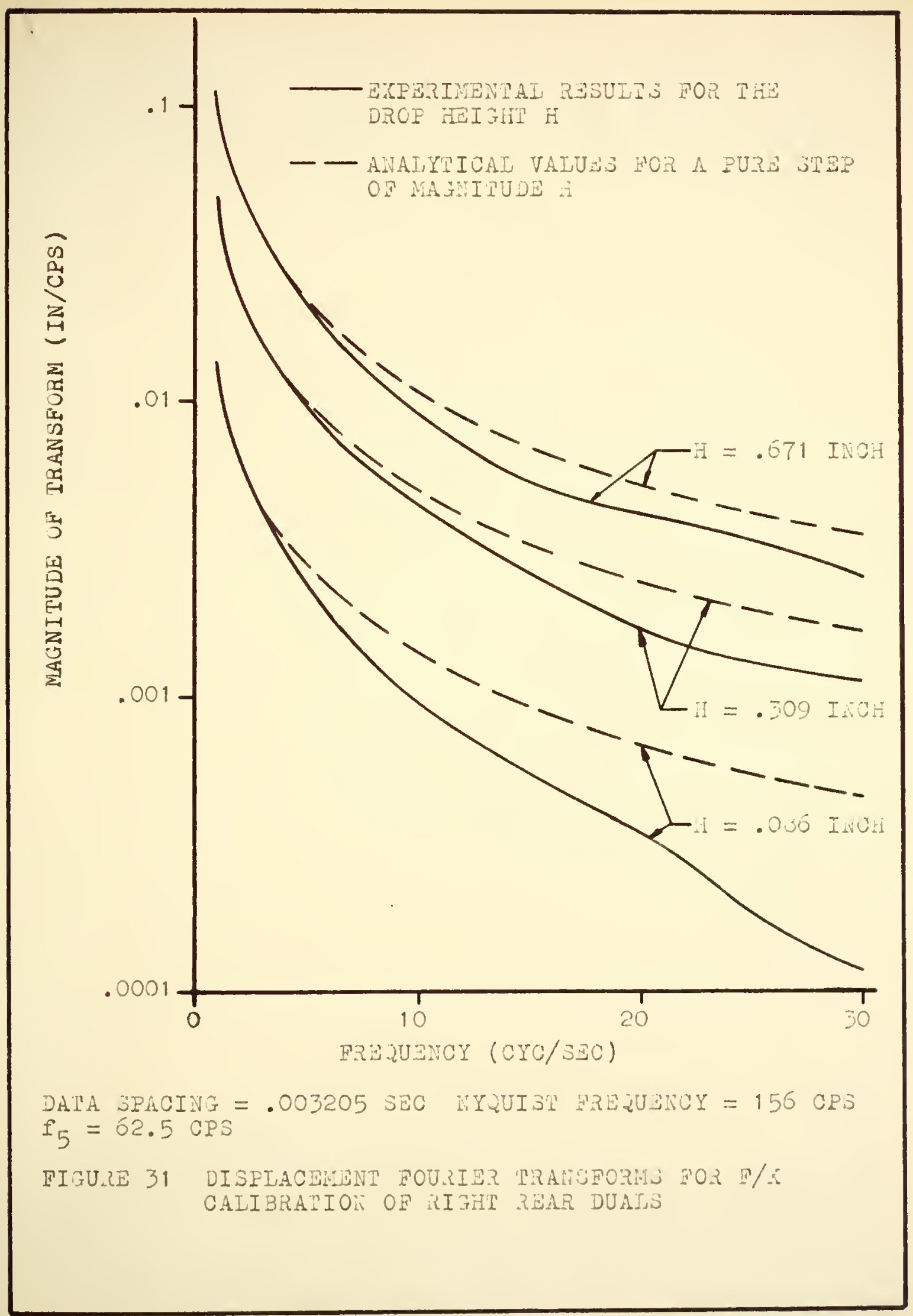


The low frequency portion of the .0 .36 inch drop $y / 5$ frequency response and the transforns of the input and output are illustiated in Ficure za. zne transform of the input does fall below the je line at about 4 cps but it dors not exilibit the usual erratic behavior associated if th a small transform masnitude compared to the readinj error. The mapitude of the force transform rould appear to be a more lojical choice to wich to apply the e criterion since it does exhidit this behavior when the magnitude is small. However, the deficiency of the frequency content is not the reason fo: tho deviation among the $\mathrm{F} / \mathrm{I}$ irequenct response curves at the lower frequencles. Dhe loit fiequency results of all three $\mathrm{H} / \mathrm{a}$ frequency responie curves a:e jiven in 1 jure $3 z$. jelot about 3 aps the curves vire

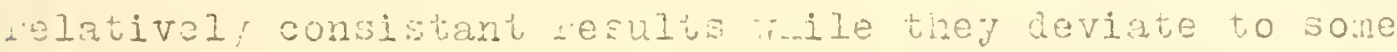
herres above tins frequency. ispecially note that the Lesonaroe at 3.6 cps doos not reach the same magnitude fo:

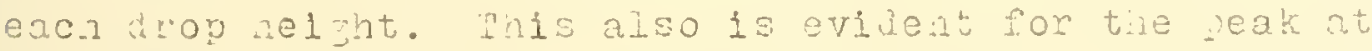
4.4 cys. lisese pears correspond to portions of tue force

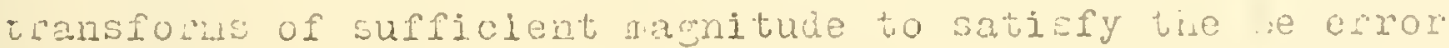
criterion. Fre apranent reason that these curves deviste can be found by insoection of Elsure an. liote that all of the irput aisplacement recods are simflar in shape but of different mantude and hence all of the rourier tiasforns of these icoords rould be expected to be similar in siape 


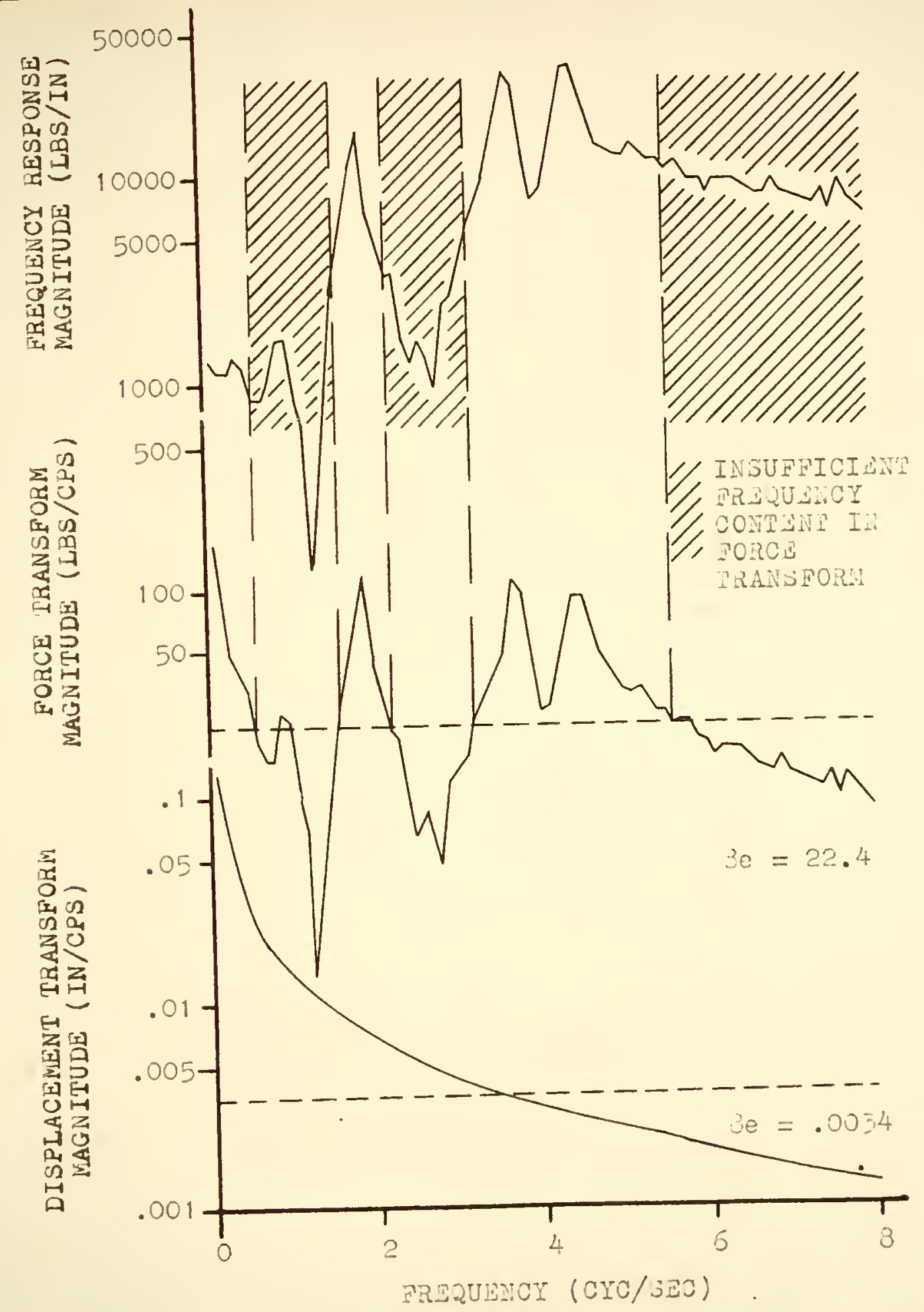

TIGURE $32 \quad \mathrm{I} / \mathrm{A}$ TEST RESULTA TROHA A .036 INCH DROP PEST OF THE RIGHT RAAR INNER DUAI 


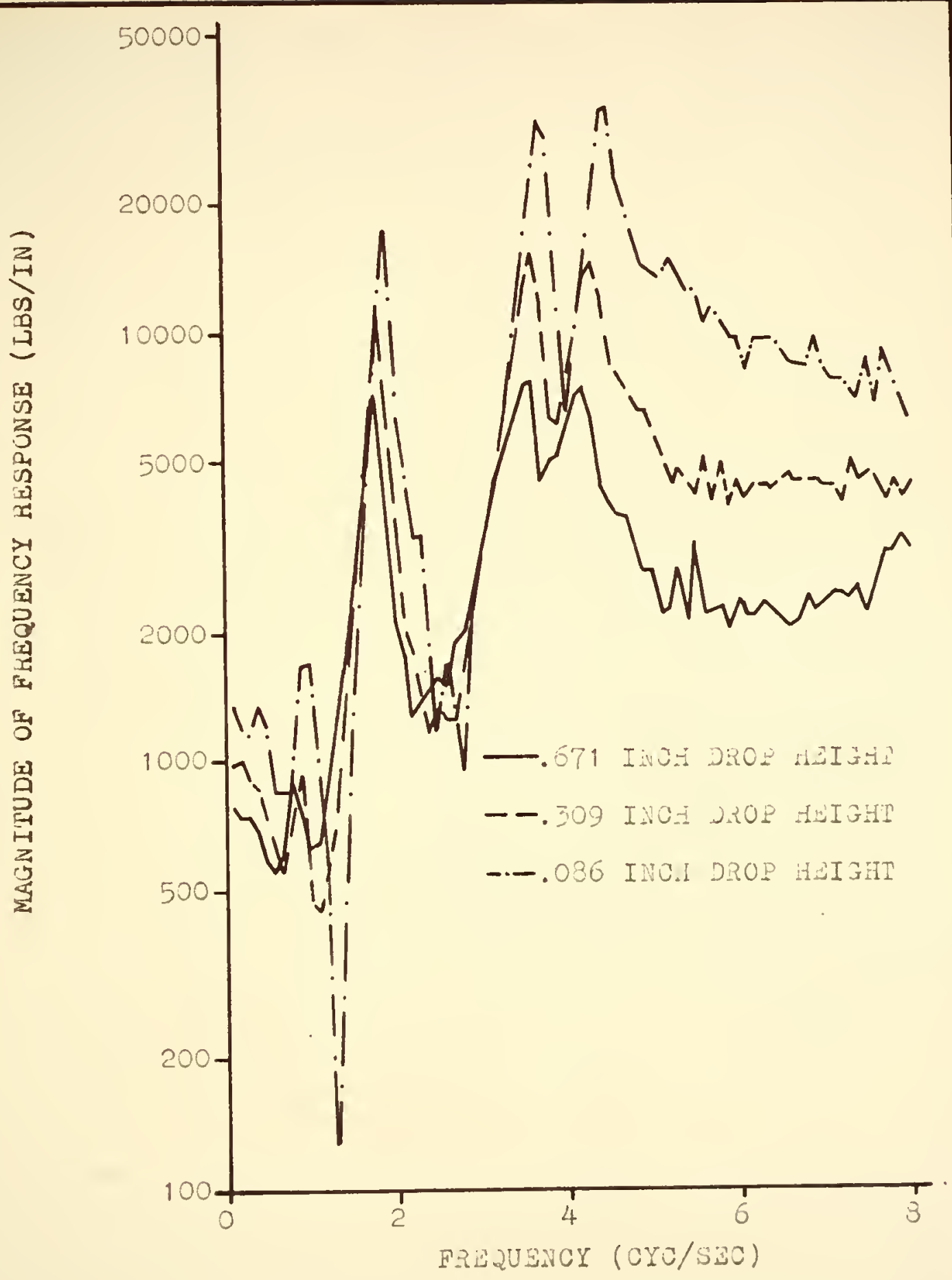

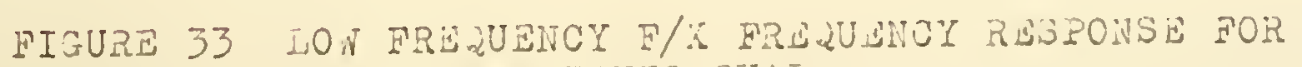
IITHT REAR INICR DUAL 
but of different wagnitude. The results in pizure 31 concur with this expectation. For a linear vehicle suspension system, all of the force records would be crpected to be of similar suape but different manitudes. Ihis vould also be expected of all the fourier transforms of the force output. lote, howeve", that all of the force records in pigure $2 u$ are not sinilar in shape near time zeso. Fur the .671 inch drop there are several aistinct cycles of a 15 cps decaying sinusoid, in the . 309 inch drop record there is one cycle of this transient, and in the .0 jó incn drop record the transient did not occur. "hle type of result would be expected lin certain types of nonlinean systems. Ihis effect is nare clearly indicated in tire force transforms of pigure 21 where at 15 cps there $1 \mathrm{~s}$ a hish relative agnitude of the transform for the .671 incir masults and a low relative waynitude of the transform for the .000 inch results.

ine most probable cause for obteining this type of force response is roulomb friction in the lear springi of the suspension system. Fijures 34 and 35 1.lustrite a possible seven dewee of freciom nodel of the truci for motions of $z, \theta_{1}, \partial_{2}, Z_{T}, \theta_{1}, z_{2}$, and $\theta_{2}$. ine Coulomb dampers are indicated by $3_{1}, B_{2}, 33$, and $B_{4}$. For large displacement inputs, the dynamic forces are larce enourh to overcome these damping forces and to permit the rear axle to vibrate between the sprunf mass and sround. I'his mode 


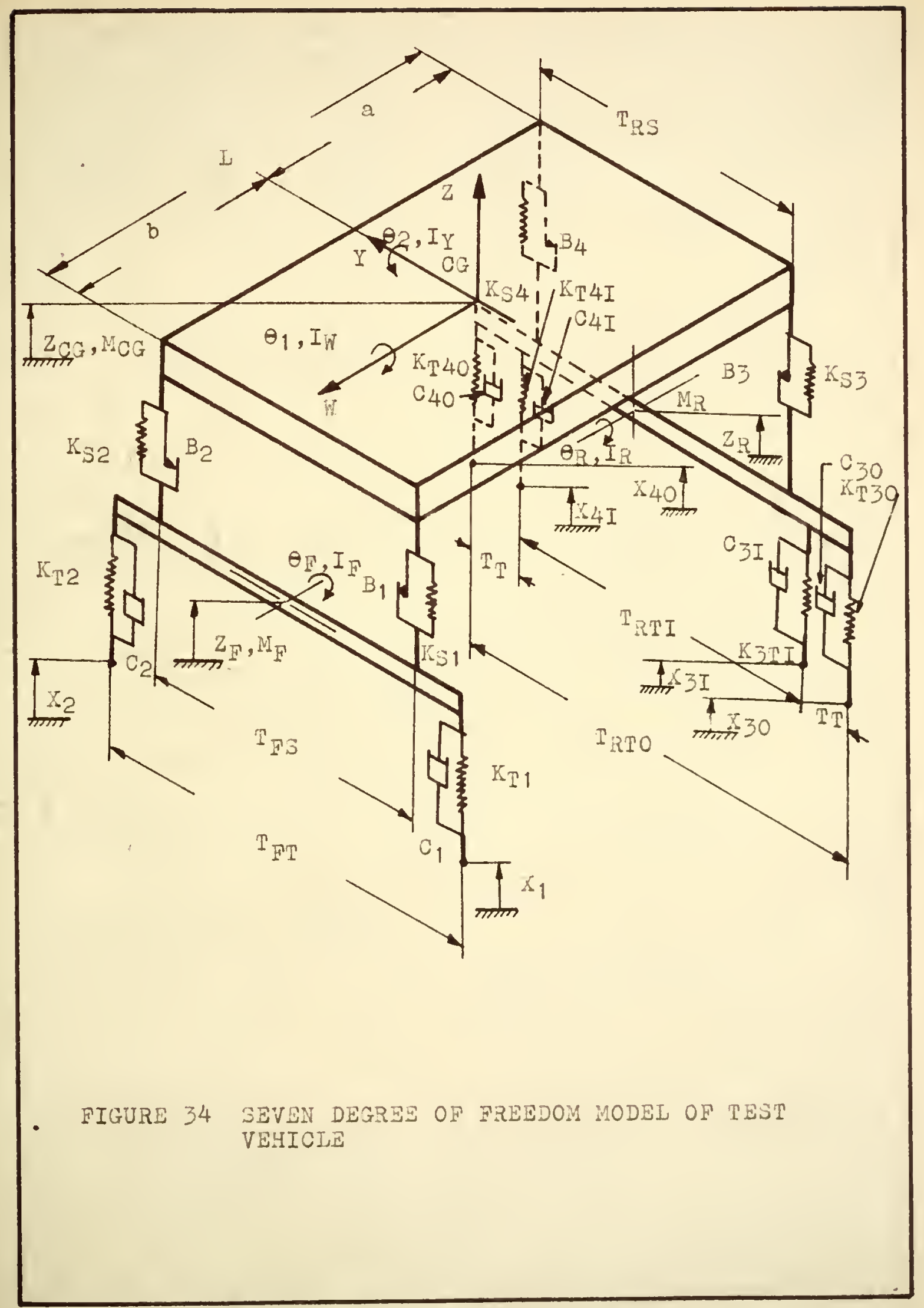




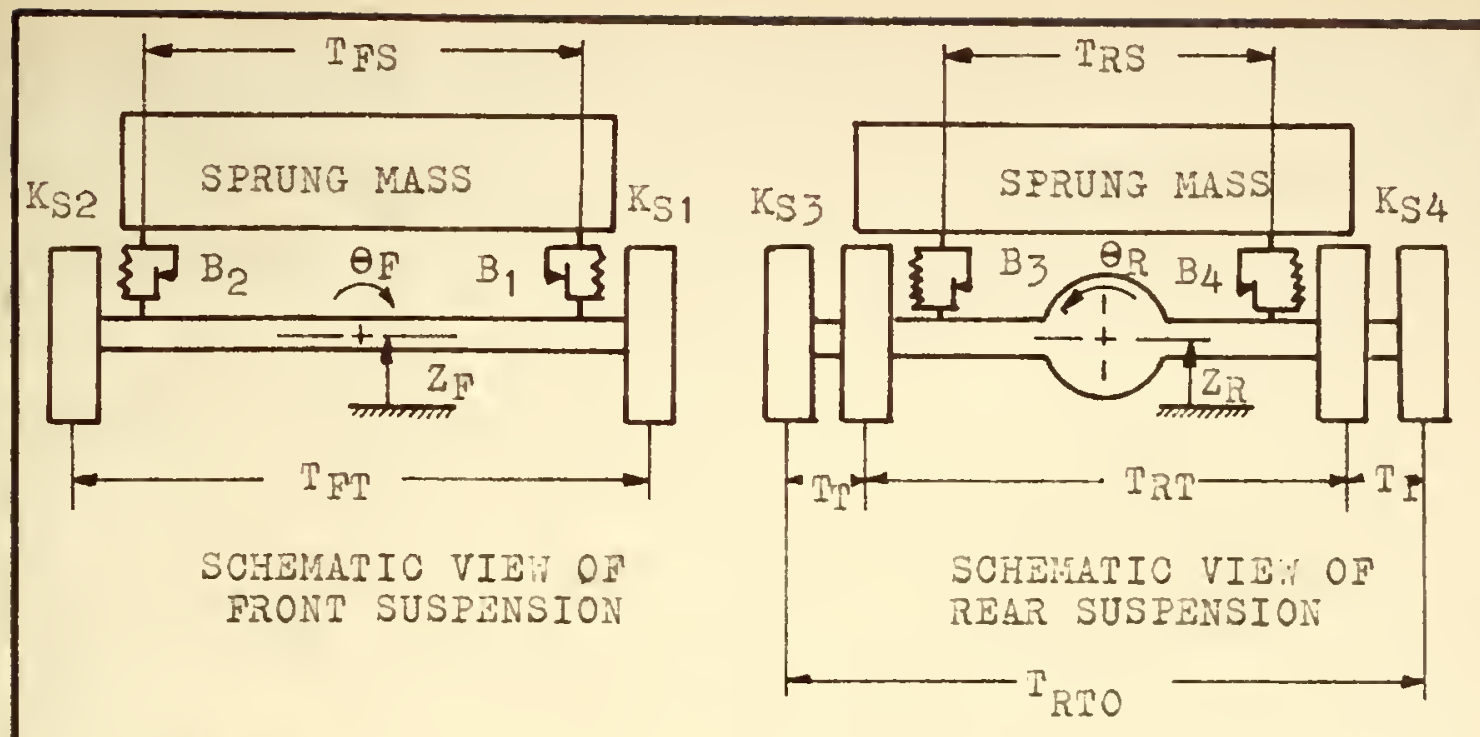

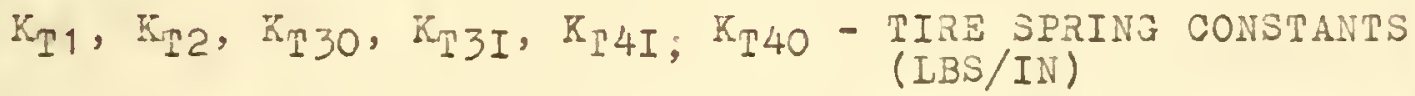
$c_{1}, c_{2}, c_{30}, c_{3 I}, c_{4 I}, c_{40}-\frac{\text { TIRE DAMPING COEFEICIRNTS }}{(\mathrm{IBS} / \mathrm{IN} / \mathrm{SEC})}$

MF, MR, MGG - MASS OF FRONT AND REAR AKLES AND BODY $\left(I B-S B C^{2} / I N\right)$

$I_{F}, I_{R}, I_{Y}, I_{W}-\frac{M A S S M O M B N T S}{\left(I B-S Z C^{2}-I N\right)}$ OF INERTIA

$K_{S 1}, K_{S 2}, K_{S 3}, K_{S 4}-$ SUSPENSION SPRING CONITANTS (LBS/IN)

$B_{1}, B_{2}, B_{3}, B_{4}$ - SUSPENSION COULOMB DAMEING (IBS)

$x_{1}, x_{2}, x_{30}, x_{3 I}, x_{4 I}, x_{40}-\frac{\text { TIRE DISPLACEMENTS }}{(\text { IN })}$

FIGURE 35 DEFIMITION OF TERMS USED FOR SEVEN DEGREE OF FREEDOM MODEL OF TEST VEHICLE 
is sometimes referred to as "axle hop" or "wheel hop." For small displacements the dynamic forces are not large enough to permit this mode of oscillation. It is not possible to state whether or not there ras a relative displacement between the axle and the sprung nass for the smallest drop neight by observing the force records directly. It is conceivable that the rear axle motion could be in phase with the motion of the sprunc nass. This node can not be recosnized in the force records as readily as the wheel hop mode. Although there are several other elements of the suspension system that are nonlinear to a degree, the coulomb friction in the leaf springs is considered as the most inportant. No tests vere made to determine if any relative displacenent between the sprung mass and the rear ayle occured during the calibration tests. However, several road tests vere nade were relative displacements or the rear axle relative to the truck bei were recorded. The experimental results woula correspond to tive displacenent of $\overline{\mathrm{K}}_{\mathrm{j}} 4$ and $B_{4}$ in Fizures 34 and 35 . Some typical results of these tests are shorn in Fioure 36. At 20 aph there was virtually no relative displacement, while at nigher speeds relative displacenents were recorded. The pear at the left of each record is the result of passing over a one inch plpe used as an event maricer. .

An interesting effect was noted during tne callbration tests. As the beam was licted to the initial neignt, the 


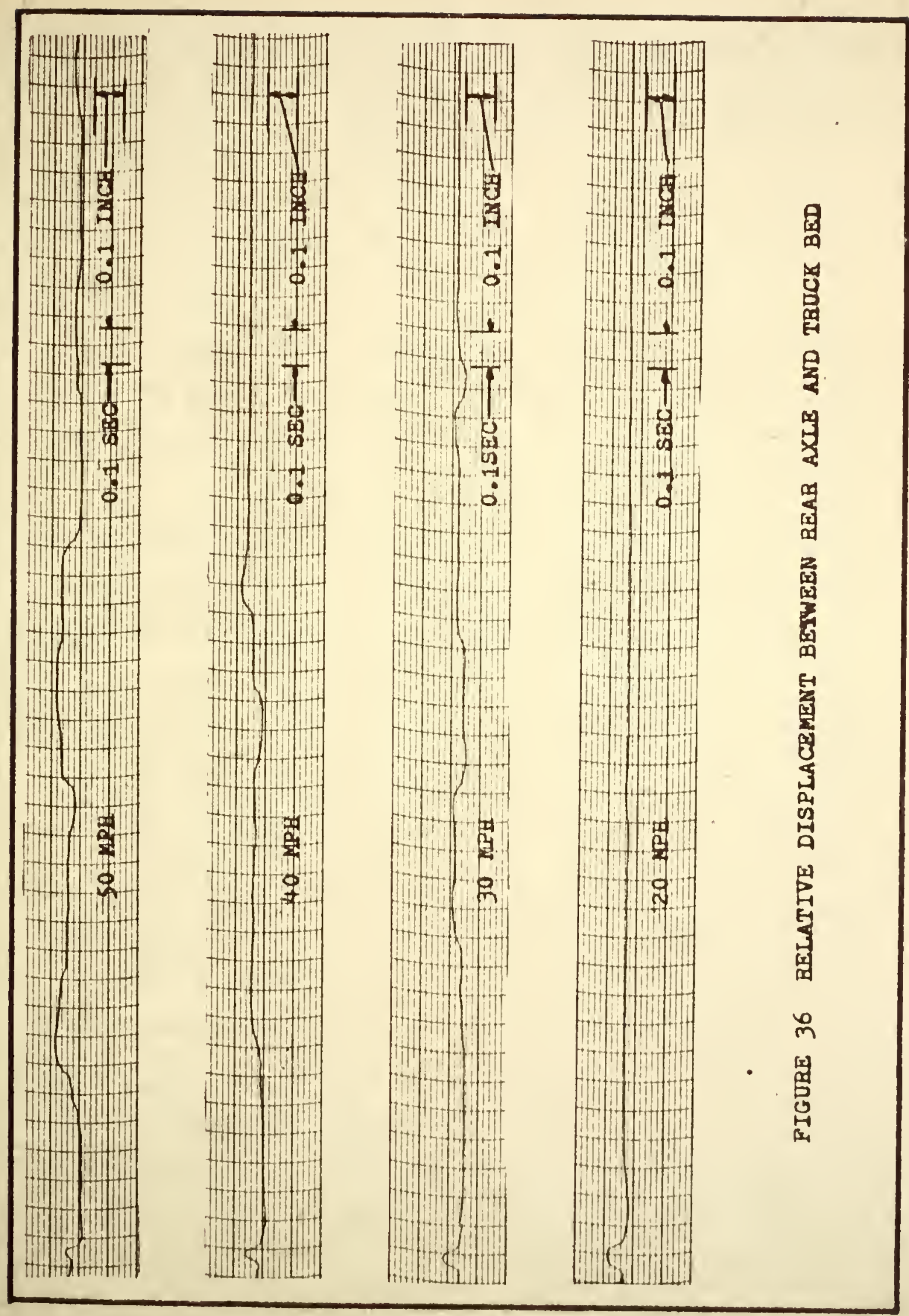


static force rould change under each dual tire. The force under the inner tire vould increase winle the force under the outer tire vould decrease. Pigure 37 illustrates these observations for the right rear set of duals. The force change is due to several causes. Ine reason that tie inner tire force increases and the outer tire force decreases is due to the relative angle betreen the rean axle and the bottom of the two tires. Inis is the angle $\theta_{.}$in the Figures 34 and 35. Apparent in Figure 37 is the fact that, as the beam is Iffed, there is a net increase in force at the rioht rear corner of the vehicle. ihis results from the resistance offered by tho otien springs at the otrer corners of the vehicle. Phere is a further effect that rould tend to cause a net reduction of the total force transmited by the tire, that is, as the trucis is tilted in the $\theta_{1}$ direction the center of gravity ill lie slijitly closer to the left side tiran to the uight, similar to an inverted penaulum. A chanje in force due to the latter tro reasors has been observed when testing sutomodiles. In attempt was made to experimentally measure the total force distribution among the rijit and left rear duals for various truck dispositions, but due to instrunentation difilculties and time limitations, the exact total force beneath eacn tire was not determined.

For purposes of comparison, the frequency response curves for an automobile, a snall truck, and the test venicle are 


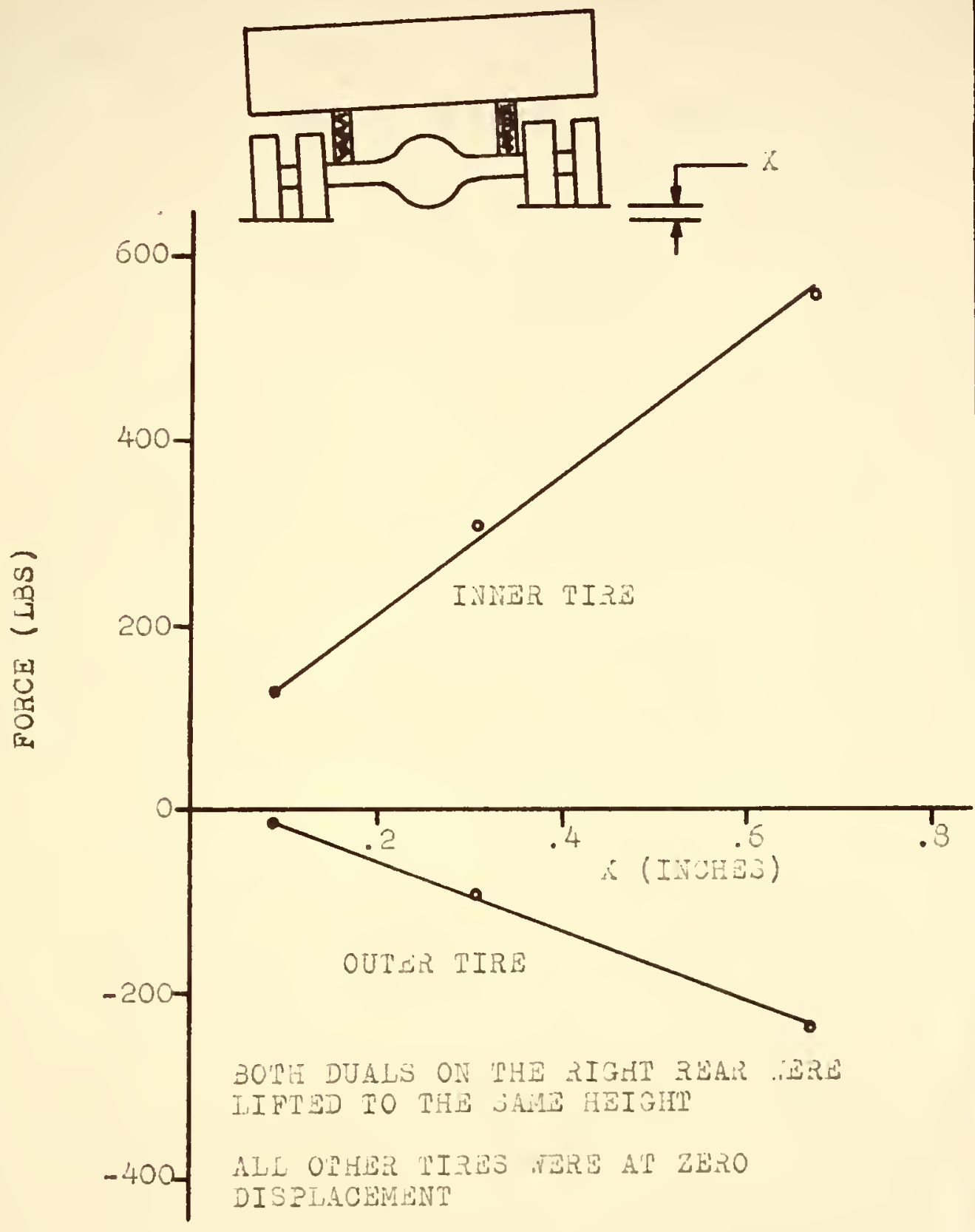

FIGURQ 37 C.AANGE IN STATIC LOAD UNDER IIRES FOR STATIC - ChANGEO IN DISPLACEMENT 
shown in ploure 33. The automobile had a jross vehicle weight of $4400 \mathrm{lbs}$ and the tires vere inflated to 30 psi. The automobile $\mathrm{F} / \mathrm{S}$ characteristic whom $1 \mathrm{~s}$ the result of a transient test where displacement and force rere recorded at the rloht front tire when tile right front tire ras subjected to a .17 inch drop on a calibrator similar to tiat shorr in Fijure 13 . Lihe small trucir had a gross vehicle wetght of 7300 los and the tire inflation pressure was 45 psi. Ine F/ characteristic shown is for a .5 inch drop displacenent of the wi pht rear aul tires and tive force under tive outer rigit rear tire. Sige resulto for tine test truch are from the . O in inch irop test. 1're $M / x$ ciaracteristic is for the outer risht rear iual. nue peaxs in the characteriatics at $17 \mathrm{cps}$ for the $7 j 00 \mathrm{G} . \mathrm{V}$. . and the automobile correspond to the rimeel hop nodes.

since tile 26000 j.V. . truck used in tils investi,gtion was on lown from the Indlana jute il may Commission, the time that it was availabie for testing was limited. For tinis reason, the major effort of tine investization ras airected toward developinj the pressure measurinj systems and conductin; road tests iith the stresses and Jeflections Group. Consequently, there vas little time avallable to investiogte the venicie suspension sjstem. Inforration obtained pertaining to the trucis suspension system was manly in the form of $F / P$ and $T / S$ calibration records. Ine load on the front and rear axle and varlous vehlcle dimensions were 


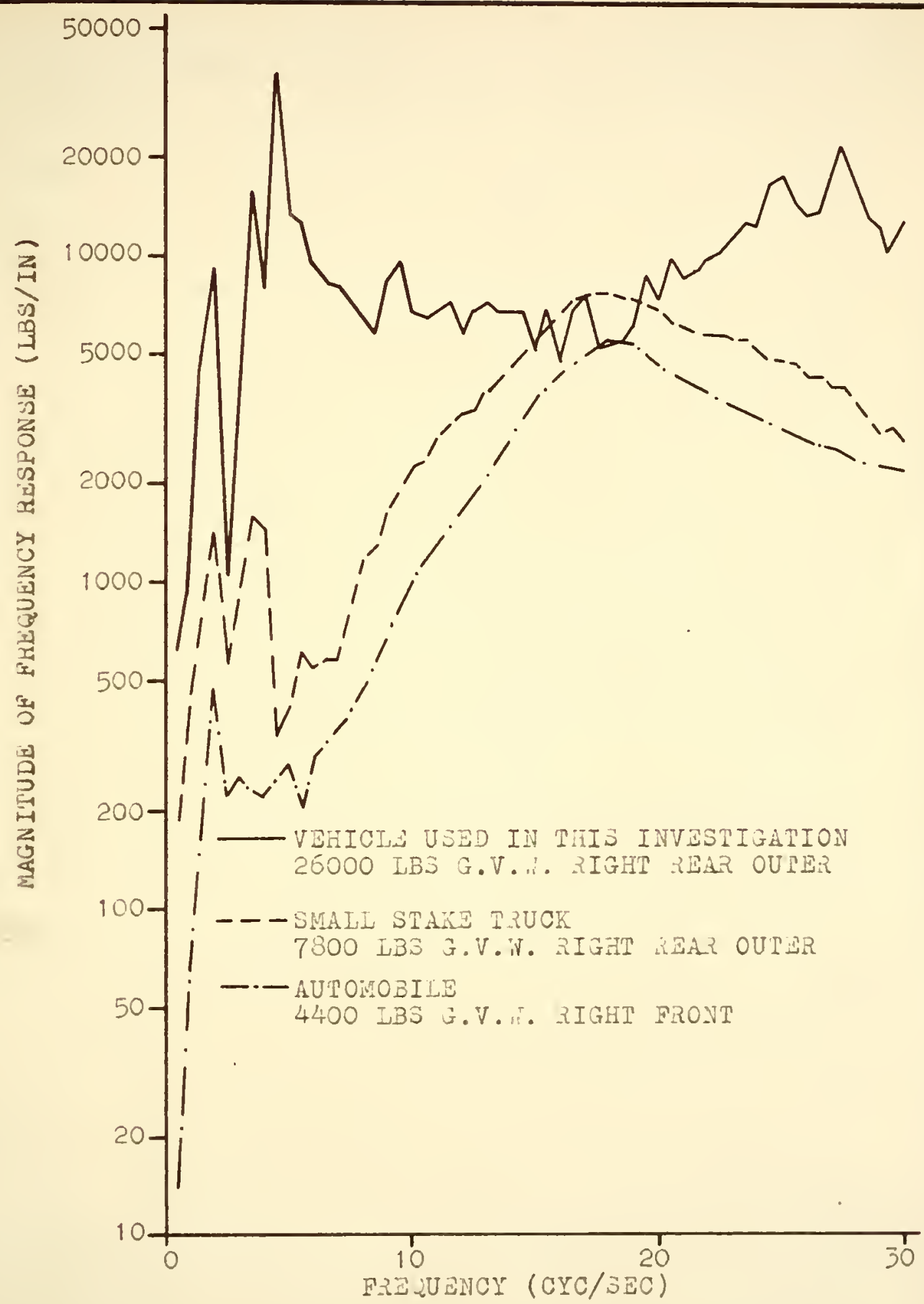

FIGURE 38 COMPARISON OF IT FERUUENCY RESPONSE FOR THREE DIFTERENT VEHICIES 
also determined, horever.

ith this Iimited information, it is aifficult to choose an experimental characteristic tiat will best describe the truci. If nonlinear theory vere to be used to predict the dynamic forces from nighwy elevation measurements, a more detailed study of the suspension systen is in orde:. Fovever, if Iineas theory is to ve employed for an approximate prediction of the dynamic tire forces from elevation measurements, it appears from the results sinom in Fijure 36 and 23 that for low speeds the ca.ipration results fron the .036 inch drop tests rould provide tie best information about the truck that is experimentally available. For the hi her speeds, the truck becomes more nonlinear and the results of the 056 inch irop tests rould be expected to be less accurate.

Since doth the vehicle suspension system and tie pressure vezuring systems vere calibrated when tire veincle tias parised, the question arises as to the effect tirat vehicle speed has on the $\mathrm{g} / \mathrm{i}$ and $\mathrm{g} / \mathrm{P}$ calibration. Fie tire tread has mass and hence the pressule measuring systen perfornance iould depend on the whel rotation speed. This problem is beyond the experiuental facilities that are currently available. Other poasiole problems of the pressure measuring system that nay not be aetected during tire calibration are: (1) eccentricity of tie tire or wheel assembly, (2) mechanical vibrations of the pressure tubins 
(3) a rockin the tire tread. However, the existance of any of these problems may sometines be found from a power spectrum analysis of the actual road test records.

The velocity dependence of the dynamic force exerted on the pavement by the truck is an important problem that must be considered in detail. experimental facilities are not available to thorounily investigate this problem. This problen will be discussed with reference to a mathematical model of the vehicle suspension system. The model show in Flsures 34 and 35 could be used except that tile numerical values of 3 it parameters are required. The values of only six of tnese paraneters rece detemined durins the time that tine truck was available. Because of the extended nature of the corresponding equations of motion, they are not listed. Substantial simplification can be cealized if the assumption is made that the leaf springs in the suapension system do not deflect. This assumption is justifled for lov vehicle speeds by the results of Figure 36. The assumption completely i snores the possibility of the axle hop mode, but road test records indicate that this mode is not usually excited at any speed. The primary effect of the leaf springs vould be to produce a smaller effective spring constant at each conner of the vehicle. The model based on this assumption is shoin in ligure 39.

For this model, mowledze of 10 parameters is needed. of these, six are known. Approximate values of the other 


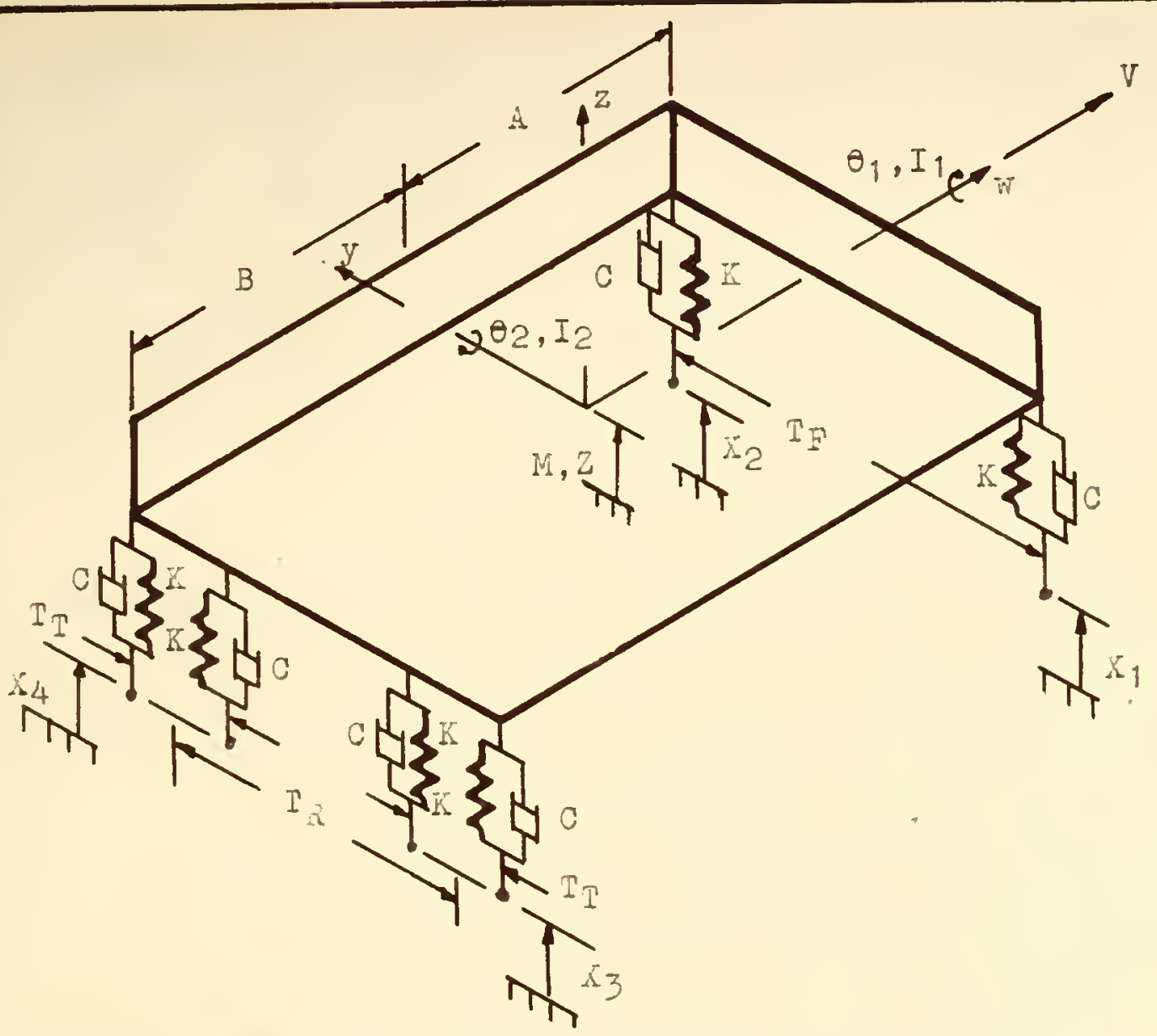

K: TIRE SPRING CONSTANT (IB/IN)

C: TIRE DAMPING CONSTANT (LB-SEC/IN)

$I_{1}, I_{2} ;$ FASS MOMSNTS OF INERTIA $\left(I B-I N-S E C^{2}\right)$

Y?: VEHICLE NASS (IB-SRC2/IN)

Z: VARTICAL DISPIACENENT OF CG (IN)

$x_{1}, X_{2}, X_{3}, X_{4}$ : VERTICAL TIRE DISPLACEHENI (IN)

V: 'VEHICLE' VEIOCITY IN W DIRECTION (IN/SEC)

FIGURE 393 DEGRES OF FREEDOY HODEL OF A TRUCK 
four constants were obtalned from references (4) (20). In Figure 39 the wyz axis is fixed to the center of gravity. The equations of motion are similar to those in reference (21). There is a small difference between these equations and those derived in reference (22). For small deflections about the static equilibriun position, the equations of motion are:

$$
\begin{aligned}
& I \ddot{z}+6 C \dot{z}+6 K z+2 O(2 B-A) \dot{\theta}_{2}+2 K(2 B-A) \theta_{2} \\
& =\mathrm{KX}_{1}+\dot{C}_{1}+\mathrm{KX}_{2}+\dot{C X}_{2}+2 \mathrm{KX}_{3}+2 \dot{C O}_{3}+2 \mathrm{KX}_{4}+2 \dot{C O}_{4}
\end{aligned}
$$

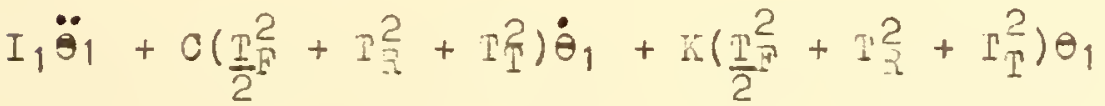

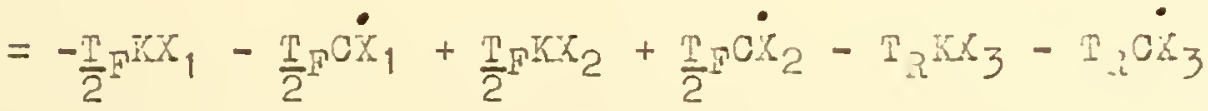

$$
\begin{aligned}
& +T_{2} K_{4}+T_{2} \dot{C O}_{4}
\end{aligned}
$$

$$
\begin{aligned}
& I_{2} \ddot{\theta}_{2}+2 C\left(A^{2}+2 B^{2}\right) \dot{\theta}_{2}+2 K\left(A^{2}+2 B^{2}\right) \theta_{2}+2 C(2 B-A) \dot{Z} \\
& +2 K(2 B-A) 2=-A K X_{1}-A C \dot{X}_{1}-A K X_{2}-A C \dot{X}_{2} \\
& +2 B K X_{3}+2 B C \dot{X}_{3}+23 K K_{4}+2 B C \dot{X}_{4}
\end{aligned}
$$


The dynamic forces exerted at the right rear inner and outer wheels are:

$$
\begin{aligned}
F_{I}=K\left[X_{4}-Z\right. & \left.-B \theta_{2}-\frac{1}{2}\left(T_{R}-T_{T}\right) \theta_{1}\right] \\
& +C\left[\dot{X}_{4}-\dot{z}-B \dot{\theta}_{2}-\frac{1}{2}\left(T_{R}-T_{T}\right)_{\theta_{1}}\right] \\
F_{O}=K\left[X_{4}-Z-\right. & \left.B \theta_{2}-\frac{1}{2}\left(T_{R}+T_{T}\right) \theta_{1}\right] \\
& +C\left[\dot{X}_{4}-\dot{z}-B \dot{\theta}_{2}-\frac{1}{2}\left(T_{R}+T_{T}\right) \dot{\theta}_{1}\right]
\end{aligned}
$$

Tiro nethods are avallable for checing the accuracy of this model. One is to determine tire tire force from equations 17-21 when $x_{1}, x_{2}$, and $x_{3}$ are zero and $x_{4}$ is the tire displacement recorded durin; an experimental calibration test. The Initial conditions for this orocedure are:

$$
\theta_{1}(0)=\frac{T_{3} x_{4}(0)}{\frac{\left.T_{T}^{2}+T_{i}^{2}+T_{T}^{2}\right)}{2}}
$$

$$
\theta_{2}(0)=\frac{x_{4}(0)}{2(A+B)}
$$

$$
Z(0)=\frac{A \times 4(0)}{2(A+B)}
$$


A comparison is shom in Figure 40 of the force-time relationship computed from the model for the .086 inch drop input and the corresponding experimental values.

The other way to check the nodel, wilcin would be equivalent to the first method if the truck vere linear, Is to compare the analytical frequency response of the model Hith the experinental frequency response of the truck. This comparison is made in Figure 41 with the .036 inch drop test results. rom pigures 40 and 41 it is evident that the analytical transient response and frequency response do not exactly duplicate the erperimental results although they are of a similar character. It does appear that the theoretical frequency response does agree with the results of the .026 inch drop in some regions as vell as do those of experiments conducted using largor drop heights.

Although the model does not exactly represent the real system, it does approximate it closely enough so that some general conclusions may be reached concerning the vehicle velocity relationsinips. It is assumed that both the inner and outer rear dual whecls experience the same input. It is furthe assumed trat when the input of a front tire is considered, the wheel path of the front tire is the same as the comnon rear rineel path.

The ray that velocity enters into the vehicle response is the time lag involved for the vear tires to experience an input after the front tires have cxperienced input. This can be illustrated by the following hypo- 


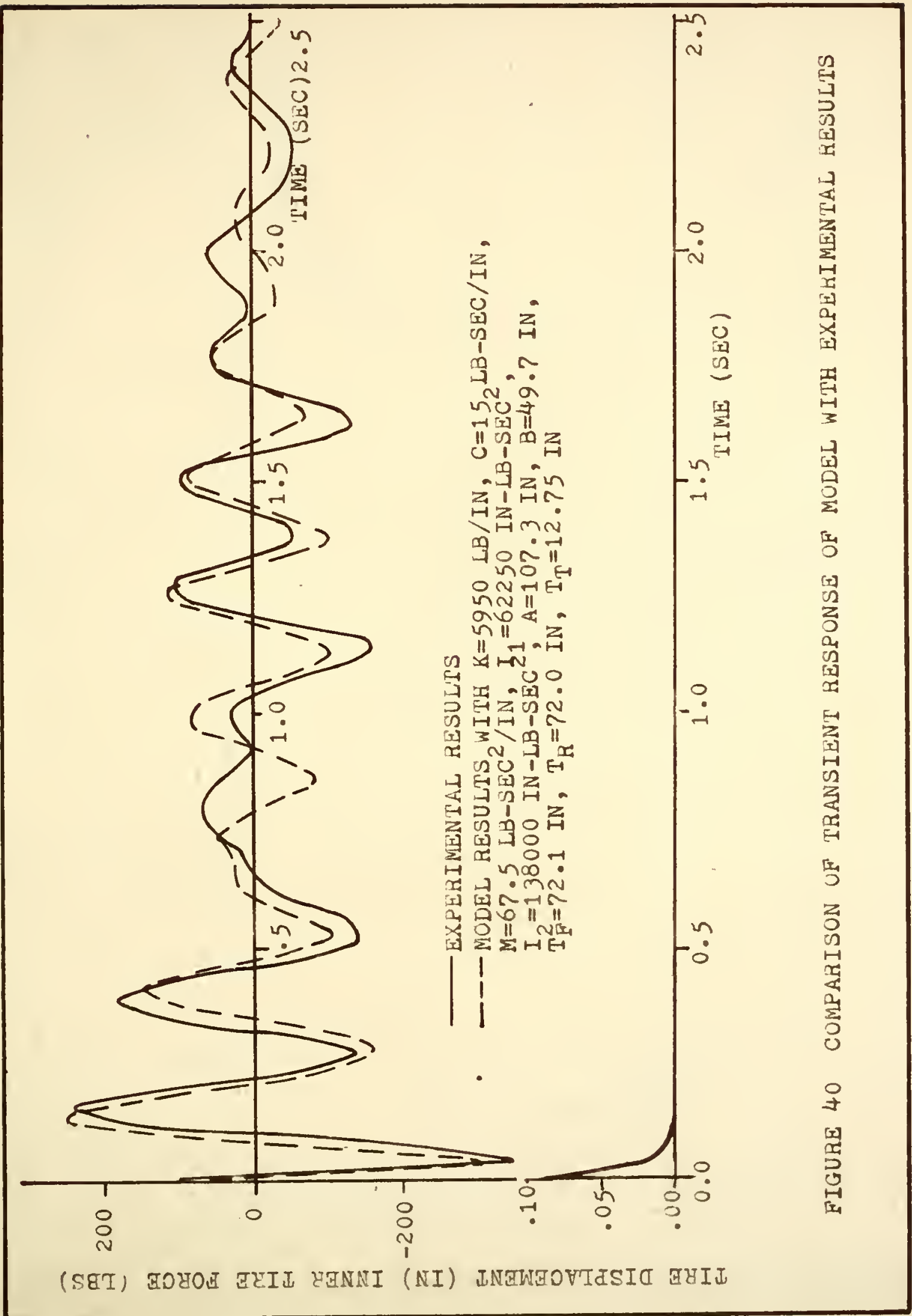




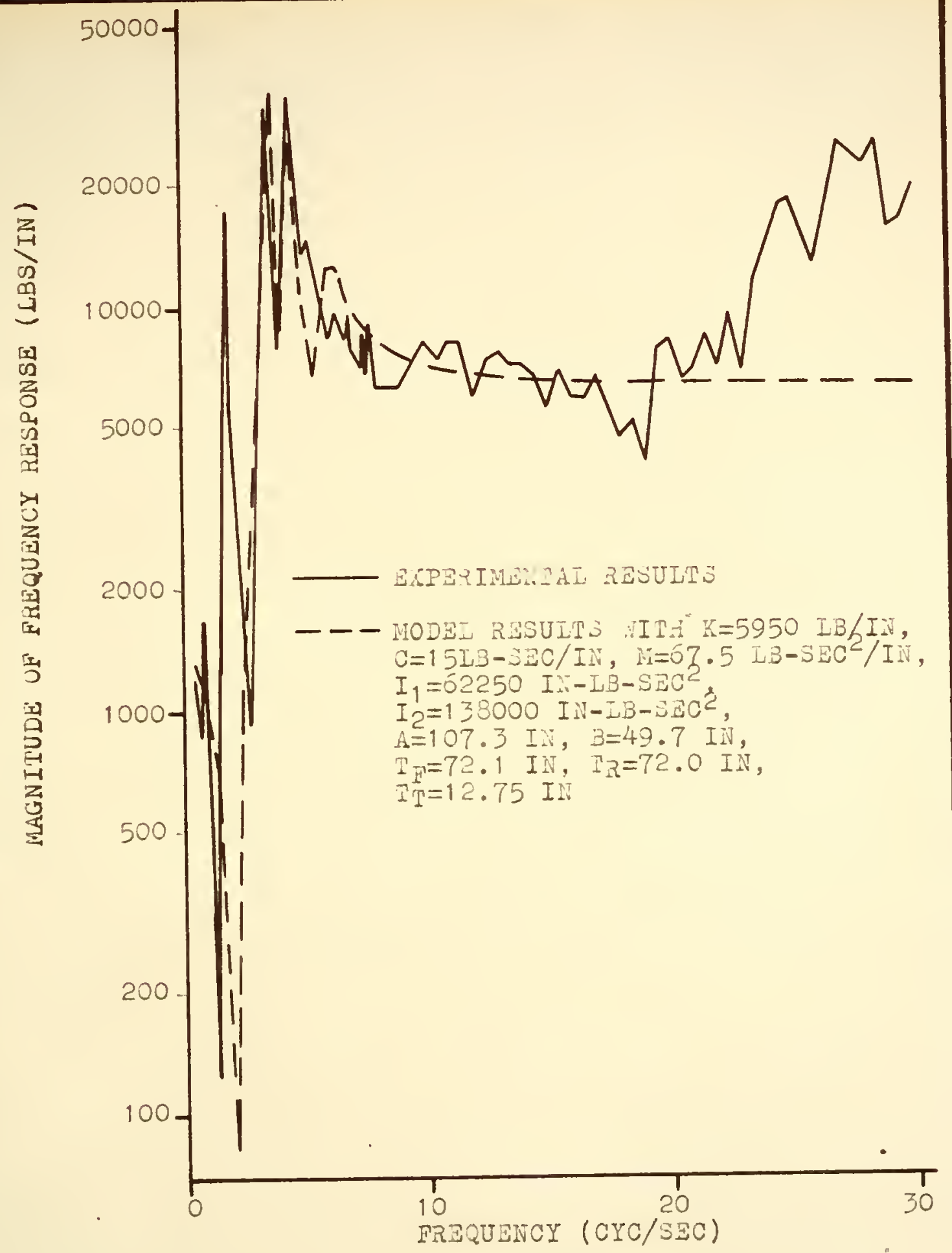

FIGURE 41 COMPARISON OF THE MODEL FRELUENCY RESPONSE VITH EXPERIMENTAL REJULTS 
thetical example. Assume that tro equal anplitude sinusoidal roadways are avallable--one with wave lengths 20 feet long and the otiner with wave lengths 10 seet long. Conslder the excitation of a venicle with a 10 foot theelbase as it traverses eitiner of these tro roadrays. Then the vehicle traverses the road witi the 20 foot wave length at a speed of 20 feet per second, it experiences a one cycle per second input. However, since the road wave lengtin is twice the wheel base, the front wheels are exactly out of phase with the rear wheels, and the net result is a pure pitching input to tine venicle. when this same vehicle traverses the roadray With the 10 foot rave lengths at a speed of 10 feet per second, it still will experience an input of one cycle per second. On this pavement, since the rosd wave lenctic is equal to the wheel base, the front and rear tires will be identically in phase and the net result 1 s a pure vertical mode input to the vehicle. Whe vehicle would not be expected to respond to these t:ro different types of inputs in the same nanner.

These observations may be furties studied by considerins three cases involving the nodel and the appropriate inputs. These particular situations were chosen because they represent various assumptions that have been found in the Iiterature. The various frequency response relationsilps are given in Appendix 1. The variable of interest wll be the $\mathrm{I}_{\mathrm{I} / \mathrm{K}_{4}}$ frequency response where $\mathrm{F}_{I}$ is the force under 
the rint rear inner dual and $x_{4}$ is the displacement of the pight rea.r duals. mequency is the product of the velicle velocity and the reciprocal of the pavement wave lensth. Case I 1llustrates the assunption ${ }^{10}$ that the vehicle derives excltation from only one input, that beins the displacenent of the right lear dual tires. The other tires are inplicitly assurnea to be held at the aero level. The Ieft tires and the right front tire are thus riding on a level track while the riont rear cual tires are riding on a sirusoldal track. Since theme is only one input for this case, there are no time lags. Thus the frequency response wil not depend on veilcie velocity.

The frequency response curve fow case I to gether with an lilustiation of the velicie excitation are shown in Fizure 42. Frequency response curves obtained exverimentally on tile drop bean calibrato mould correspond to this curve. only the low frequency portion of the curve is shorm since this curve shows the important low frequency resonances. These resonances rill account ro: rost of the aynamic forces when the vehicle is operated on the hishay. As frequency increases the vehicle body is essentially motionless and tre FI/ $\dot{s}_{4}$ relationship is merely the tire spriro constant. Horever, because of the tire dampins, as the frequency becones infinite, tire FI/ $x_{4}$ ratio will also become infinite. 


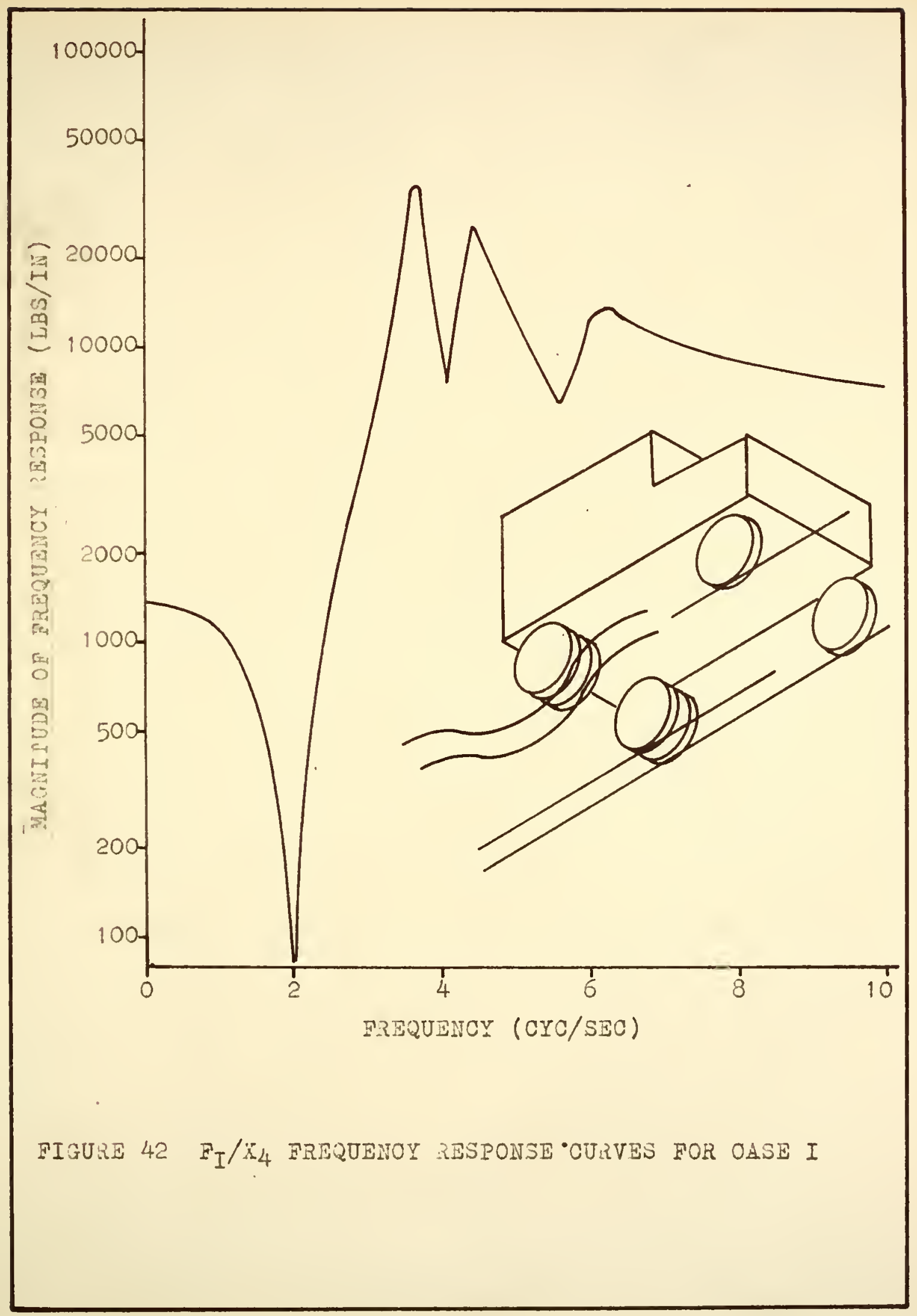


At zero frequency the nonzero value of $\mathrm{F}_{\mathrm{I}} / \mathrm{x}_{4}$ is the result of a force being necessary to nove the mass from the static equilibrium position. This point is partially verified by rigure 37 where the experimental value of the static value of $\mathrm{F}_{\mathrm{I}} / \mathrm{x}_{4}$ appears to be $800 \mathrm{lbs} /$ in instead of the value of $1300 \mathrm{lbs} / \mathrm{In}$ as given for tine model. Note that no account was nade in the model for the center of gravity shift because of tilting. This would tend to make the zero frequency value of $\mathrm{F}_{I} / \mathrm{X}_{4}$ smaller. An automobile would also exhibit a nonzero $\mathrm{F} / \mathrm{A}$ characteristic at zero frequency.

An important point here, and it applies to passenger cars as well as the truck, is that when the assumption is made that there is only one input it is implicitly assumed that the other tires are held at zero level. If an elevation profile is used as an input to one set of tires, misleading results may be obtained if there is a grade or a hill in the input data. The input wheel would follow the h1ll or grade and the other three inputs would remain at the zero level. Thus if this point is not recognized it would be possible to unknowingly have mathematical situations that would correspond to some unrealistlc situation such as the input wheels at a 2 foot elevation whlle the other tires were at zero elevation. Very large forces would then be predicted incorrectly.

Some investigators have assumed a Case I situation for an automobile by reasoning from the following experi- 
mental results for a vehicle that was not moving: when the input aisplacement is applied to one wheel and the dymamic force is measured at another wheel, the cesults are ve-y sinall when compared to the results obtained when the input and output are at tine same rheel. Thus tiey conclude that by neslecting the inputs at the other wheels, the final results ill only change by a small amount. In actuality, by neglectin; the other wheels they could impose an artificial conition that could alte. the resultiv raen a brade or hill is present in tire elevation data.

Case II las not found to be used by any investijators in the Iterature but it is a lojcal extension or case I. The situation is that tiro aisplacement inputs are considered, one for the sight front and te other for the right rear dual tires. The truck excitation and tie fiequency response curves for various speeds are jiven in ligure 43. The left wheels of the truck are traveling on a level track and the right whels are on a sinusoidal tiack.

Since trere are tro inputs, velocity will alter the irequency response because of the time required for tie disturbance to reach the rear wheels after reaching tie fxont wheels. The frequency response at zero frequency, i.e. When the rifht front and rear tires a lo lowered or raised the same amount, takes a nonzero value because the venicle has dual tires. As one side of the truck is raised, the force on tire inner and 


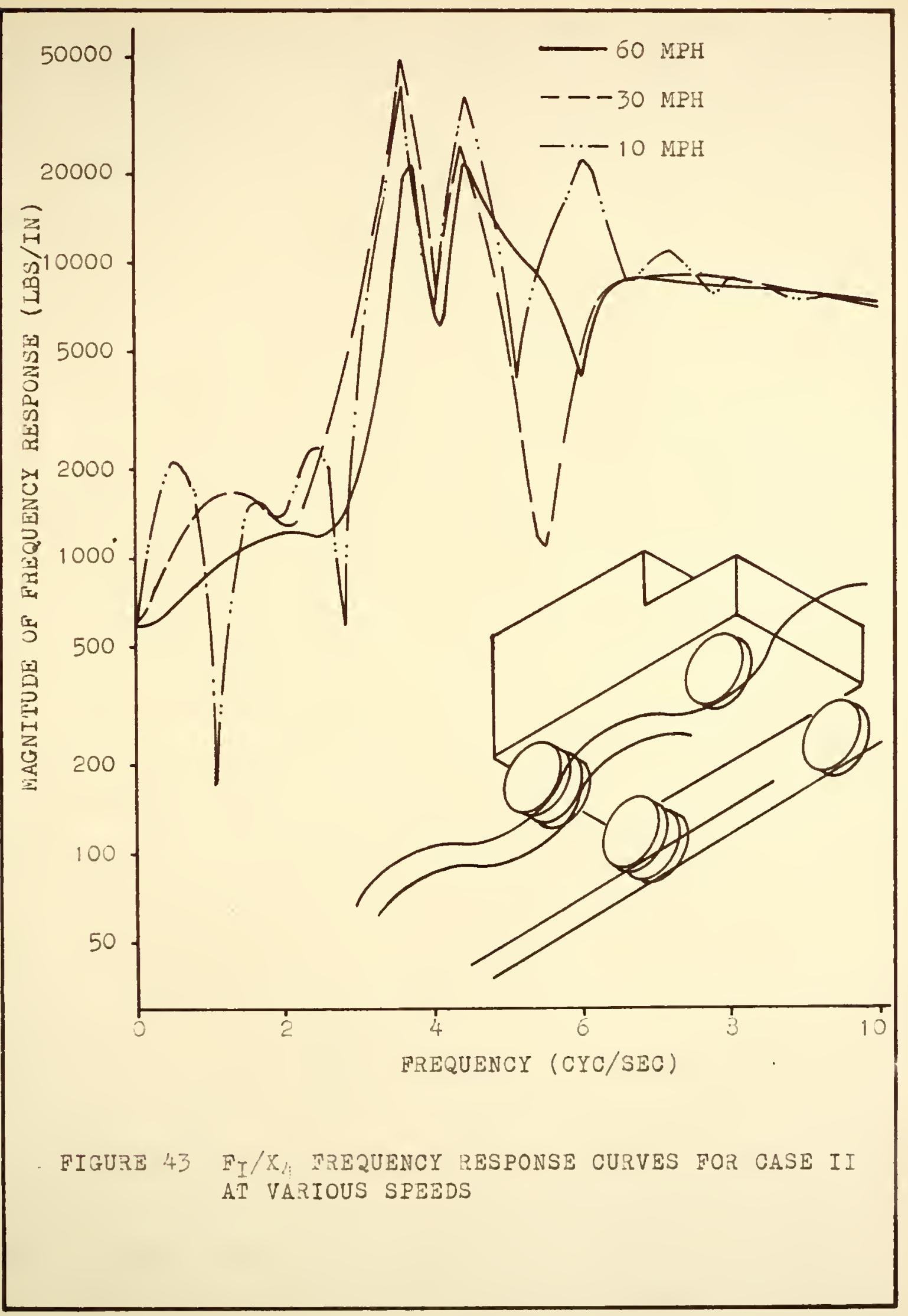


outer right rear duals will change because of the relative angle, $\theta_{1}$ in Figure 39, between the truck and the sround. For an automobile, the zero vilue ordinate would be zero If a similar model were used. However, the fact that the center of gravity shifts when the velicle is tilted has not been accounted for in the modeI. In the actual venicle, there will be a change in the static force due to the center of gravity silift as the vericle is tilted.

Note that the frequency response masnitude at zero frequency for Case II is smaller than Case I. Ihis is because the right front tire no lonjer is fixed. The high frequency region would be similar to Case I. Note, however, that the resonant peaks are higher for Case II than for Case I at low speeảs.

Case II illustrates the assumption that all tires receive inputs, and tne roadway is identical in the rijht and left wheel paths. Finds assumption was used in reference 23. The frequency response and trucli excitation are shown in Figure 44. Note that the zero frequency ordinate is zero since there are no springs to resist when a displacement is simultaneously apolied to all wheels. A passenger car would respond similarly at low frequencies. The high frequency portion is similar to Case I and II. The resonant peaks are higher for this case than the other cases. Also there are only two prominant peais since the rolling mode, tilting from side to side, is not exclted. 


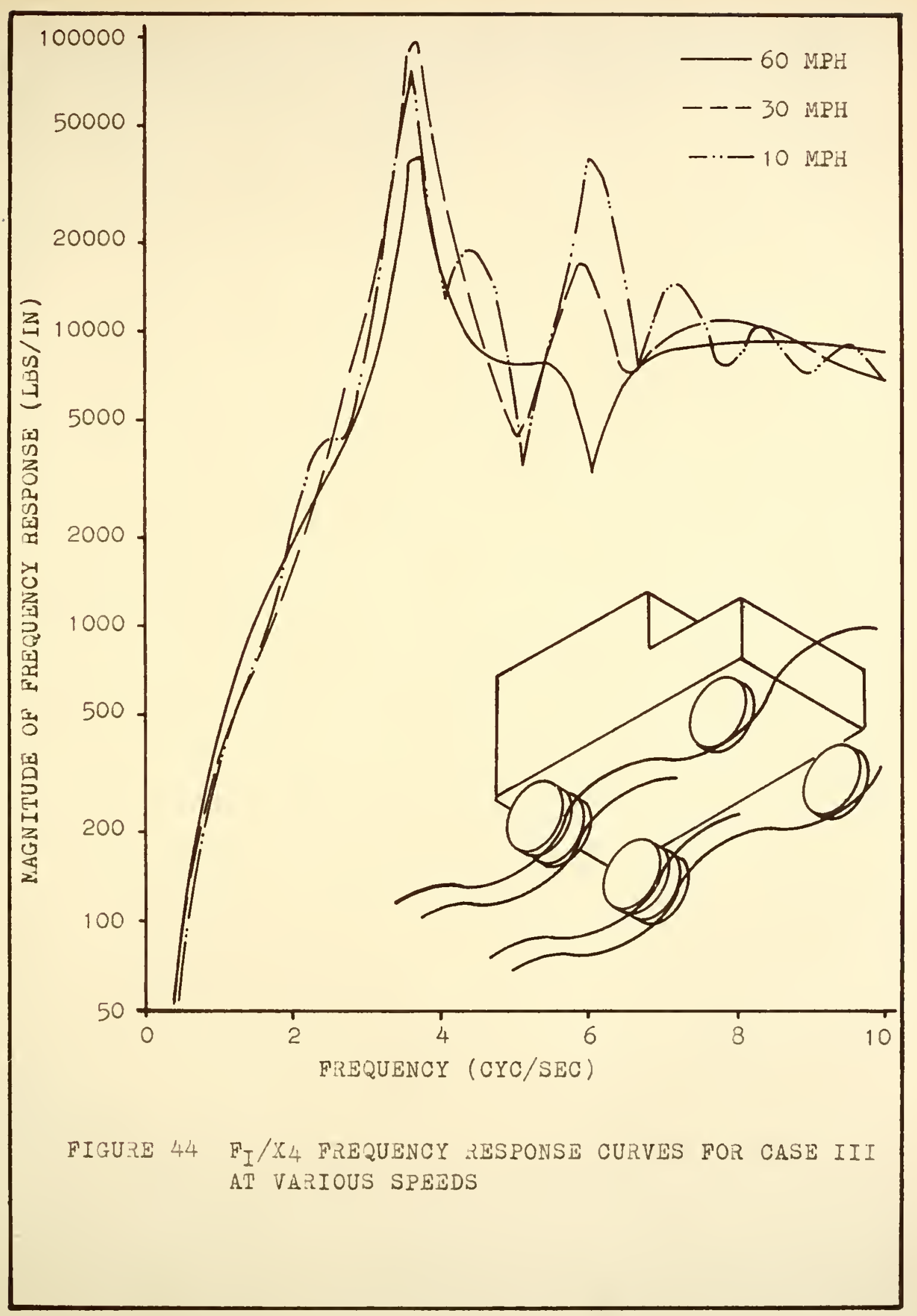


A Case IV could be discussed where one frequency sine Vave rould be applied to one side and another frequency to the opposite side, but the results rould not be such as to be easily presented and hence vill not be discussed. Information about both wheel paths would be sequired. 
The primary objective of this investigation was to measure the dynamic tire forces that a large vehicle ezerted on the pavement durins highway tests conducted jointly with the stresses and Deflections Group of the Civil Ingineering School. The pressure measuring systems were developed for this purpose. The force records obtained during these tests were used by the itresses and Deflections Group as pavement loading information.

The highway tests vere made rith the test vehicle in the same condition as when the pressure measuring systems were calibrated. During these tests, the tire pressure in the inner and outer left rear dual tires was recorded as the truck traversed a region near a test point in the pavement. The truck ariver mainteined a given constant speed in the reglon near the test point. As the truck passed over this refion, the Stresses and Deflections Group measured, among other things, seismic accelerations at various depths in the parement and sub base.

In order to locate the test section on the pressure records, one inch pipes vere placed across tine left wheel 
path at equal distances before and after the test point. These pipes produced characteristic impulses in the pressure records that were easily distinguishable from variations in the pressure caused by the normal road profile. The Stresses and Deflections aroup used strip switches to activate an event marise on their oscillogian. Inese switches ire usually placed in ti.e left wheel patin at equal distances before and after the test point and were activated when the truck passed over the switch. Phis siltcin rould also produce a small characteristic pulse in the pressure record that ras distinuishable in most of the recoras. These pulses vere used to correlate the time base for the truck pressure records with the records obtained by the Stresses and Deflections Group.

At the start of each run, the truck was stopped and the tire pressure systems allowed to come to equilibrium. The output of the pressure instrurentation was balanced to a zero position. The trucis rould then accelerate to the given speed for the run anj pass over tine test section. After tiae truck had moved aray from the inftial position, the relative elevation of the initial contact point of each of the six tires was measured with a rod and level. It was intended to later place the truck in a similar disposition on the calibrator to determine the static value of the force at each of the left rear dual tires. In this ray, the dynamic forces could be aded to the initial static 
force to obtain the total force. Because of time limitations and instrumentation aifficulties these static tests were not performed. The static fose under each tire of the rear axle was therefore assumed to be 4500 lbs.

Particular attention was jiven to this last detail because the vehicle did not use the normal wheel patho during the hi hhway tests. The test point was located approximately 11 inches to the left of the pavement cente: line and in order for the left rear dual tires to be centered over the test point, tize left wheels had to assume Wheel paths in the left lane. ner the left rear dual tires ivere centered over the test point, the left rear inner dual tile was almost on the crom of the road, and consequently, the left outer aual, spaced 12 inches to the left, was on a wheel path at a lover elevation tian the inner tire wheel pati. Thus for this cordition the static locd vas larger on the fnner tire and, as shown in sigure 45, the dynamic forces were also larger. These records are for various speeds and for the left rear wheel paths centered about the test point. The large forces near the test point are tine result of a depression in tie road caused from the installation of the instrumentation in the road. Figure 46 lilustrates the force records at the same speeds but for wheel paths centered approximately 11 inches to the rigit of the test point. Fol these wheel patis, the static forces are more nearly equal since the left rear tires are 


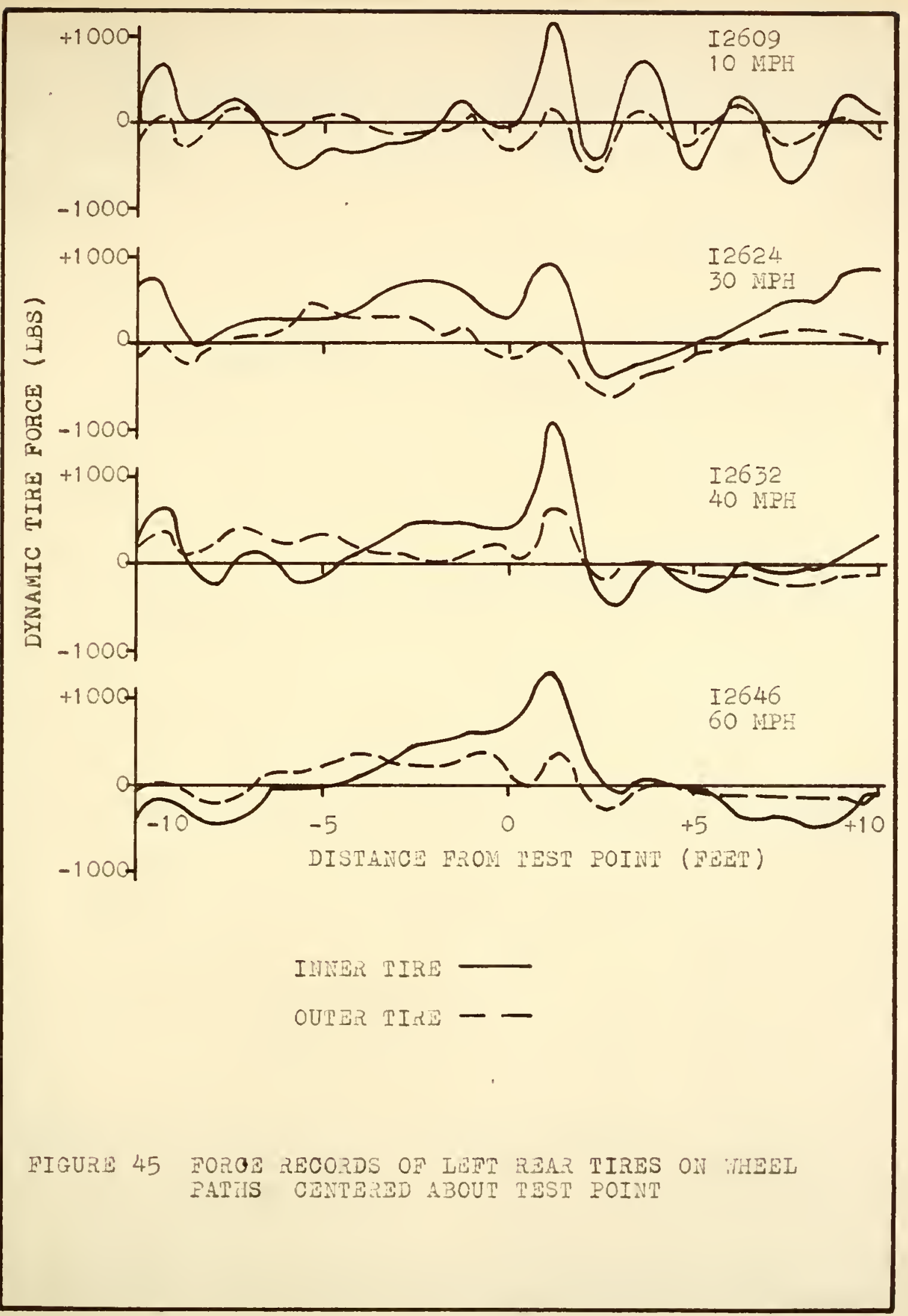




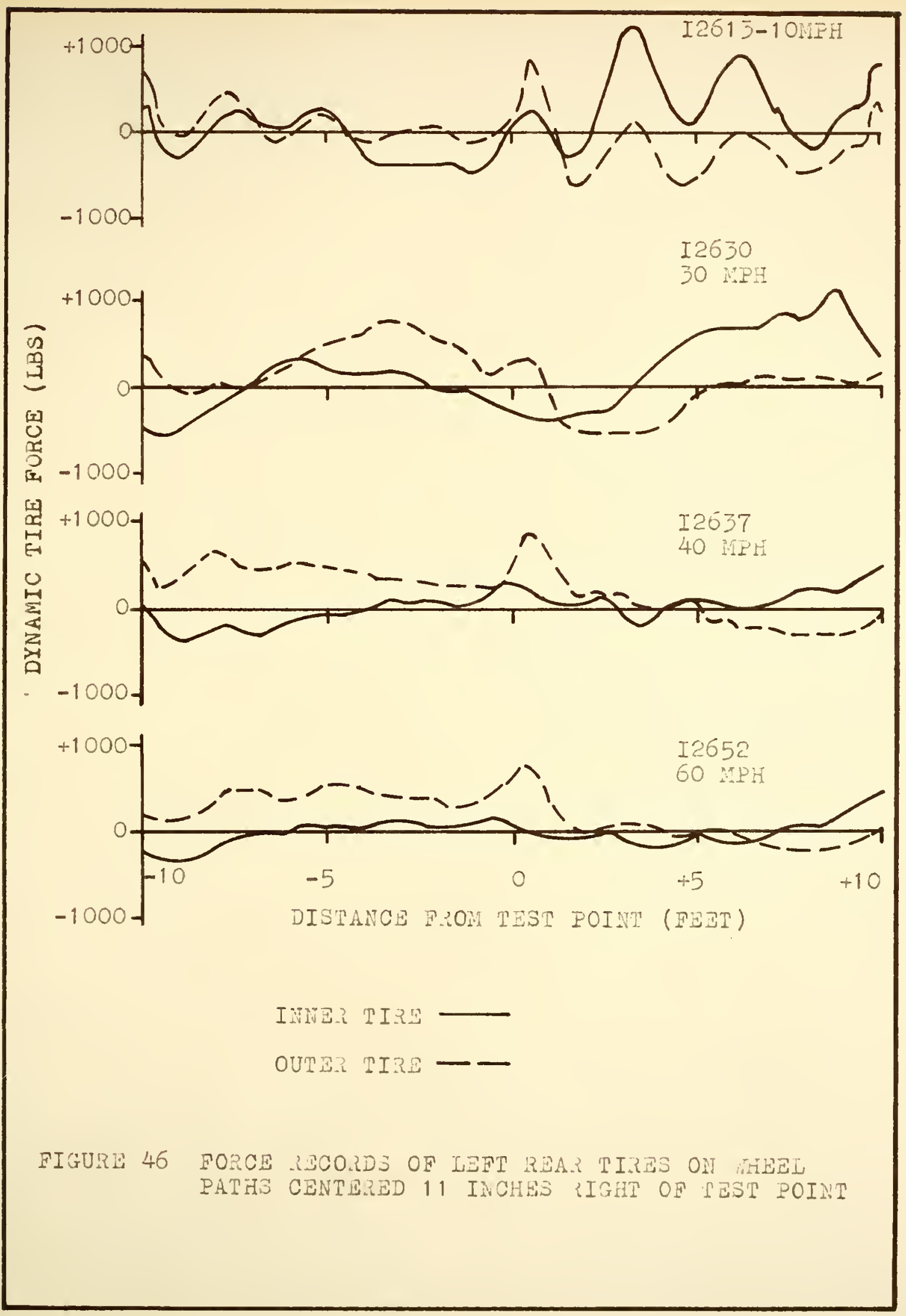


on elther side of the croin. It is interesting to note that tine road profile nea. the test point appears to excite larger dynamic forces at tire lorest speed rather than at a uish speed.

some typical combined results of the highray tests are jiven in Iigure 47. The vehicle speed ras $20 \mathrm{mp}$ and tine left reax theel patis centeres about the test point. In the upper portion of tire figme, the total force of the inner and outer tire aie shom as a function of the distance of the rear axle from the test point. In the lover portion, the results obtained by the Stresses and Deflections Jroup are illustrated. Tre curve shows the displacoment of the pavement surface at tie test point also as a function of distance of the rear axle from tire test point.

The dynamic force records that are shom ane typical of the hishray test results. Are records have been converted from tie aynamic oressure recorus. lile force records that were obtained durinj these tests rere olotted, printed and punched on IBir canis. Inexe nese 131 sets of these records and, are now on flle with tae stresses and Deflections Group.

The Veilcle Dynanic jroup ras primarily concernez nith the problems involved in maring these records and developing data processin: procedures to convert tie pressure reco:-ds to force records.

Several procedures may be employed for the conversion 


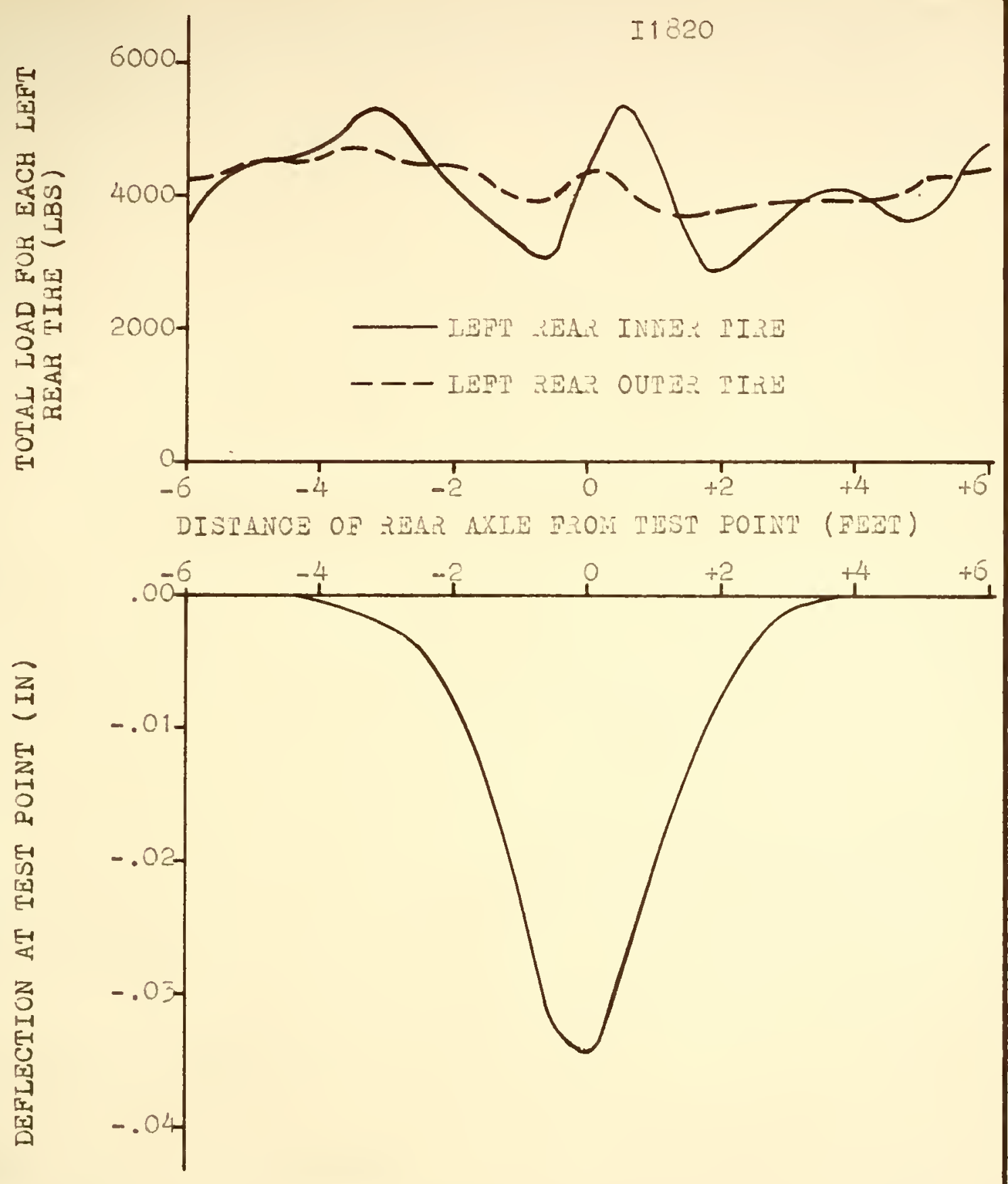

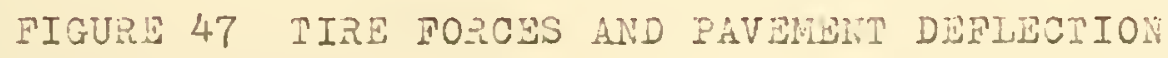


of the ti.e pressure records to tire force records. One method involves the use of the impulse response of tire pressure system and the convolution integral. If it were possible to subject the tire to a force inpulse, the resultant pressure transient $w(t)$ would be called the impulse response. If the system here linear, the pressure response $p(t)$ to any general force excitation $f(t)$ would be jiven by

$$
p(t)=\int_{0}^{\infty} r(\tau) f(t-\tau) d \tau
$$

The apolication of this technique to the present problem rould recuire the solution of squation 25 for $f(t)$. Mhis roula not be an easy task.

owever, bf assumiaj $f(t)$ anj $p(t)$ have the pourier transforms $F(f)$ and $I(f)$ respectively, iquation 25 may be transformed to

$$
P(f)=I(f) F(\hat{I})
$$

Where $Y(f)$ is the frequency response of the pressure system, or in terms of tile $\mathrm{I} / \mathrm{E}$ frequency response obtained from the calibration tests

$$
F(f)=[\mid F / A(f)] P(f)
$$

Inus an expression for the rouries transform for the force 
record $F(f)$ has a relatively simple chanacter. In order to take a Founier transform of $p(t)$, the integral

$$
\int_{-\infty}^{\infty}|p(t)| d t
$$

must exist. The pressure recoras obtained from the road tests do meet tinis criterion since the truck started from rest and stopped after it passed through the test region. However, the runs rere each several minutes long, and since there were 131 runs, this technique was juiged not feasible because of the stafserin; amount of date required and data processing errors assoclated with sucl long records.

In order to bring the data processing procedure into reasonable bounds, an alternate procedure was used for the Fork with the stresses and Deflections Group. A Fourier sine series was made of a portion of the pressure records that included tine section near the test point. The components of this series vere mitiplied by the proper value of the magnitude of the $F / P$ Irequency response and the individual sine waves were shifted by a paase determinej from the piase angle of the $\mathrm{F} / \mathrm{P}$ frequency response.

In general, as more terms of the Fourier series are used, the series 111 more closely approximate the true function. lorever, finding the Fourier coefficients requires numerical evaluation of the following integrals: 


$$
\begin{aligned}
b_{n} & =\frac{2}{T_{0}} \int^{T} p(t) \sin \frac{n n t}{T} d t \\
n & =1,2,3, \ldots \ldots \ldots \ldots \\
T & =\text { length of record containing the test section }
\end{aligned}
$$

These integrals are subject to the same data processing errors as were discussed in chapter II. Only a finite number of these terms in the Fourier series wll most accurately represent the pressure wave because of the various processing errors.

Since there are many records to be processed, the pressure values vere read at a relatively larse time spacing when compared to the calibration record reading discussed in Chapter III. The Nyquist frequency, the maximun resolvable frequency, is fixed by the time spacing selected to represent the record. The time spacing selection was based on (a) accuracy required to resolve tho experimental record, and (b) the economy of reading the records. Thus the Nyquist frequency was limited to a relatively lower value for these tests. There was then some frequency content above the Nyquist frequency and hence a sinall amount of aliasing was to be expected.

Simpson's rule was used to perform the nunerical integration, so the associated distortion was also expected. For an illustration of these effects, a typical pressure 
record is illustrated in Figure 43a. It is desirable that the Fourier sine series repiesentation should be identical to this original pressure record. Shom in figure $43 \mathrm{~b}$ is the Fourier sinc series approximation of the pressure recond that was made up of each sine component up to one-half of the Nyquist frequency. It is apparent that tire sharp peaks in the original record have been filterea out by truncating the series, but the overall reproduction is zood. The effect of increasirg the number of components is illustrated in Fisure 43c, where frequencies up to the iyquist frequency are used. The data processinj errors irtroduce an erroneous oscillation into the record. These results are typical of the records that vere processed in this fashion. Trie optimum number of terms to use in the series representation of the pressure record has not been resolvea. inotier cordition must be conside a wen selecting the maximum frequency. That is, the $F / P$ calibration results tend to become iraccurate as frequency increases (Fisure 20).

Basez on tirese consioerations, in all calculations for the Stresses and Deflections Group, the limiting frequency of the "ounier sine series representation of tae pressure record was taken as one-half of the Nyquist frequency. Because of the relatively flat $F / P$ frequency response, an estimate of the dynamic force can also be obtained from the pressure-time records by simply multiplying 


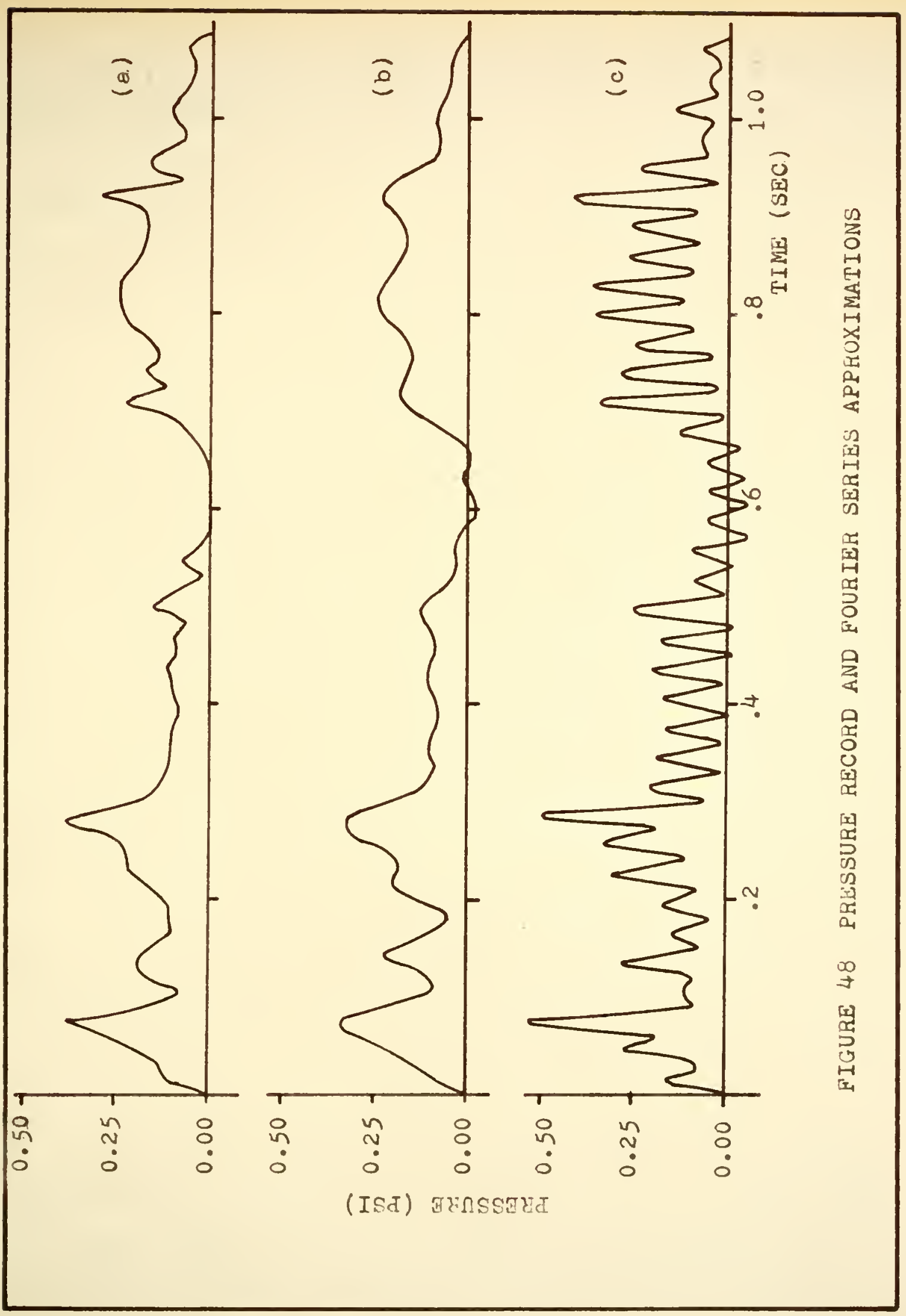


the pressuce record by a suitably selected constant as previously discussed in Chapter III. Fioure 49 is a comparison of the tire force obtained by using tais method with the tire force obtainea when the tire pressure record is resolved into frequency components. The vehicle speed is $40 \mathrm{mph}$. The force record obtained by $\approx$ imoly multiplying the pressure record by a constant appears to laj the other record because of the lead characteristic of the F/P frequency response. The reason t at the outer dynamic tire force is less tnan the inner tire force is because the inner tire ras riding on the crom. Tine time lag way be easily accounted for by croice of the time orisin.

There is no lange difference in the nagnitudes obtained by either of these two nethols. Since the tecinique of conventing to force records by fourier methods allows the possibility of a varying frequency cesponse, it should bive the better results.

The impulses caused by the one inch pipes ane apparent in the original pressure record in Flgure 4ta. Lack of pressure transients is a furtier indication tiat tire frequency response is flat and that multiplication by a constant vill give valid results.

IIIustrated in Figure 50 are some corparative results of the total tire force of an automobile and the test truck. The truck results are for the right rear inner dual tire and the car results are for the right front tire. Both 


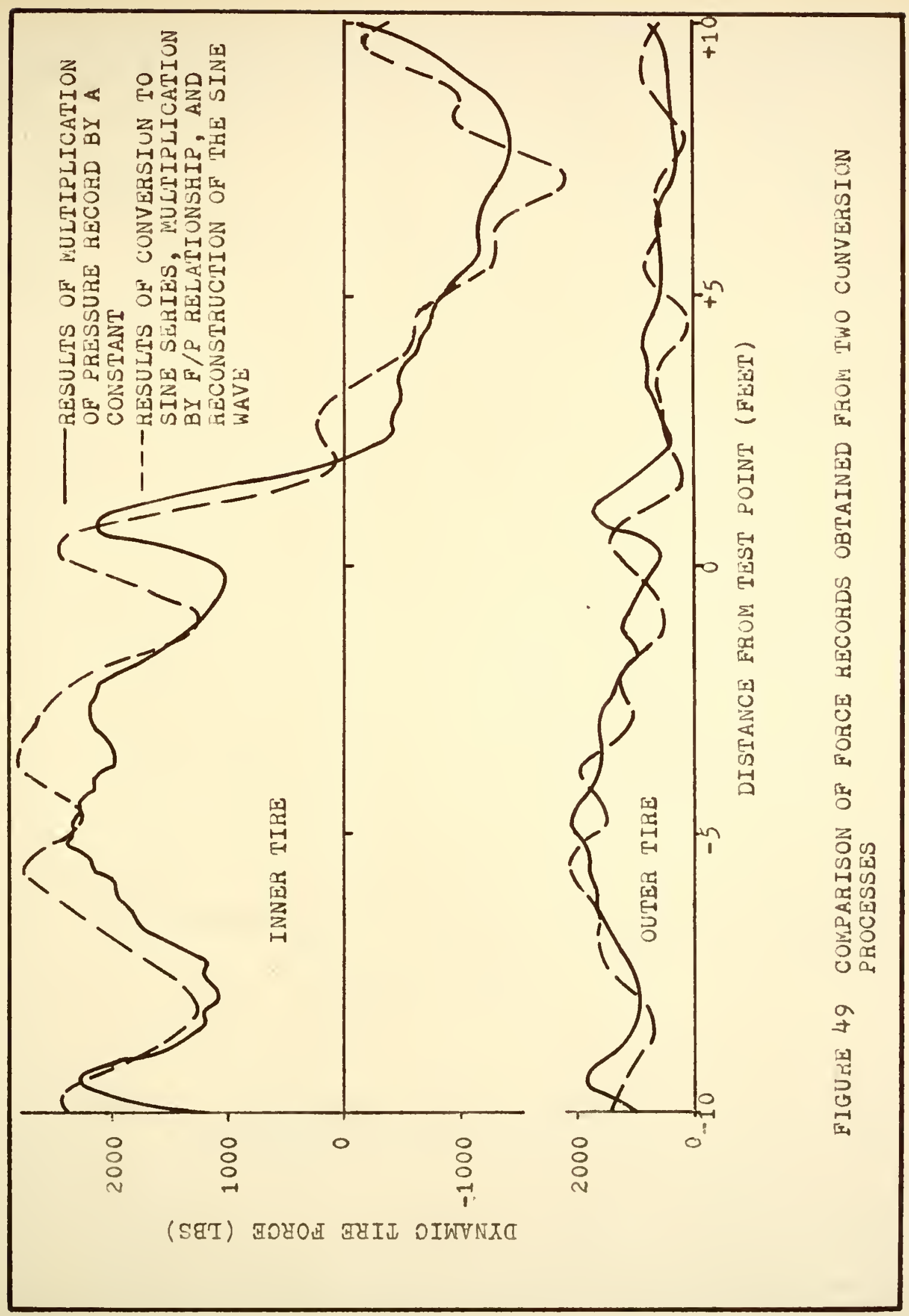




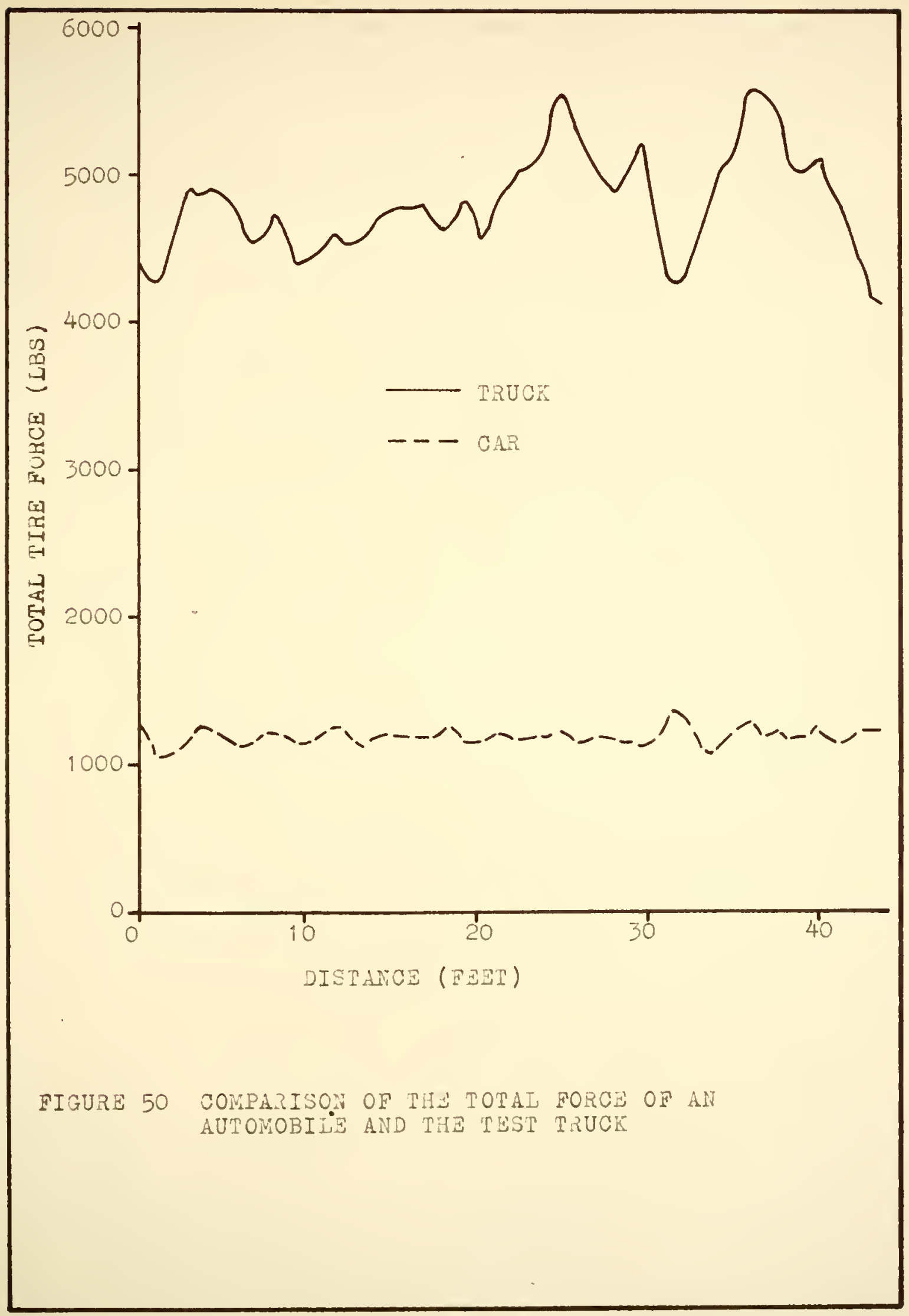


vehicles were operated over the same section of pavement at 40 mph, but the record for the truck was made about one year after the record was inale for the car.

Another interesting comparison is shom in fisure 51 where tne dynamic force is expaessed as a percentage of t.e static load for an automobile and the test truck. Tris plot vas made from the same data used to make fifuce 50. This comparison appears to indicate that the dynanic forces of an automobile and a trucr are about the sane percentage of the static tire forces. 


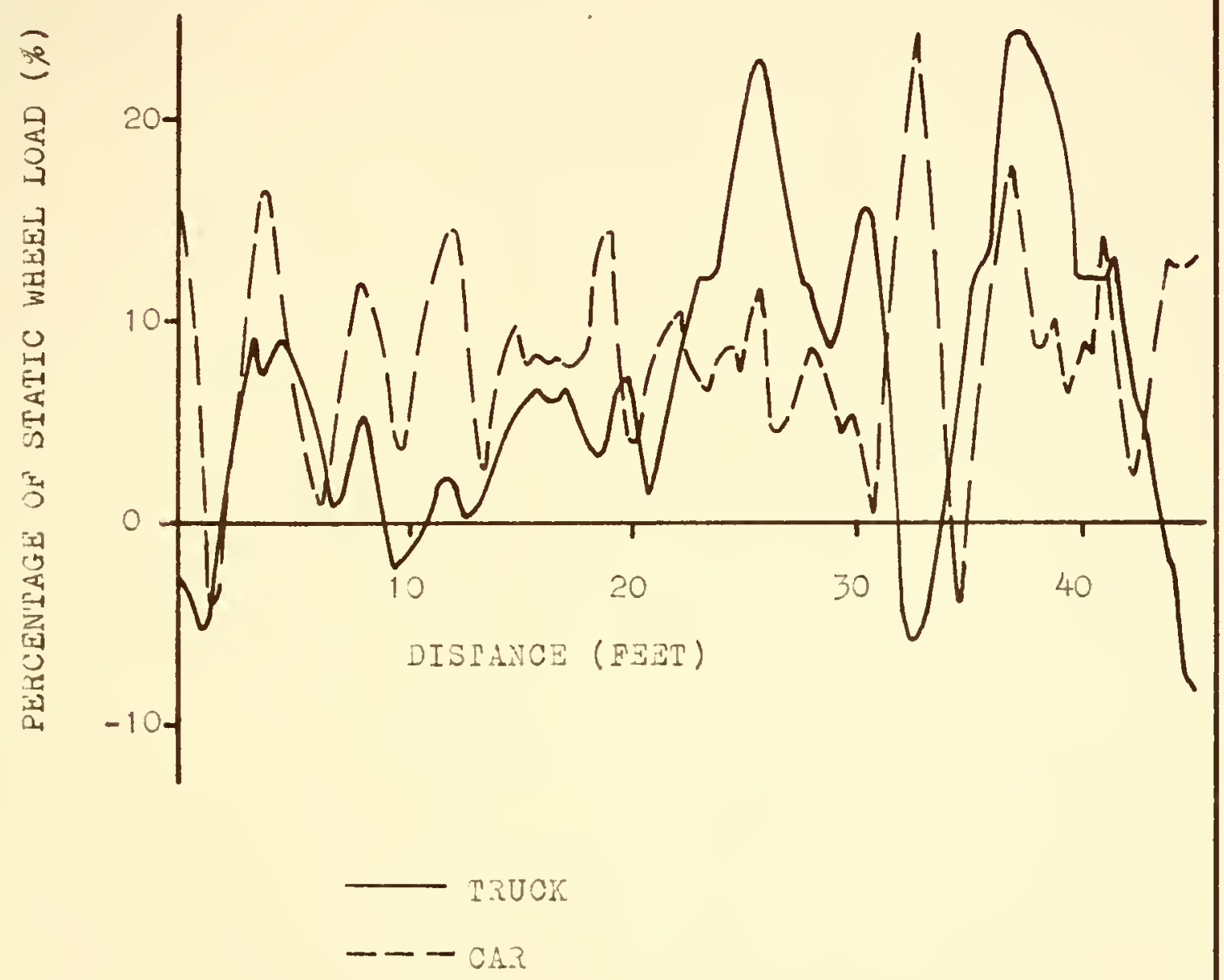

PIGURE 51 COMPAKISON OP THE AUTOHOBIIE LND TRUCK DYNAVIC TIRE FORCZS EXPRESSRD AS A PERCEIPAGA OF THE STATIC THEEL LOAD 


\section{CAAPTER V}

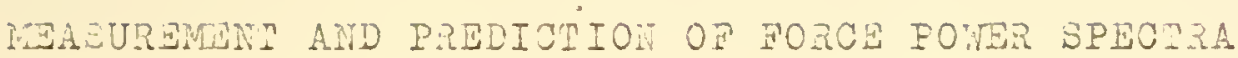

A statistical method w111 now be considered for describing tie highay profile and the dynamic tixe forces. The statistical characteristic of interest is the power spectrum of the quantity in question.

The method of 3 lacliman and pukey 9 was used to calculate the required spectra for this investisation. Por the complete details of this method, the reader is referred to the orisinal reference. One attractive feature of this method is that an approximate confidence interval may be associated with the spectral estimates. The principle steps of the nethod as used in this investisation are as follows:

The first step is to preprocess the data in order to remove a nonzero mean value and undesirable low frequency components. If the data have a nonzero mean and larje amounts of power concentrated at the low frequencies, the autocovariance function wil not approach zero rapldy, a primary requisite then using spectral techniques. The next step is to calculatè the autocovariance function fror the preprocessed data. This fuiction is calculated for lass 
of lensths that are increment raltiples of the data spacing. The third step is to calculate the Fourier transform of the autocovariance function to form a first estimate of tie pover spectrum. Phese estinates may be further cerined by convolution witi an appropriate function. The expectea value of each of these refined estimates is the averageover-frequency value of the true power spectrum of the process. Tile area under this curve is an estimate of the mean square value of the process.

Since equi-spaced discrete data are use?, the spectral estimates are vulnerable to aliasing. Prapezoldal rule integration is used for tine nunericai calculation of the Fourier transfom. Shis procedure is subject to the distortion as illustrated in Fisure 9.

If the true spectrum is approrimately flat on "white", a confidence interval may be assigned to these refined spectral estimates by treating them as if they followed a

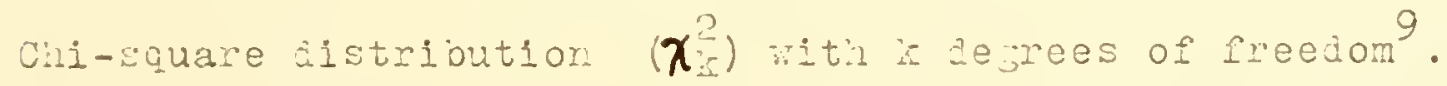
A G.i-square random variable vil become less variable as the number of dejrees of freedon increases. The equivalent number of deprees of freedom, wici is a convenient injication of the statistical stability of the ppectral estimates, is jiven by

$$
k=2\left(\frac{i N}{m}-\frac{p}{3}\right)
$$


risere

$$
\begin{aligned}
y= & \text { nubber of data values } \\
a= & \text { muber of las values } \\
p= & \text { number of independent records that are conoined } \\
& \text { for the total datz lengti. }
\end{aligned}
$$

The if for the zero frequency estinate and the wighest frequency estinate, mich is the Nyquist frequency, is one-hali of the value ilven by jquation 29.

Tre confidence interval assipned to the ratio of the value of a $\boldsymbol{X}$ ? random variable to tine exvectel value of the ranion variable is illustrated in rigure 52. Mnese curvas nay be plotted from a cunulative vhl-square distribution table or from tice tabulations in vererence (9). Use of the cunves iz exemplified as follows. If a powe spectrum calculation as made from 1017 data values ifon a singe recori using 50 laj values, the equivalent le mees of iseedon iould be $k=2(1017 / 50-1 / 3)=40$. By entering pifure 52 at $k=40$, it is îuil that there is 00 percent confidence that the ratio of each estimate to the expected value of trie estimate rill be betreen .73 and 1.3 .

Slince nost real spectra are not wite, tile relation iven by Equation 29 should serve only as an mpper linit. If the spectrum consists of a single narror peak, the equivalent number of derrees of freedon are appoximately trio (refecence 9 , paje 24). 


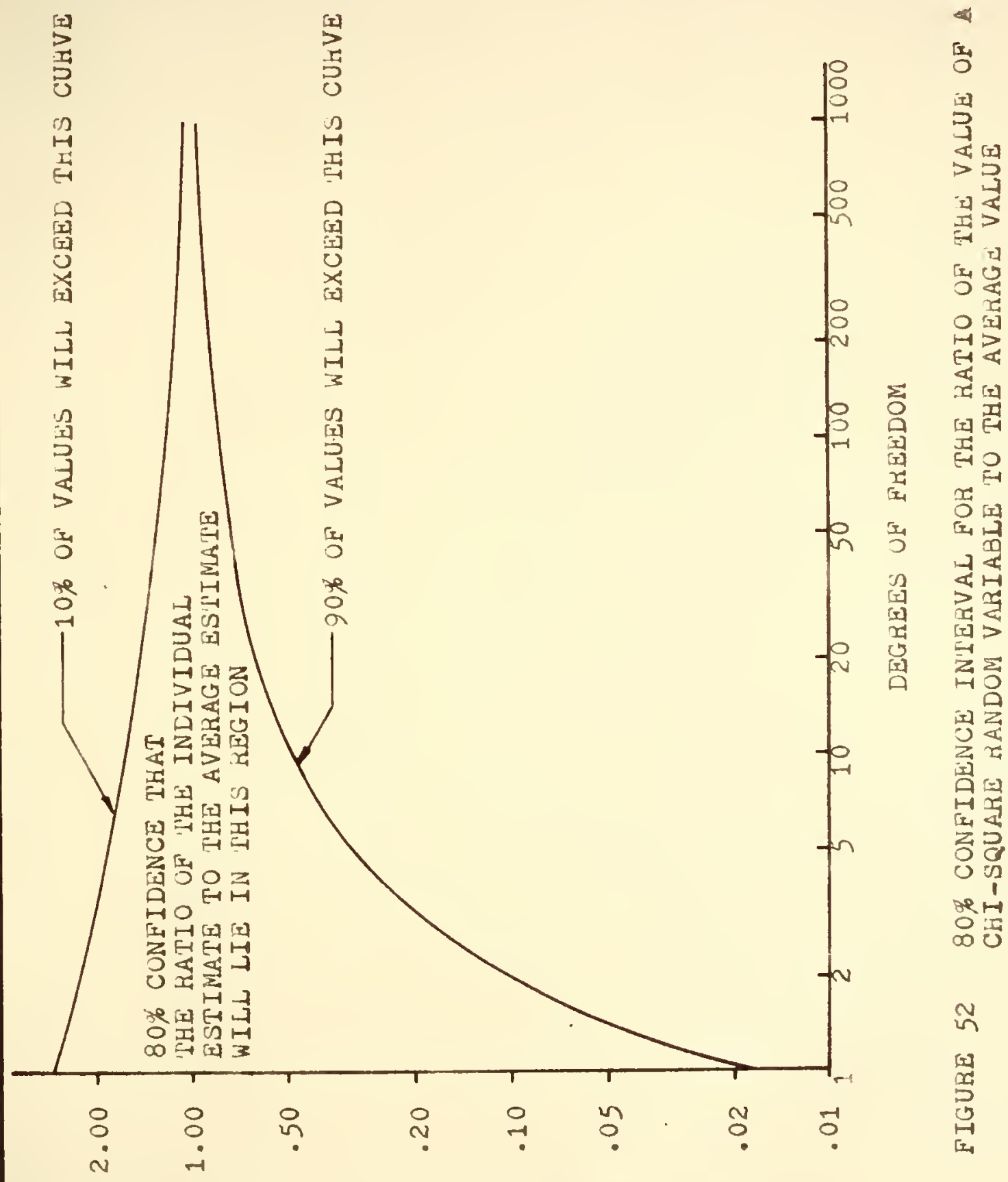

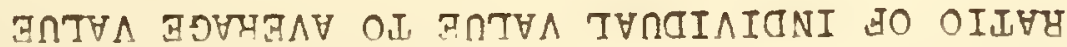


As s.own in Jquation 29, the statistical quality of the spectral estimates increases men ferer la js nare taken. However, as m decreases, tire frequency resolution of the spectrum decreases since there will be m+1 spectical estimates equally spaced between 0 and the iyquist frequency. Thus the choice of $\mathrm{m}$ will be a compromise between frequency resolution and statistical quality.

For two degrees of freedom associated witi a sinjle narrow peak, Figuce 52 inicates that poor results will be obtained. The best results are obtained when tae porter spectrun is white. Mis situation can sometimes be realized by subjectin; the data to severel preprocessinj opecations that remove every spectral pear before the pover spectrum is calculated. This is called "preninteninz" the data. After the porer spectrum is calculated, the filtering effect of the preprocessing llaj be divided out of tne porer spectruin. Inis is called "recoloring". Reference $(10)$ gives examples of tils process. ..owever, in this investigation prewhitening greatly increases the computation effort and affects the results only slighty.

A pover spectrun fumishes statistical information in the frequency domain. Spectral theory ani Iinear system analysis can be comolned to fom very convenient relationships. An lmportant cesult that is kerived in reference (24) deals Hitn the response of a linean tineinvariant single input systen having a statlonary random 
process as input. If tre power spectiun of tne ingut is $P_{X}(f)$ and the frequency cesponse of the sjsten is $Y(f)$, tue spectruis of tine outout is

$$
P_{y}(f)=|Y(f)|^{P_{D}}(f)
$$

squat10: 30 can be used to prejlct a power spectrum of the dynamic forces exented by the vericle on the pavenent. As was discussed in chapter III, the conitions acconnaninj the equation ane only approximately isue for the teuck usei for tils investigition and thus tae piezicted results must be vleirel as estlmatez.

In alition, there are problens associatei rith the calculation of eievation porer spect.r. Tilere are nunesous a:ticles that jive the results of calculatiors of elevition pore: spectra for pavementa, but the relationsilp between these calculations and otiler comonly used crltersa of pavement condition has not yet been completely astailsued. Until it has been sionn tiat the elevation porer spectrum correlates hi wly with other colterla of pavenent conjition, there exists the posslblitty of error when usins the elevation power spectrun as a pavement characteristic. Furtae: researci in this area is described in reference (25).

An elevation porer speotrun is a jeometric statistical c.racteristic of the parenent tiat ind1cates the listribuilon of the mean square value of deviations of the elevation 
measurements over a distance based frequency. The dimensions of frequency are cycles per foot (CPa) and the najnituae of the spectim has the units of feet aquared per cycle per foot ( $n^{2} / 0 p$ ). Ihis spectrun may be converted to a tine based spectrum for any vohicle velocitj.

Tie reason tiat reliable results are lifficult to obtain wen calculating an elevation porer spactrun 1 s that tine anplitudes assoviated ritiz ills and valieys are very large when compared to the sarter wave lengti components wil. are of mo co cosequence to tae venicle suspension systen performance. Consequently, there is an ext-anely laine peat in the elevation porter spectrum near zero frequency that rill distort many of the other spectral estimates. An equivalent iniication of this distortion for a nurrou spike 1 s juen by tio rejuction to approrinately trio, of the equivalent chi-squa:e number of iejoes of freelom of the spectaral estimetes.

a common procedure tiat is used for jealin titil this situation is to prerhiten the acta. Je vries ${ }^{10}$ discusses in detail several variations of tiss proceiure. A tecinique sugrested in this reference ras chosen for use in this lnvestijation. The technique is to preprocess the data by dividin; the record of the elevation profile into several subsections, Iint a least wquares best flt second order curve for the data in cacn separate subsection, and then use the ceviations of tile lata values from the curve 
to calculate tie elevation pover spectrun. lihese deviations are illustrated in the upper part of Bi juie 53. Fisis technique vill filter out the lowser vave lenths 1 in the elevation profile data as indicated by the porer flutering character associated vith this poocenre in the lorer part of Figure 53. The porer fliterinj characteristic is toe square of the majnitude of tine associated frequency mesponse for this data prepiocessing tecinique. 10 Ine 100 foot base Iine ras usea for tie calculation of tne elevatiois pore: spectra.

Mornaly, this characteristic rould be divijed out of tice spectrum after the elevation pore: spectrum ras calculatea (recolored), but since a similar filteria; proceiume ifil automaticaliy occur vith the measuren fonce data due to the equalization nestriction of the pressure measuring system, tins adaltional step ias not taken ior this investifation. Furthemore, tre pavement must be dividei into relatively sirort sections, so trat the asumption that the vehicle derives the input from only one weel may be used.

..en interpretinj these resulting elevation power spectra, it is necessary to iecojnize several points. rise first is that the lov frequencies (10nj wave lenstis) will be removed and tire spectra will only represont ule hivie frequencies. A secori point is tant a oseudo-pear will occui in tne spoctra near the break polit of the data preprocessing filten. Iiss pear is tue tesult of comblains 


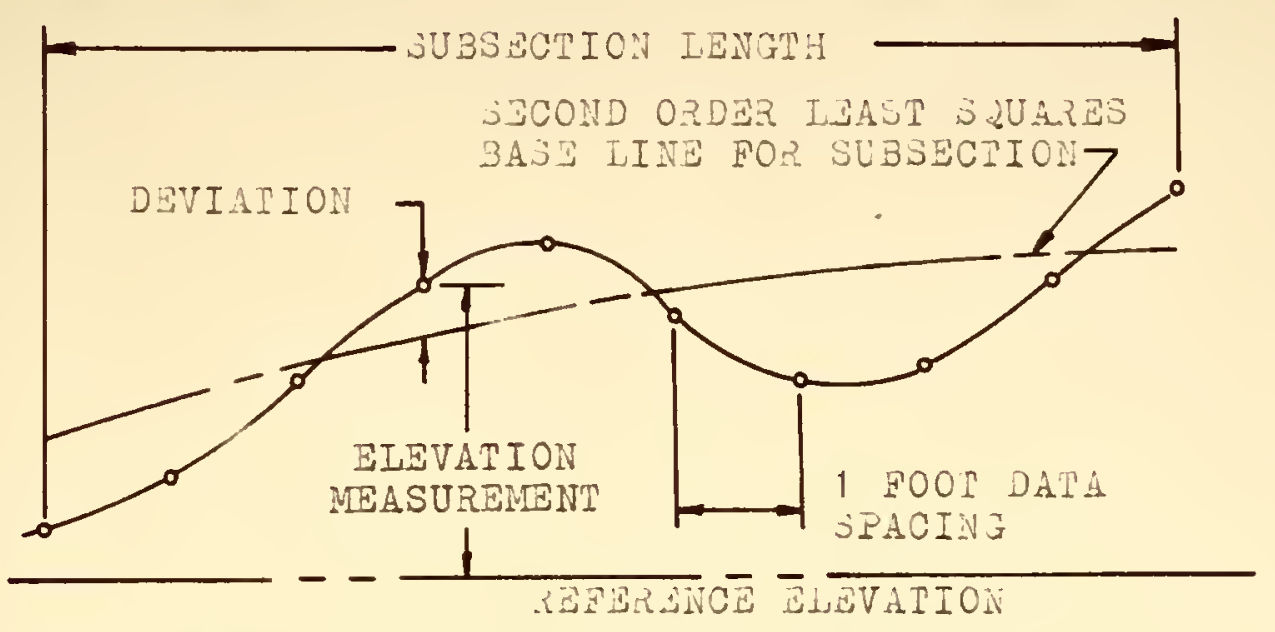

ILLUSTRAIION OP DAIA PREPROCESUING

勿

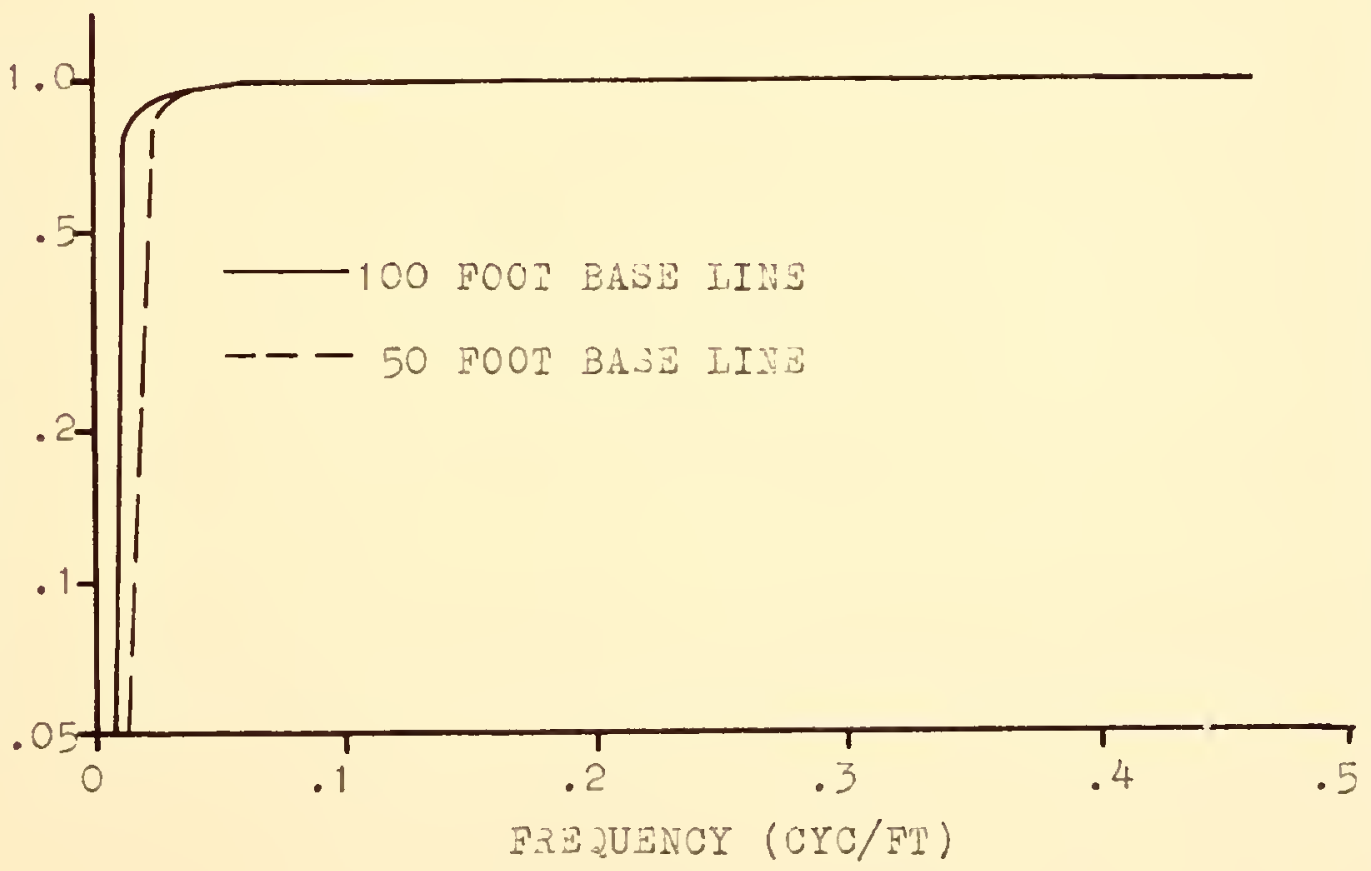

PO IRR FILTERING CHARACTERISTIC

FIGUAE 53 DARA PREPROCESTING AND PO FER FIITERING CHARACTERISTIC FOR DATA PREPROCESSINJ 
the sharp low frequency cut-off of the data preprocessinj filter (Aisure 53) ana the rapidy decreasins elevation power spectrum. line true elevation spectrum najutude should be very large at zero frequency because of the hills and valleys and then decrease as rrequency increases. The third point is that the statistical quality of t.o estinates of ine calculated porer spectra will be better than if no preprocessing were used. To illustinate tisse points, an elevation pore. spectrum tas raje for a 400 foot length of pavement usire the deviations fron tre mear of all the data values to calculate the spectra. A spetiun was then made ritil the same dave using the leviations fron foun second orler least squares base lires 100 Ieet lons. The results are shom in Fisure 55. nivere are tro dejrees of freedom assoctated with the estinates of tire fi stitechique and $2<<15.3$ associated inti the secont order base lines technique.

The section of pavement used to predict onc neasure the force porez spectrum was on Indians jtate Roaj 20 approximately three niles west of iest jafarette, Indina. The pavement was of bituminous construction 21 feet rije. The elevation profile was measued with a rod and level at stations one. foot apart, 30 incues in from the soutl. esie of the southeast bound lane. "nis section was suveyed in 1962 and arait in 1904. 


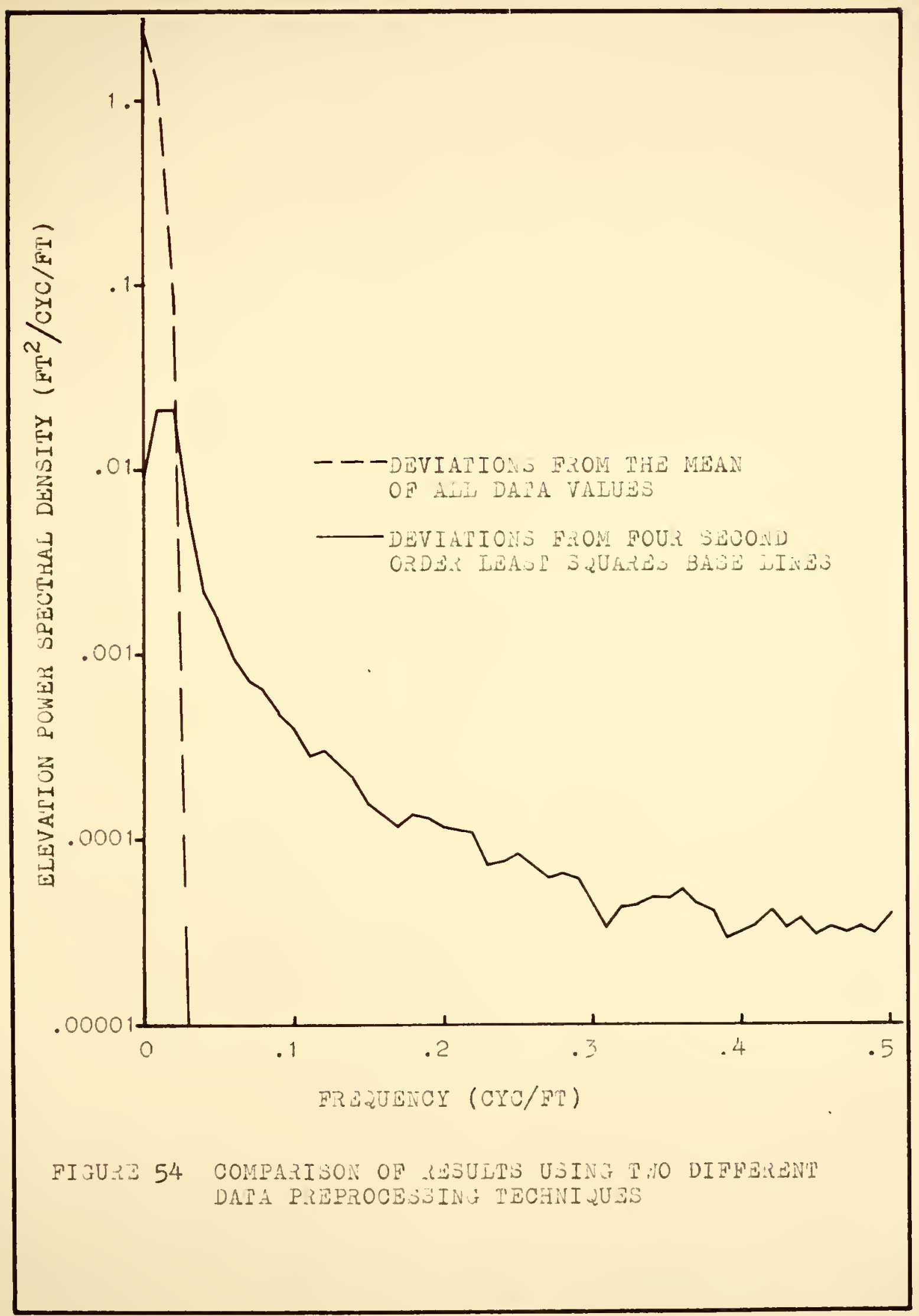


The elevation power spectra for the 1962 and 1964 survey are shown in pioure 55. The satl difference between the two curves indicates that the characteristics for this section vere essentially unchanged after two years of usage. The mean square deviation of the 1962 survey was .5 percent larger than that of the 1904 survey. Ihis small difference could possibly be due to the fact that the measufements in the 1962 survey were made with a .005 foot minimum elevation resolution wile tire 1964 survey was made witi a .001 foot ininimum elevation resolution.

It is interestin: to note the comparison of the minimum resolution of the 1962 survey (.005 foot) to the marbnitude of the minimum drop hei ht used for calibration (.006́ inci or .0072 foot). Another interesting comparison is that this resolution is about twice tre pavement surface deflection indicated in Figure 47.

A predicted force spectrum was calculated for tile right rear inner tire at the speed of 27.0 fps (approximately $20 \mathrm{mph})$. The experimental $\mathrm{F} / \mathrm{x}$ characteristic from the .036 inch arop tests vas used. For comparison, a predicted force power spectrum for the nodel described in Chapter III, assuming that left and rid heel paths were identical, was also calculated. The predicted force power spectrum for these two calculations are shown in Higure 56.

To illustrate the effect of speed upon the predicted force power spectrum, results that were available for 


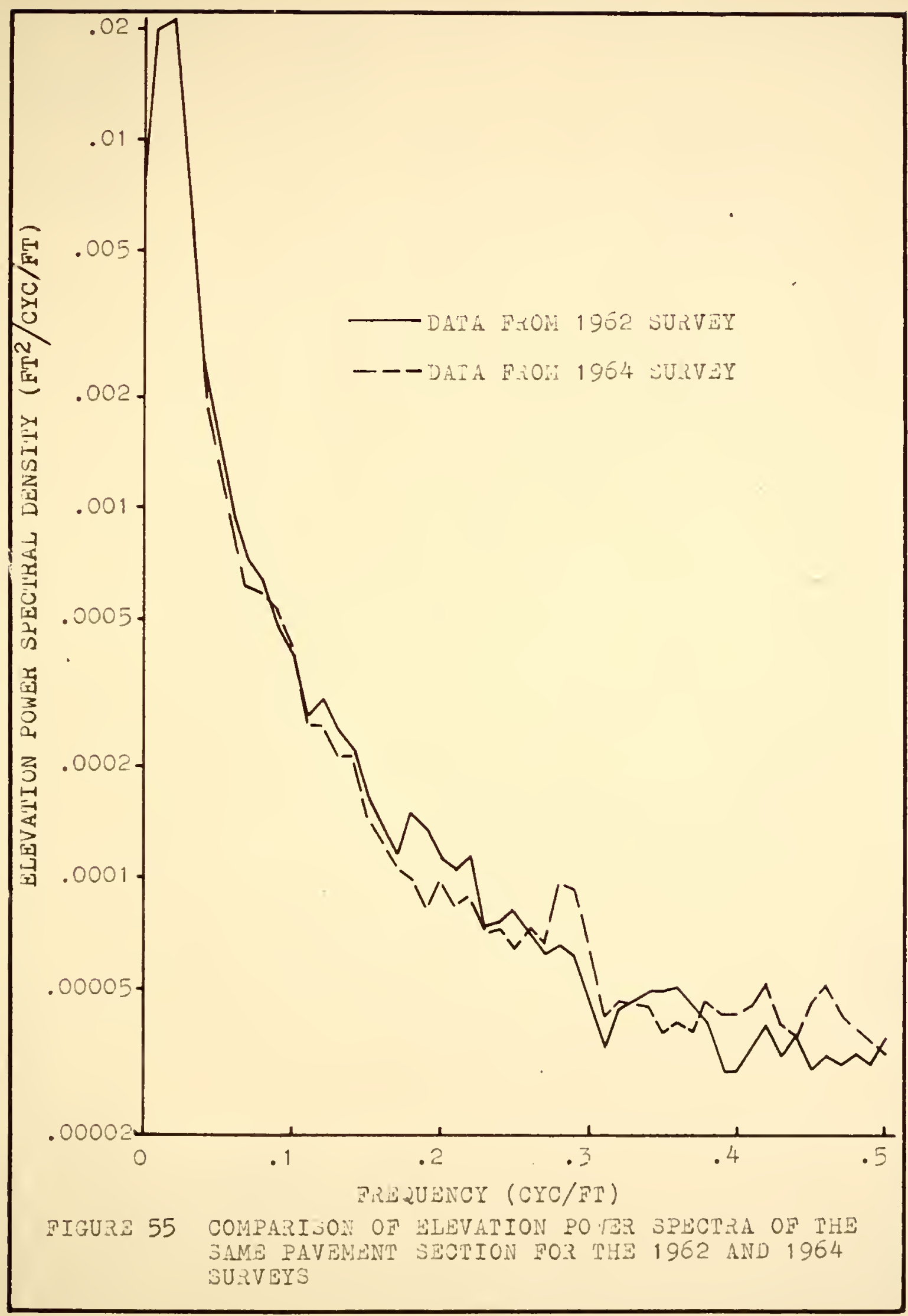




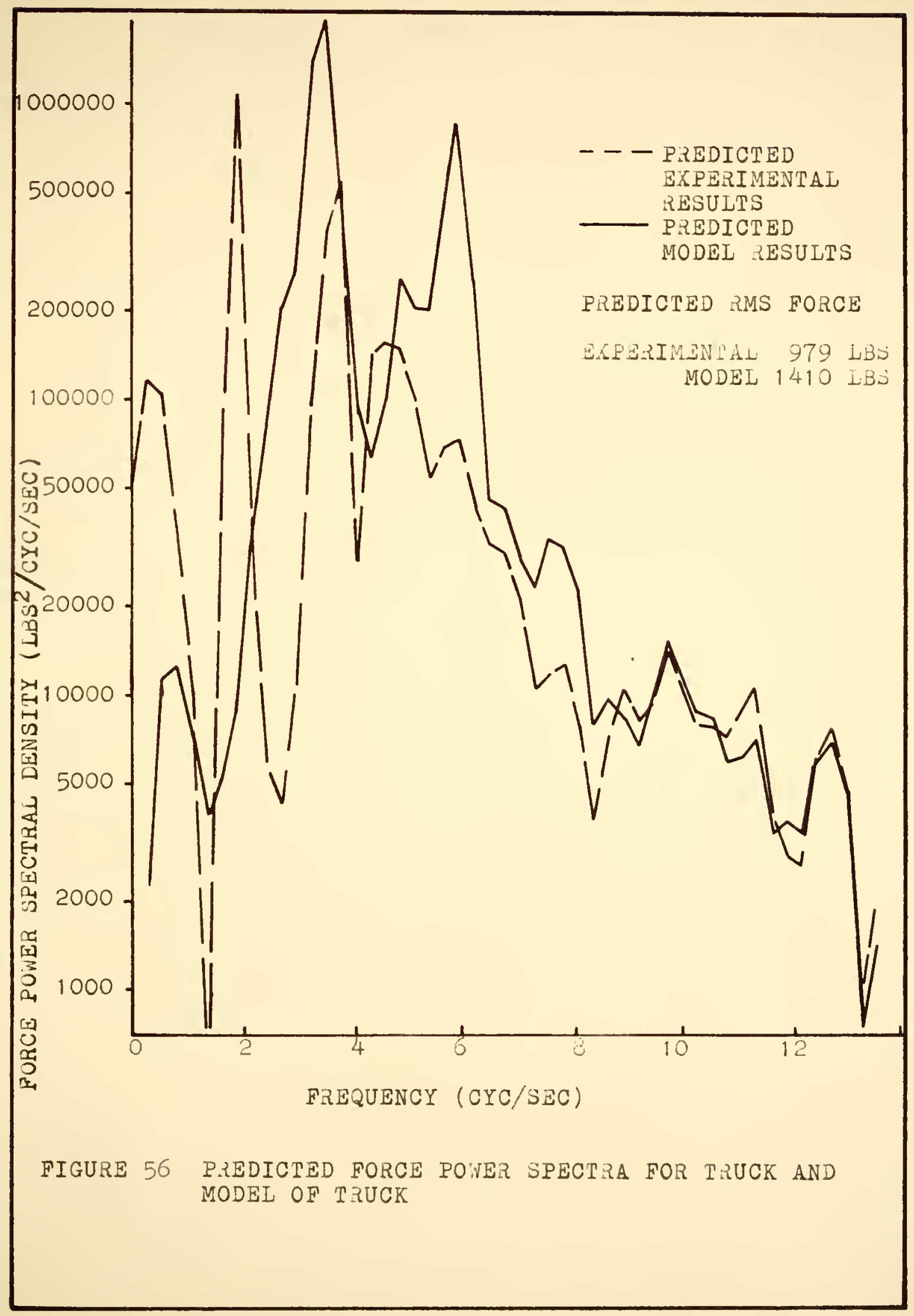


spectra at five different speeds calculated from the elevation pover spectrum using the .671 inch drop $F / x$ frequency response characteristics for the rifit rear inner tire are shown in Figure 57 and 53. It should be noted that the one foot spacing of the elevation measurements limits the ityquist frequency to only $13.5 \mathrm{cps}$ for the 27.0 fps (20 mph) calculation. The Nyquist frequency will increase with speed: Because of a larger frequency increment associated witis the higher speeds, some of the peaks in the frequency response cuaracteristic will fall betreen adjacent spactral estirates anc the associated curve betreen the spectral estimates mil appear to be attenuated. Tils effect is especially apparent for the 73.7 frs $(60 \mathrm{mph})$ curve at $3.5 \mathrm{cps}$. Experinental tests were then conducted at the site previously described to checis the results of tiese calculations. The stresses and Deflections aroup did not participate in this series of tests. Tae tests rere conducted in a similar manner as described in Chapter IV. The truck useà the normal meel paths for these tests and the imer and outer right rear dual tires experienced forces of nearly equal majnitude.

Tests vere conducted at venicle speeds of approximateIy $20,30,40,50$, and 60 mph. The truck $\because 3$ in the standard conaition as when callbrated. A series of tests were also conducted at $40 \mathrm{mpn}$ with tire inflation pressures of 55, 65, 75 , 25 , and 95 psi, but this data vas not reduced. 


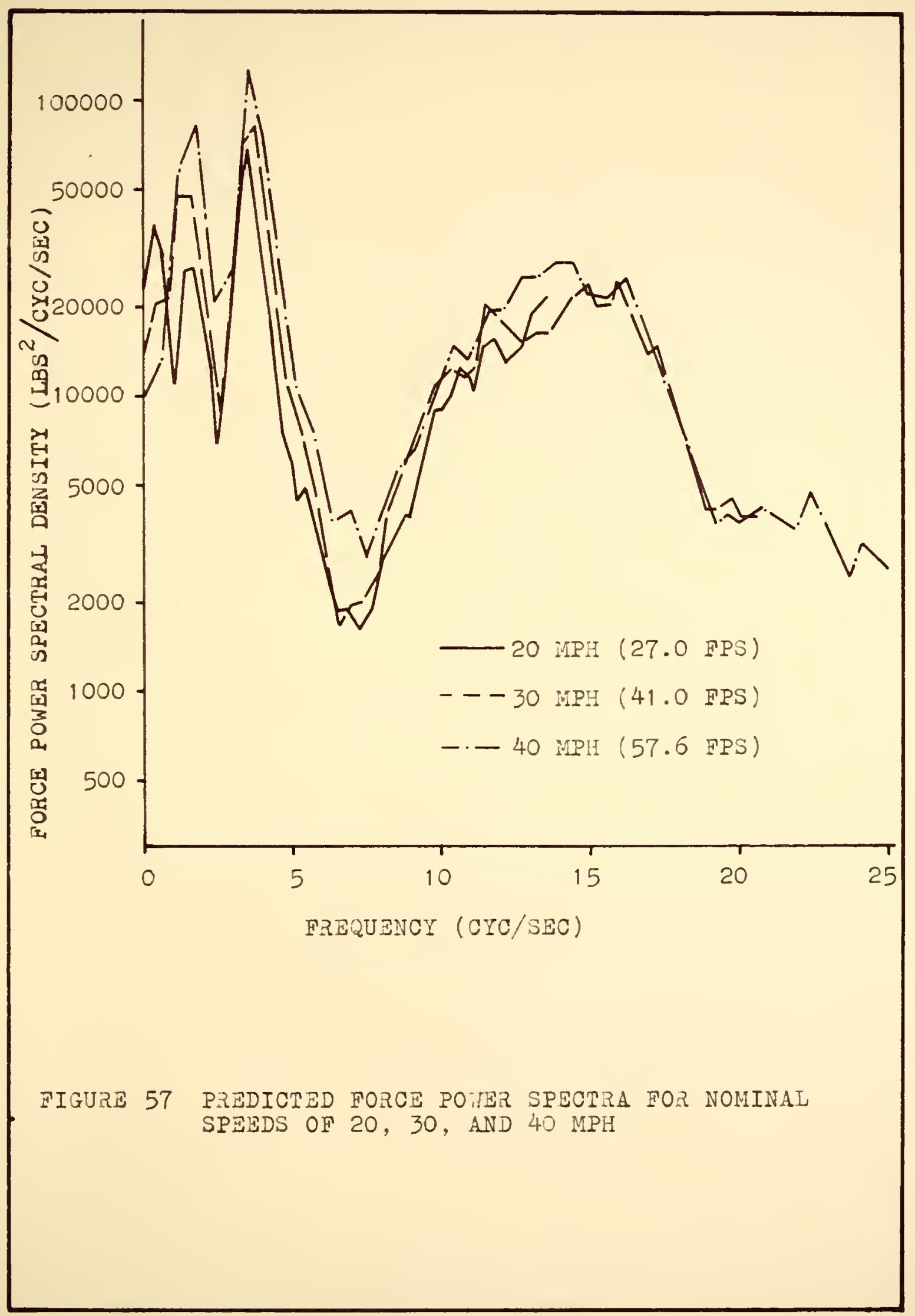




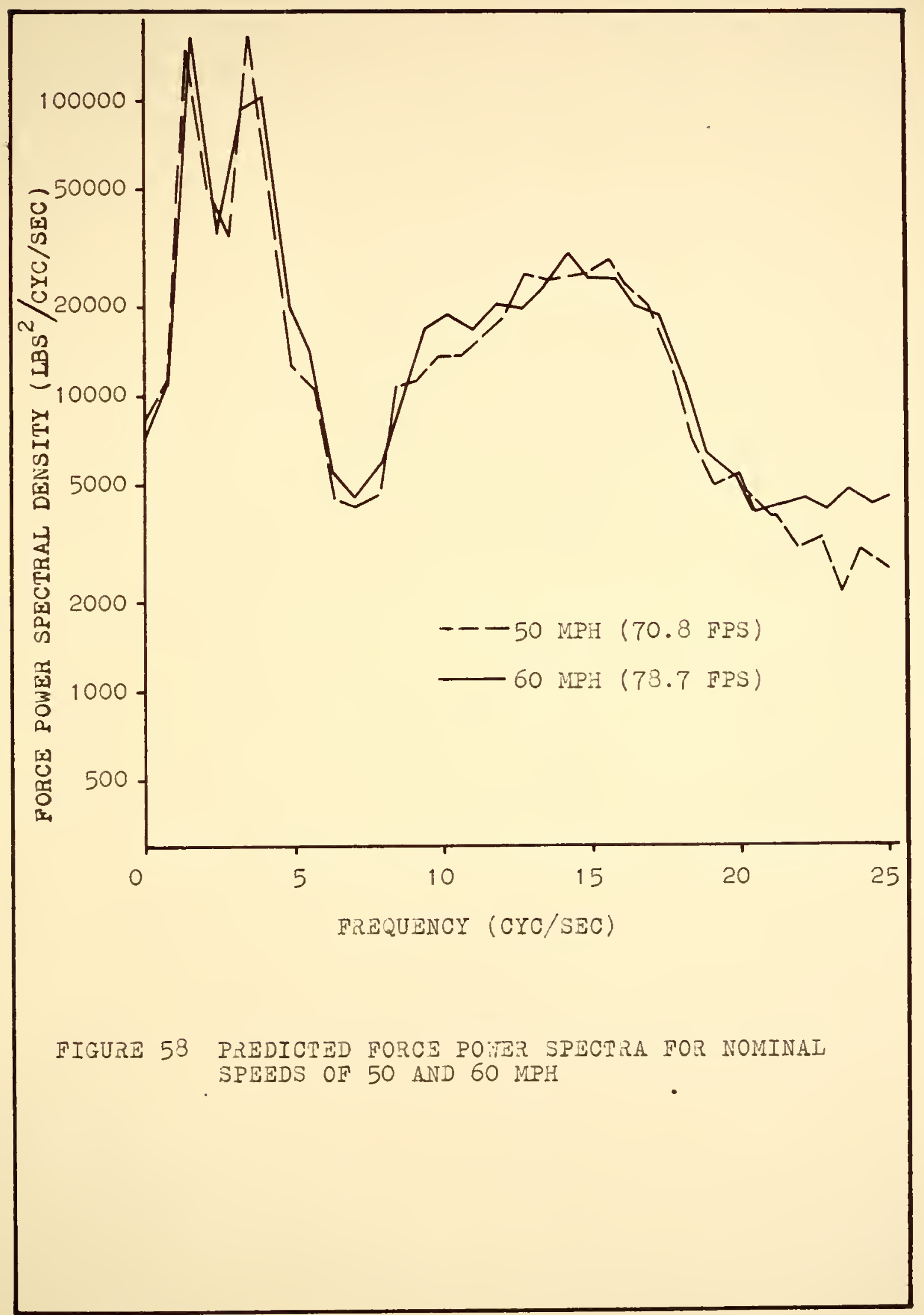


The experienced force power spectra that were calculated from force records of the right rear inner tire at various speeds are shown in irigures 59 and 60. These spectra were each calculated from $\$ 01$ data values that covered 6.06 seconds for a Nyquist frequency of $66 \mathrm{cps}$. $A$ second order base lines tecinique ith a base line corresponding to 100 feet of pavement was used for preprocessing. Because the equalization restriction in the pressure system acted as a hish pass filter, this preprocessing had little effect on the force spectra beyond the zero frequency estimates. There are approximately 23.8 degrees of freedom assoclated Hith each porer spectrum curve except for the zero frequency values.

rote that the power is concentrated in one broad peak between 0 and 5 cps. This could be due to insufficient frequency resolution since each of the three peaks in the F/X frequency response had a width between half power points of only .2 cps (see Fijure 32). Another explanation would be tine possibility that only one mode vas excited. It is apparent from these experimental spectra that above 3 cps, the curves are similar in tinat there is no definite trend assoclated with a speed change. Absent from the records is any indication that the wheel hop mode was excited. irore noterorthy, perhaps, is the fact that as the speed is changed froin $40 \mathrm{mph}$, the RMS force (the square root of the area under tize curve from 0 to the ryquist frequency) 


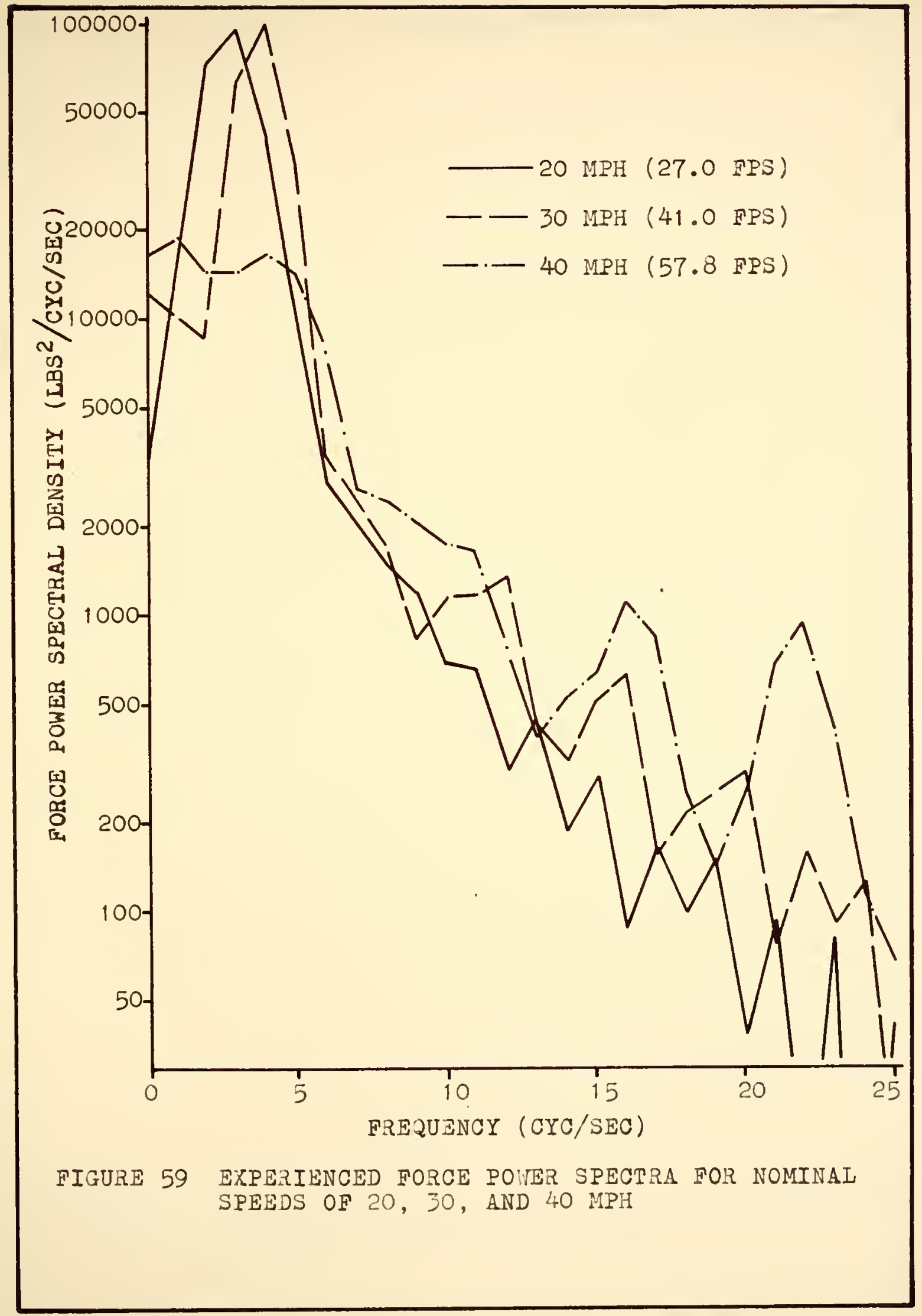




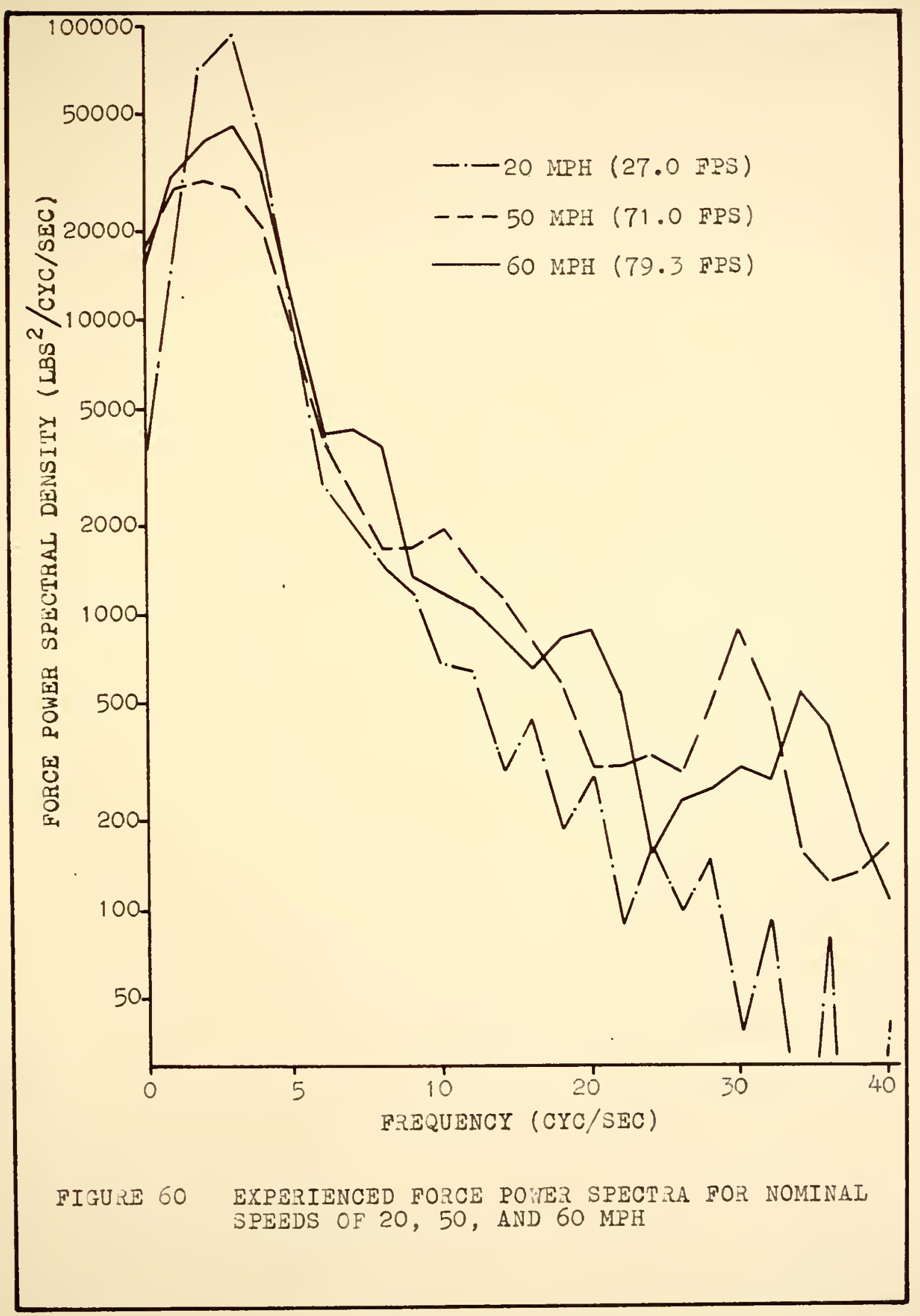


increased. Thus $40 \mathrm{mph}$ is the vehicle speed (for speeds ranging from $20 \mathrm{mph}$ to $60 \mathrm{mph}$ ) for this particular section of pavement for which minimum dynamic tire force exists.

For each of these tests, the truck passed over at least two one inch pipe event markers. The correspondins pressure pulses were faired out of the record when the data was read.

Figure 61 was included to sinow the comparison of the performance of an automobile and the truck. Inese spectra were calculated from the same data that were used for Figures 50 and 51. At the automobile wheel hop frequency (15 cps), the automobile spectral magnitude is only slifhtly less t.an the value for the truck.

inen calculating power spectra for the specific purpose of comparing the measured force spectra with the predicted force spectra for the same section of pavement, more importance was attached to the frequency resolution than to the statistical stability of these two spectral estimates. Thus these special purpose estimates vere calculated using a laçer maximum lag value than for usual calculations. Phis results in lower quality estimates for both of tie true power spectra. However, the statistical fluctuation in the measured force pover spectrum is not independent of the statistical fluctuations in the elevation power spectrum. Figure 62 illustrates the comparison of the predicted spectrum with the measured spectrum for $20 \mathrm{mph}$. The raximum 


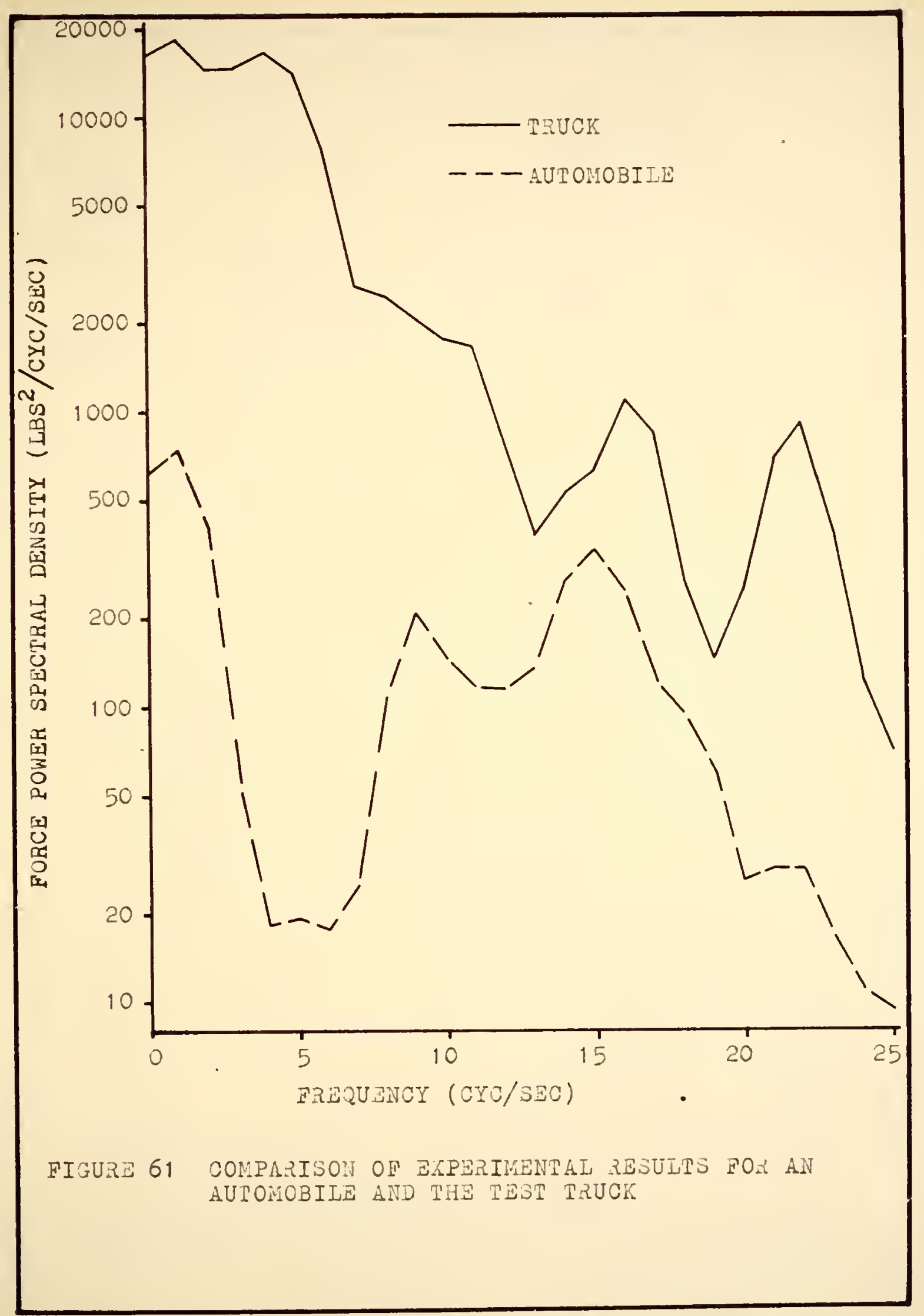




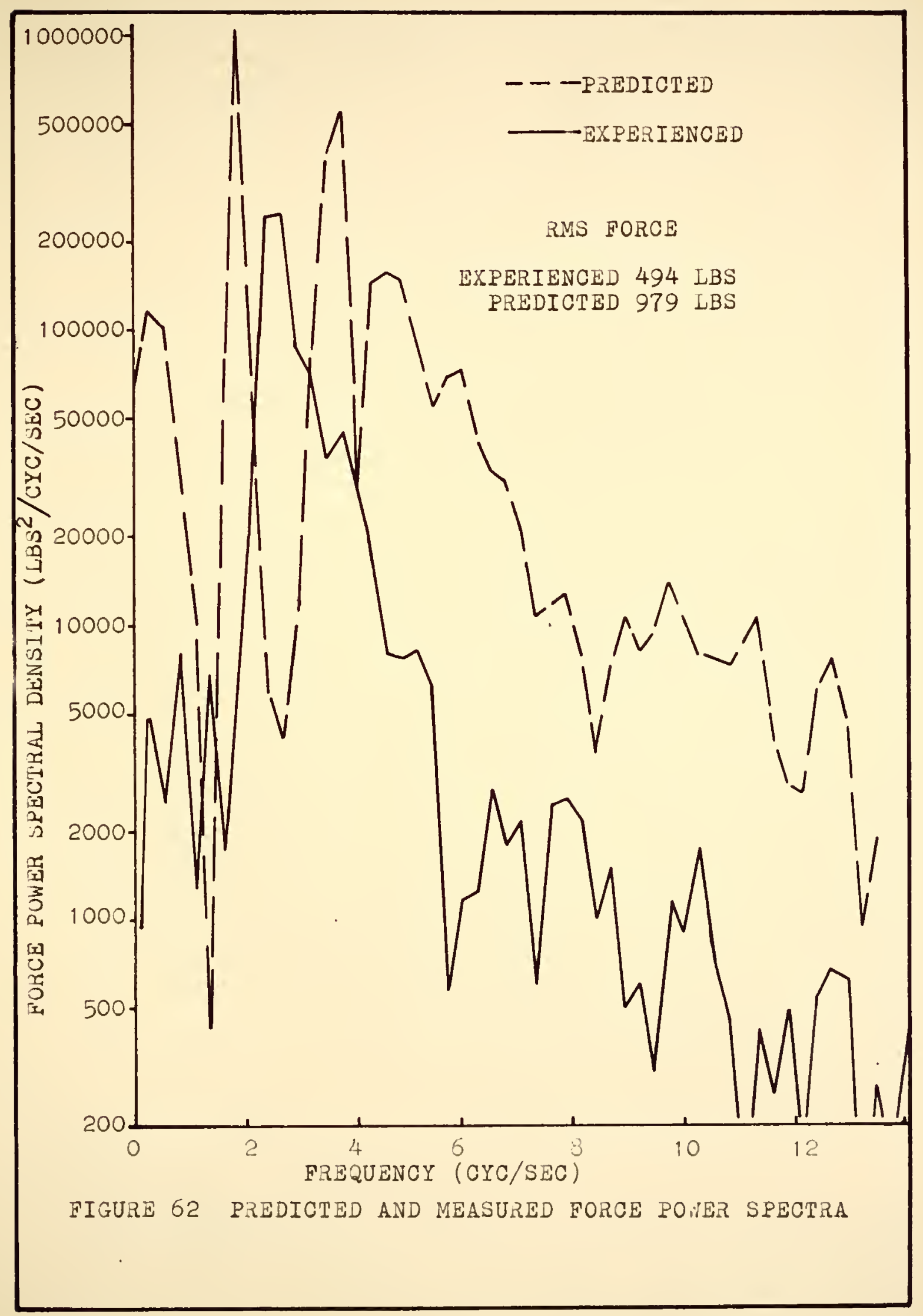


1a; was 30 percent of the total data length. Pile predicted spectrun was calculated from an elevation spectrum using the .0 .6 drop $F / R$ frequency response results. The peals of the preaicted force power spectrum do not fall at tine same frequencies as tre experienced force spactrum. Further, the predicted spectrum shows mucin larger ordinates than the experienced force spectrum. The Mis force of the experienced spectrum (the square root oi the total anea under tine power spectrum curve from zero to the Nyquist frequency) is 494 Ibs and the RNs force of the predicted spectrum is 979 lbs.

Figure 63 facliltates the comparison betieen the experimental results and the predicted results that were shown in Fipures 53, 59, 61 and 62. This figure 1llustrates the relationship between the vehicle speed and the zis dynamic tire force. The oredicted point at approximately $20 \mathrm{mph}$ is expected to be in error because of the low liyquist frequency of $13.5 \mathrm{cps}$ as 1liustrated 1n figure 57. Phe true value should be greater than that illustrated.

The kis forces compare well for 20 and $30 \mathrm{mph}$, but differ by a factor of trio at 40,50 , and $60 \mathrm{mpir}$. The predicted spectra do not show the minimum ass force at 40 mpa as exhibited by the experimental results. Aovever, as the specd increases above $40 \mathrm{mph}$, both curves increase at appoximately the same rate.

Power spectrum techniques may be applied in order to 


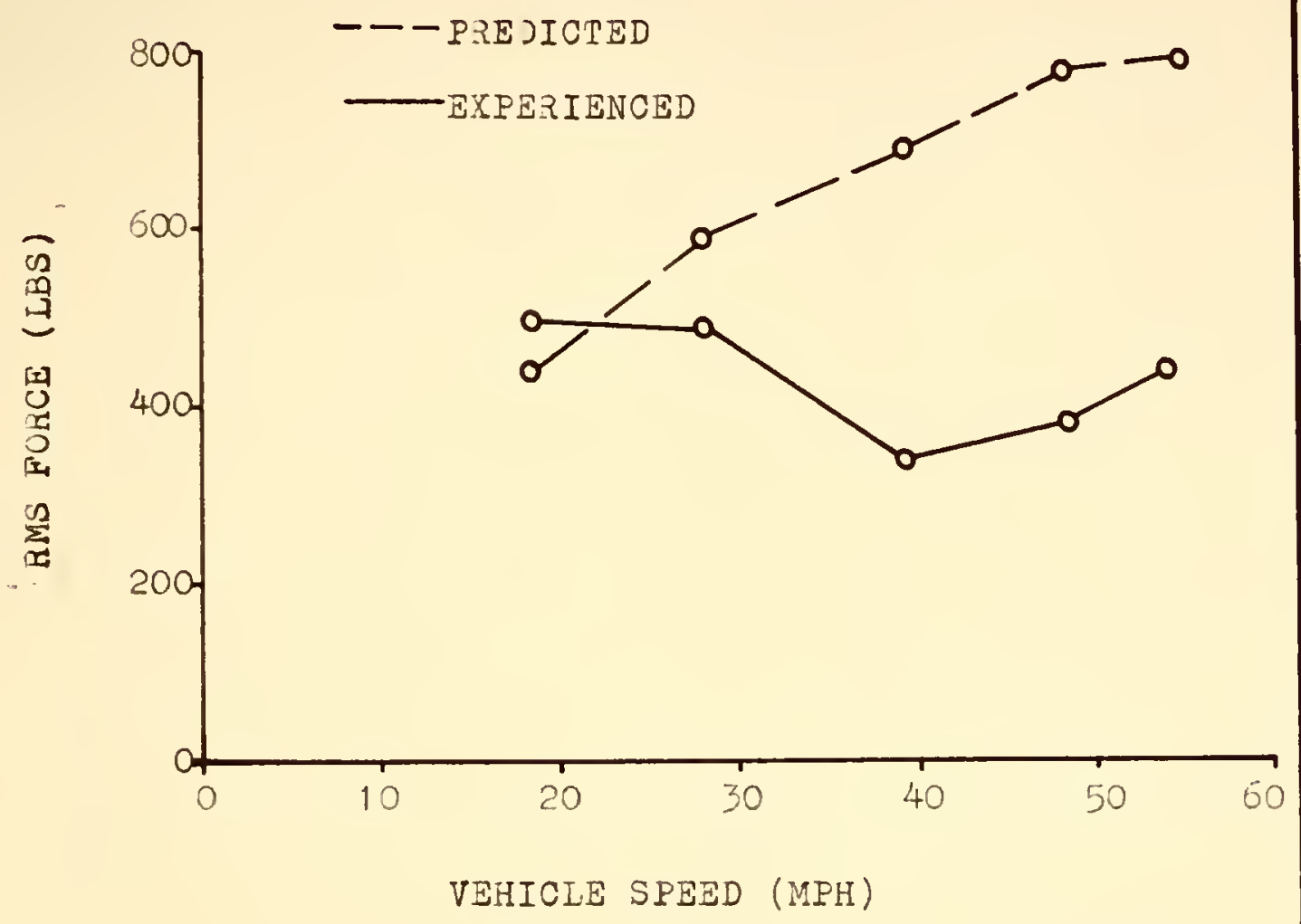

FIGURE 63 COMPARISON OF PREDICTED AND EXPERIENCED RMS FORCE 
study related variables. The effect of speed upon the pressure measuring system could not be determined during the calibration tests. Porer spectra of the pressure records for the right rear outer tire revealed an unexpected peak located away from the main single peak. Ihis peaks ras not in the spectra of the rixht rear inner tire recoris for 40, 50, and $60 \mathrm{mph}$. line results of these tests are shom in Figures 64 and 65. The ertra peais occurs at a frequency that coincides ril the rireel rotation speed which indicates either an unbalancej or eccentric tire on a malunction in the pressure systen. The effect of any of these situations could not be duplicated with the calibration equiprent. If the tire vere out or balance, then the record rould be correct; out if there were a pressure system malfunction, the results rould not be correct.

To chech the results por the left tires, a measured force forrer spectrum ias made for tio typical hish speed runs. The results are s:10:m in tigures 66 and 67 . Relatively speakins, only a ne-uli gible anount of additional power is observel at the meel rotation frequency for these tires. It is therefore evident t.lat virtually no extraneous effects are introluced by tire balance of wheel eccentricity for these tires. 


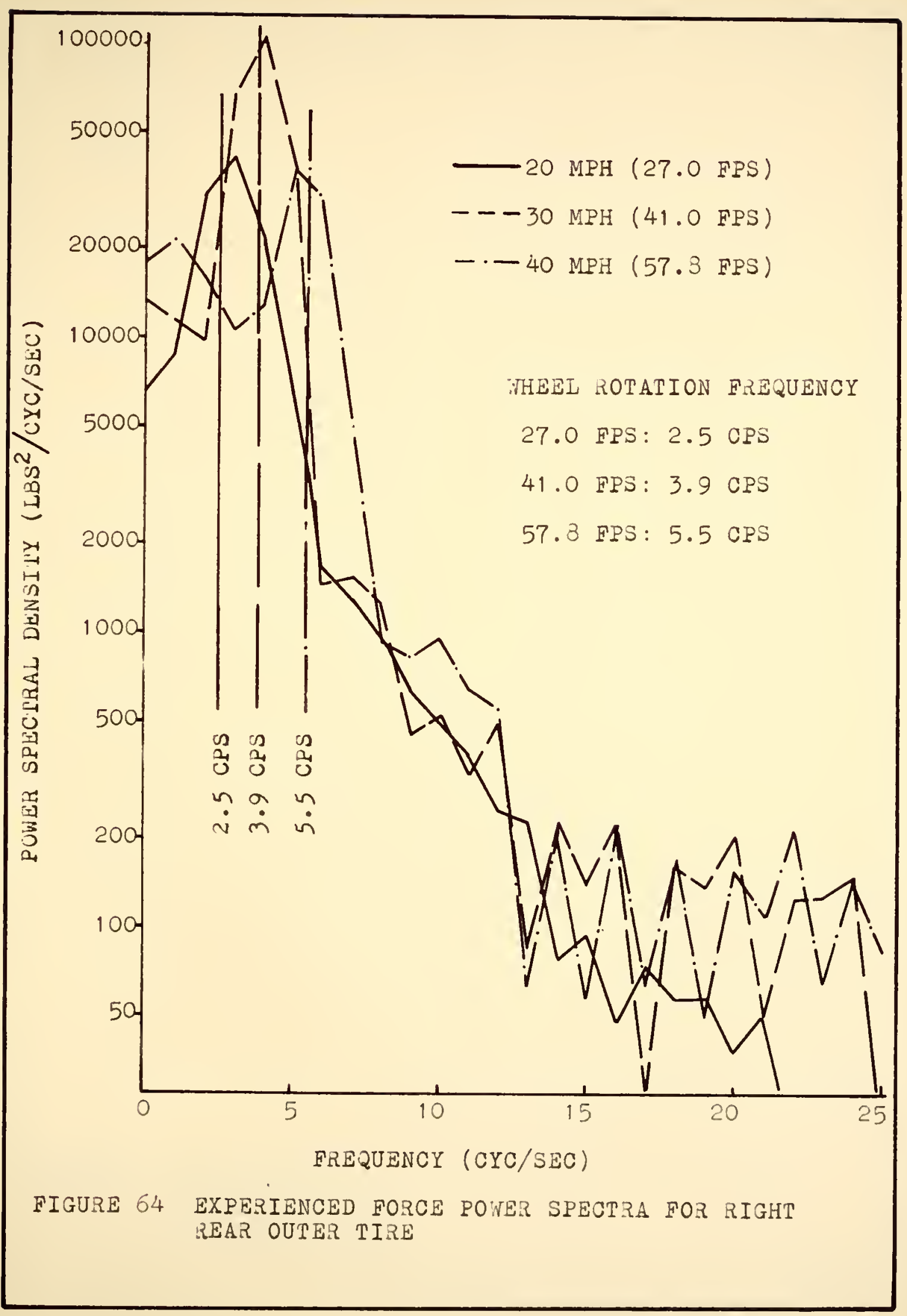




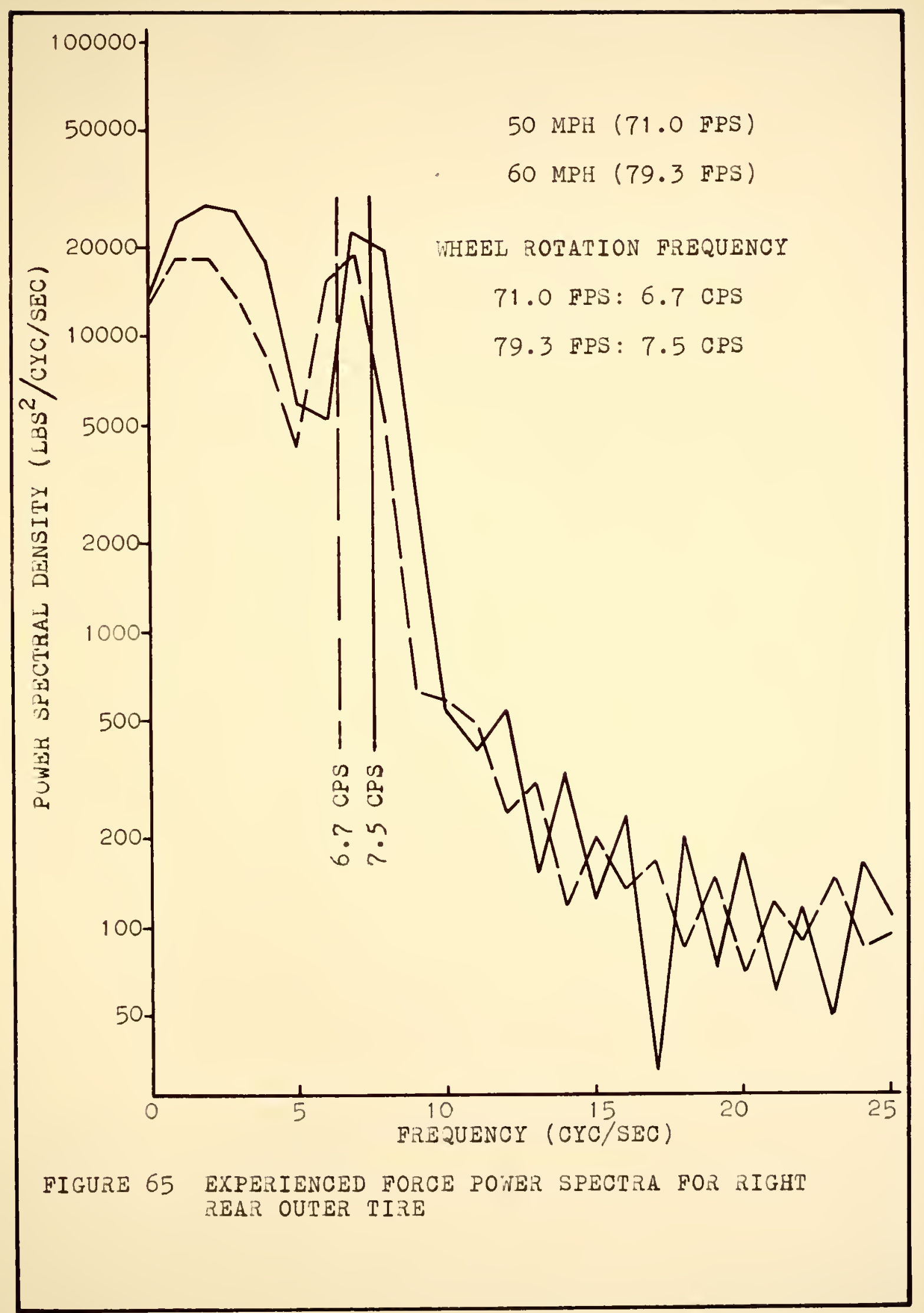




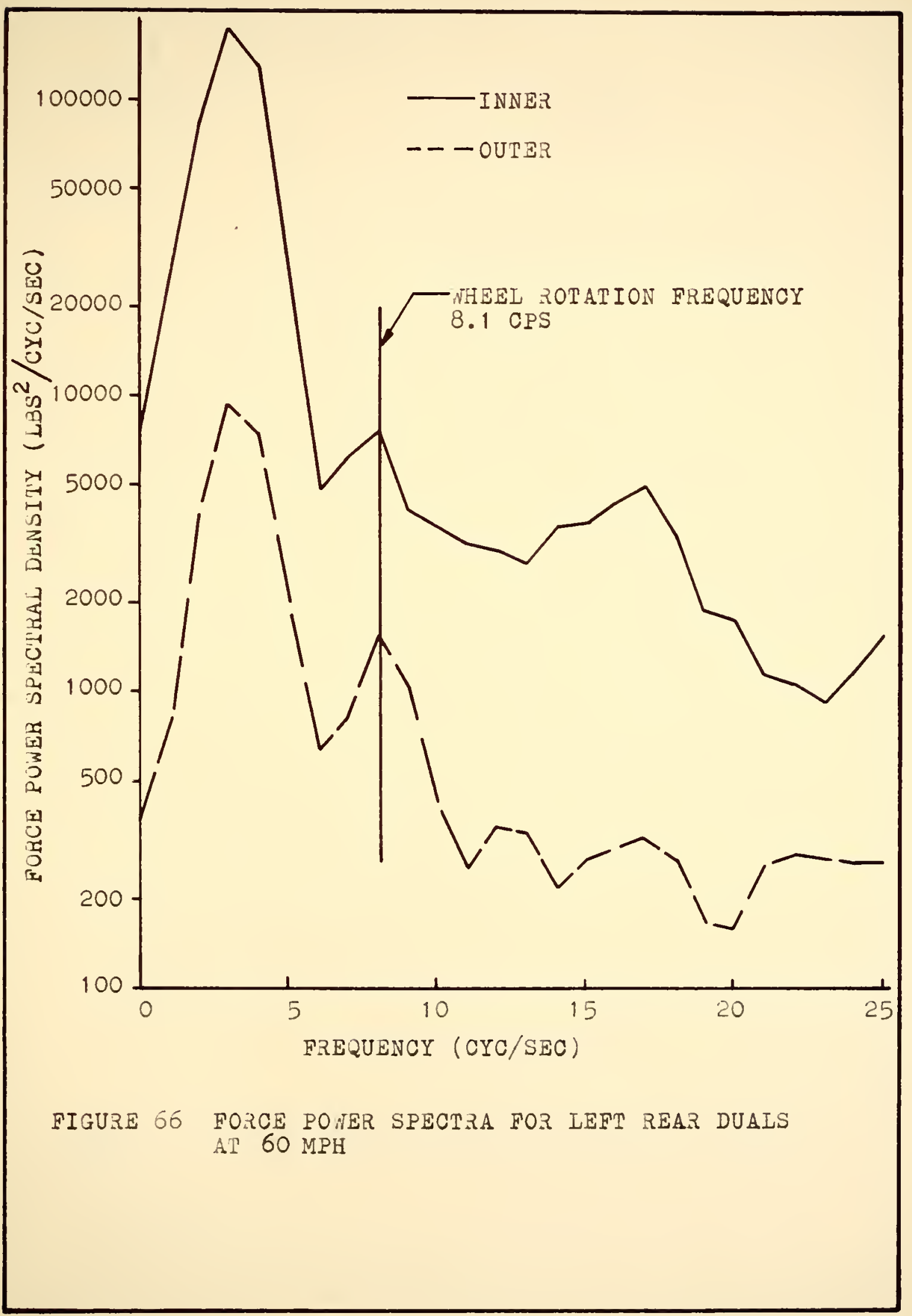




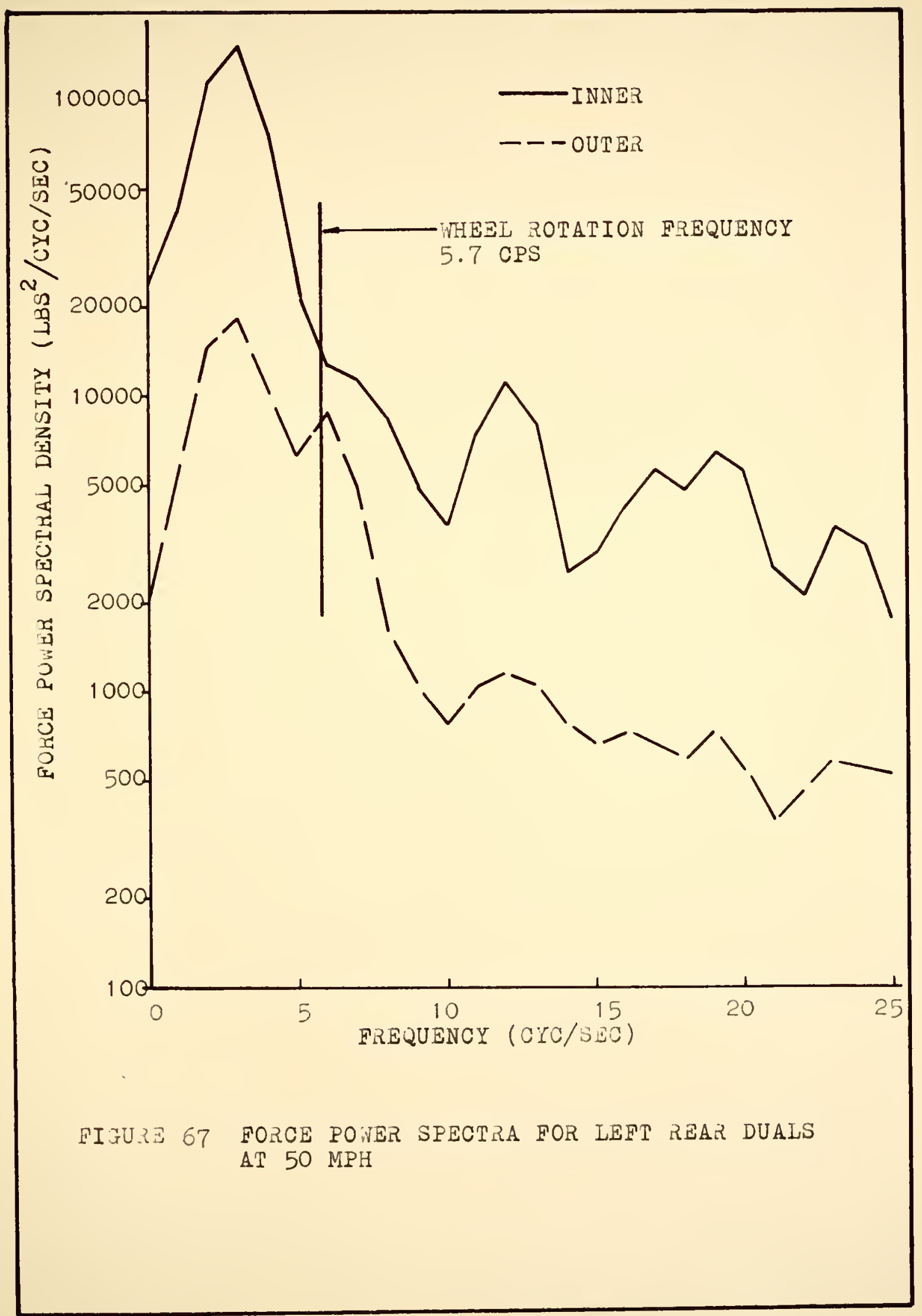




\section{CHAPTER VI \\ CONGIUSIONO AND RECOMMENDATIONS}

This investigation dealt with both tue measurement and the prediction of dynamic tire forces. The conclusions and recomendations for each topic will be discussed separately.

\section{Measurement of Dynamic Tire Forces}

Equiprent

1. The measurement of tire inflation pressure to indicate the dynamic tire force is a satisfactory procedure for large vehicles. For vehicles with lual tires, it offers the jistinct advantage of indicating the inner and outer dual tire dynamic tire forces independently.

2. The pressure neasuring systen did not show any strong resonances for the frequencies of interest.

3. A masnetic tape recorder for data recosing would be a major improvement over an oscillograph. The reduction of oscillograpi records by hand is extremely costly in money, time, and patience.

4. The possibility of converting the pressure record to a force record on an analof computer should be investigated, particularly if the data is recorded on magnetic tape. 
5. Then the inethod of calibration by transient ezcitation is used in the future, the data recoraing instrunentation should have a larger full scale recording range in order to improve the accuracy with wich the data can be read. ...

5. Because of the trouble experienced with tie right rear outer tire, facilities for centering and balancing rear truck tires shoula be available.

\section{Experimental Results}

1. The major inaccuracy in the determination of the total tire force was the initial value of the static force. It was assumed, after measurements vere carefully inade, that the static force on eaci rear tire was 4500 lbs for all tests.

2. The force values obtained by inultiplying the pressure recorks by a properly determined constant offers a substantial reduction in the calculations ifti onli a small rejuction in accuracy.

3. The dynamic tire forces fow the truck are as great as tine total force of one itheel of an automobile. However, when the dynamic tire forces are expressed as a percentage of the static load, the car and the truck indicate results of a similar magnitude.

4. The $F / X$ characteristic for an automobile at approximately 10 cps has about the same magnitude as the 
truck characteristic at the same frequency. This is also indicated by the fact that the magnitude of both force power spectra are approximately equal at this frequency.

5. Tine test results did not indicate that a wheel hop mode was exc1ted for the truck.

\section{Prediction of Dynainic lire zorces}

The predicted forces were jenerally much larger tian the experimental forces. There are several possible reasons for tinis.

1. The procedure for calculating the elevation power spectrun should be improved. The spectrum is distorted by the larse peak at zero frequency.

2. A better nethod for describing the hishray profile is needed. This method should reject the long wave lengths that are not significant as far as venicle excitation is concerned.

3. The assumption that t.re vehicle derives the input from only one theel should recelve further study.

4. The multiple peaks in the predicted force power spectra are not indicated in the experimental results for the truck. This is probably the result of the fact that there vas insufficient frequency resolution in the experimental force power spectra.

5. Another procedure for the prediction of a force 
power spectrum would be to subject a model of the vehtcle to a record of an elevation profile. A foice power spectrum could then be calculated from the force output of the model. Inis spectrum could then be conpared with the experimental force power spectrum. In this way, tie' vehicle would act as a filter of the elevation profile. 
BIBIIOGRAPHY 


\section{-BIBLIOGRAPHY}

1. Sanborn, J. I., "An Experimental Analysis of Transient Vehicle Loads and Response of Flexible Pavements," Ph.D. Thesis, Purdue University, August 1965.

2. Hopkins, R. C., and Boswell, H. H., "A Comparison of Hethods Used for Measuring Variations in Loads Transferred Through Ve:lcle Tires to the Road Surface," Public Roads, Vol. 29, No. 10, October, 1957.

3. Fisher, J. .., and Huckins, H. C., "Measuring Dynamic Vehicle Loads," Hi ghway Research Board Soecial Report 73, 1962.

4. The 14 SHO Road Test, Report 4, Bridge Research, Hi ghray Research Boand Special neport $61 \mathrm{D}, 1962$.

5.. ilson, c. C., "A Dynamic Tire Force Neasuring System," Ph.D. Thesis, Purdue University, June, 1964.

6. Hamilton, J. F., "Determination of Vehicle Characteristics Influencing Dynanic reactions on H1 ghiways," Ph.D. Thesis, Purdue University, August, 1963.

7. NoLemore, J. W., "Design of Equipment for Determining suspension Characteristics of "Heavy Vehicles, "ivife Thesis, puräue Jniversity, Ausust 1963.

8. Morris, G. J., and Stickle, J. W., "Response of a If gint Airplane to Roughness of Unpavea Runways," Technical lote D-510.

9. Blacioman, R. B., and Tuirey, J. T., The Measurement of Power Svectra, Dover Publications, Ne it York, 1959.

10. De Vries, T. W., "A Statistical Method for Estimatine Dynamic Venicle Loads on Highways," Ph.D. Thesis, January 1961 .

11. Zable, J., "Problems Associated with Power Spectral Density Characterizations of Hi ghrays, "MSME Thesis, Purdue University, January 1965 
12. Mormis, G. J., "Response of a Jet Trainer Aircraft to Roughness of Three Runways," NASA Technical Note D-2203, ivay 1964.

13. Jile, C. R. Jr., Advanced Engineering Mathematics, YCGnar-Hill Book Company, Jew York, 1951.

14. Karman, T. V., and Biot, if. A., Nathematical Methods in Engineering, McGraw-H1l. 3ook Company, ivew York, 1940.

15. Faming, R. .. iNumerical Methods for Scientists and Enineers, Mcuraw-Hill Book Company, New York 1962.

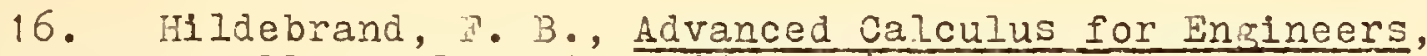
Prentice-Hall, Ingleirood Cliffs, 1949.

17. Shinbrot, Marvin, "On the Analysis of Iinear and Nonlinear Dynamical Systems from Transient Response Data," NACA Pecinical Note 3238, December 1954.

13. Filon, I. N. G., "On a Quadrature," Proceedings of the Royal Soclety of Rainburs, Vol. 49, $1923-29$.

19. Dreifke, G. E., "Effects of Input Pulse Shape and idth on Accuracy of Dynamic System Analysis from Exper1mental Pulse Data," Sc.D. Thesis, Tashington University, 1961 .

20. Janeway, ?. N., "A Better Truck Ride for Driver and Carso, Problems and Practical solutions," SP-154, society of Automotive Enzlneers, New York.

21. Carlson, J.A., "Analytical and Experimental studies of Vehicle Dynamic Behavior," Industrial Mathematics, Vol 7, 1956.

22. Younger, J. I., Advanced Dynamics, The Ronald Press Company, Hew York, 1959.

23. Tung, C. C., Penzien, J., and Horonjeff, R., "The Rffect of Runway Uneveness on the Dynamic Response of Supersonic Transports," NASA Contractor Report 119 , october 1964.

24. Laning, J.H. Jr., and Battin, R. H., Random Processes in Automat1c Control, McGraw-H111 Book Company, New York, 1956.

25. Quinn, B. E., "Problems Encountered in Using Elevation Power Spectra as a Criteria of Pavement Condition," A Supplement to the Final Report of NCHRP Project 1-2, Narch 1, 1965. 
APPENDIX 


\section{APPENDIK 1}

Theoretical Frequency Response Relationshlps for Model in Figure 39

Squations 17, 18, and 19 describe the motions of the three degrees of freedon model show in figure 39. The following derivations of the three frequency response relationships corresponding to Cases I, II, and III are simplified when operator notation is used. Using the operator $p \doteq a / d t$, these equations are

$$
\begin{aligned}
& \left(I p^{2}+6 C p+6 K\right) Z+2(2 B-A)(C p+K) \theta_{2}=(C p+K)\left(X_{1}+X_{2}+2 X_{3}+2 X_{4}\right) \\
& {\left[I_{1} p^{2}+\left(\frac{T}{2} T^{2}+T T_{3}^{2}+T_{T}^{2}\right)(C p+K)\right] \theta_{1}=(C p+K)\left(-\frac{m}{2} T^{2} X_{1}+\frac{T}{2} F_{2} X_{2}-T_{2} X_{3}+T_{2} X_{4}\right)} \\
& {\left[I_{c} p^{2}+2\left(A^{2}+2 B^{2}\right)(C p+K)\right] \theta_{2}+2(2 B-A)(C p+K) z=} \\
& (\mathrm{Cp}+\mathrm{K})\left(-\mathrm{AX}_{1}-\mathrm{AI} \mathrm{X}_{2}+2 \mathrm{B \textrm {A } _ { 3 }}+2 \mathrm{BX_{4 }}\right)
\end{aligned}
$$

For Case I (only one input $x_{4}$ ), these equations are solved for the ratios

$$
\frac{\theta_{1}}{X_{4}}(p)=\frac{T_{2}(C p+K)}{\left[I_{1} p^{2}+\left(\frac{T}{2} T^{2}+T_{3}^{2}+T_{T}^{2}\right)(C p+K)\right]}
$$




$$
\frac{Z}{X_{4}}(p)=\frac{2\left[I 2 p^{2}+2\left(A^{2}+2 B^{2}\right)(C p+K)\right](C p+K)-4 B(2 B-A)(C p+K)^{2}}{D(p)}
$$

$$
\frac{\theta_{2}}{\bar{X}_{4}}(p)=\frac{2 B\left(M p^{2}+6 C p+6 K\right)(C p+K)-4(2 B-A)(C p+K)^{2}}{D(p)}
$$

where

$$
D(p)=\left(M p^{2}+6 C p+6 K\right)\left[I I_{2} p^{2}+2\left(A^{2}+2 B^{2}\right)(C p+K]-4(2 B-A)^{2}(C p+K)^{2}\right.
$$

Equation 20 in operator form is

$$
\left.F_{I}=(C p+K)\left[C_{4}-Z-\frac{\left(T_{R}-T_{I}\right.}{2}\right) \theta_{1}-3 \theta_{2}\right]
$$

or

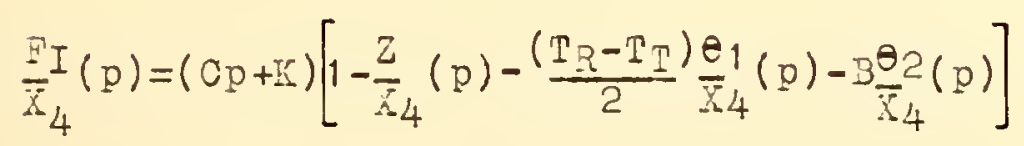

The ratios A.4, A.5, and A.5 may then be substituted into A.9. The Case I frequency response may then be obtained by replacing $p$ by j2nf. A computer was used to calculate the nunerical values plotted in Figures 41 and 42.

The Case II frequency response ( $x_{2}$ and $x_{4}$ inputs) may be obtalned in a similar fashion except that $x_{2}$ is no longer zero. $x_{2}$ is expressed in terms of $x_{4}$ as

$$
x_{2}(t)=x_{4}(t+\tau)
$$


Where

$$
\tau=\frac{A+B}{V}
$$

For sinusoidal inputs $\left(x_{4}=e^{j 2 \pi f t}\right)$

$$
\sigma_{2}(t)=e^{j 2 \pi f(t+\tau)}=e^{j 2 \pi f \tau} e^{j 2 \pi f t}=e^{j 2 \pi f \tau_{K_{4}}}
$$

Thus for Case II

$$
\begin{aligned}
& \frac{\theta_{1}}{\bar{X}_{4}}(p)=\frac{(C p+K)\left(T_{R}+\frac{T}{2} P^{j 2 \pi f \tau}\right)}{\left[I_{1} p^{2}+\left(\frac{T}{2} F^{2}+I_{R}^{2}+T_{T}^{2}\right)(C p+K)\right]}
\end{aligned}
$$

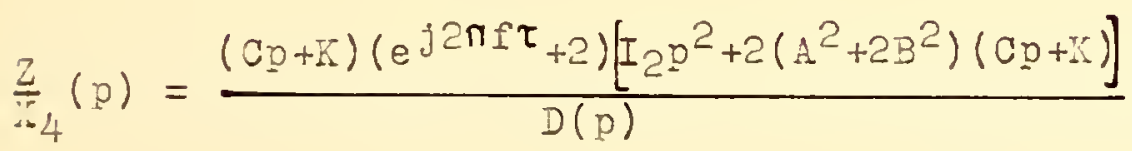

$$
\begin{aligned}
& -\frac{2(2 B-A)\left(2 B-A e^{j 2 \pi f \tau}\right)(C p+K)^{2}}{D(p)} \\
& \frac{e}{X_{4}} 2(p)=\frac{\left(M p^{2}+\sigma C p+6 \pi\right)\left(2 B-A e^{j 2 \pi f \tau}\right)(C p+K)}{D(p)} \\
& -\frac{2(2 B-A)\left(e^{j 2 \pi f \tau}+2\right)(C p+K)^{2}}{D(p)}
\end{aligned}
$$

Substitutins A.13, A.14, and A.15 into A.9 and replacement of $p$ by $j 2 \pi f$ will produce the Case II frequency response. The Case III frequency response $\left(x_{1}, x_{2}, x_{3}\right.$, and $x_{4}$ inputs) is also obtained in this manner. For this case, however,

$$
x_{1}(t)=X_{2}(t)=X_{3}(t+\tau)=X_{4}(t+\tau)
$$


Thus for Case III

$$
\begin{gathered}
\frac{\theta}{K_{4}}(p)=0 \\
\frac{Z}{K_{4}}(p)=\frac{2\left(e^{j 2 \pi f \tau}+2\right)\left[\frac{I}{2} p^{2}+2\left(A^{2}+2 B^{2}\right)(C p+K)\right](C p+K)}{D(p)} \\
-\frac{4(2 B-A)\left(2 B-A e^{j 2 \pi f \tau}\right)(C p+K)^{2}}{D(p)} \\
\frac{\theta_{2}}{K_{4}(p)=} \\
-\frac{2\left(M p^{2}+6 C p+\sigma K\right)\left(2 B-A e^{j 2 \pi f \tau}\right)(C p+K)}{D(p)} \\
-\frac{4(2 B-A)\left(e^{j 2 \pi f \tau}+2\right)(C p+K)^{2}}{D(p)}
\end{gathered}
$$

Substitution of Equations A.17, A.13, and A.19 into A.9 and replacenent of $p$ by jerf will produce the Case III Irequency response. 
VIIA 


\section{VIIA}

The author, Gary illard Kibbee, vas born on December 9, 1938, in Kansas City, Kansas. He tas graduated from Turner High School, Turner, Kansas in June 1956. The entered the University of Kansas in September 1956. During his senior year, he received the Tendo Scholarship for achievement. In June 1960, he receivea his B.s.M.E. degree (with distinction).

ile was then employed as a Research Ingineer at Smith \& Loveless, Division of Union Tank Car Company in Lenexa, Kansas. For development work conducted at this time, he vas named as inventor for United States Patents 3,168,595 and 3,195,727.

inen he returned to the University of Kansas in September 1961 for graduate study, he also conducted research for Smith \& Loveless. He did this research for his vaster of science thesis. This woris was in the area of developing a new cooling device for squirrel cage induction notors. He was granted his M.S.M.I. degree in June 1962.

The author accepted a graduate research assistantship at Purdue University to complete his work toward a Ph.D. degree becinning in september 1962. He designed and developed laboratory experiments and their associated special equipment. He later received a dual appointment as one-half time teaching assistantship and one-half time research assistantship.

He is a member of Tau Beta Pi, PI Tau Sigma and Sigma Tau professional fraternities. 

